\title{
The Influence of Selected Containment Structures on Debris Dispersal and Transport Following High Pressure Melt Ejection from the Reactor Vessel
}

Prepared by M. Pilch, W. W. Tarbell, J. E. Brockmann

Sandia National Laboratories

Prepared for

U.S. Nuclear Regulatory

Commission

When printing a copy of any digitized SAND Report, you are required to update the markings to current standards. 


\section{NOTICE}

This report was prepared as an account of work sponsored by an agency of the United States Government. Neither the United States Government nor any agency thereof, or any of their employees, makes any warranty, expressed or implied, or assumes any legal liability of responsibility for any third party's use, or the results of such use, of any information, apparatus, product or process disclosed in this report, or represents that its use by such third party would not infringe privately owned rights.

\section{NOTICE}

Availability of Reference Materials Cited in NRC Publications

Most documents cited in NRC publications will be available from one of the following sources:

1. The NRC Public Document Room, 1717 H Street, N.W. Washington, DC 20555

2. The Superintendent of Documents, U.S. Government Printing Office, Post Office Box 37082 , Washington, DC 20013-7082

3. The National Technical Information Service, Springfield, VA 22161

Although the listing that follows represents the majority of documents cited in NRC publications, it is not intended to be exhaustive.

Referenced documents available for inspection and copying for a fee from the NRC Public Document Room include NRC correspondence and internal VRC memoranda; NRC Office of Inspection and Enforcement bulletins, circulars, information notices, inspection and investigation notices; Licensee Event Reports; vendor reports and correspondence; Commission papers; and applicant and licensee documents and correspondence.

The following documents in the NUREG series are available for purchase from the GPO Sales Program: formal NRC staff and contractor reports, NRC-sponsored conference proceedings, and NRC booklets and brochures. Also available are Regulatory Guides, NRC regulations in the Code of Federal Regulations, and Nuclear Regulatory Commission Issuances.

Documents available from the National Technical Information Service include NUREG series reports and technical reports prepared by other federal agencies and reports prepared by the Atomic Energy Commission, forerunner agency to the Nuclear Regulatory Commission.

Documents available from public and special technical libraries include all open literature items, such as books, journal and periodical articles, and transactions. Federal Register notices, federal and state legislation, and congressional reports can usually be obtained from these libraries.

Documents such as theses, dissertations, foreign reports and translations, and non-NRC conference proceedings are available for purchase from the organization sponsoring the publication cited.

Single copies of NRC draft reports are available free, to the extent of supply, upon written request to the Division of Information Support Services, Distribution Section, U.S. Nuclear Regulatory Commission, Washington, DC 20555.

Copies of industry codes and standards used in a substantive manner in the NRC regulatory process are maintained at the NRC Library, 7920 Norfolk Avenue, Bethesda, Maryland, and are available there for reference use by the public. Codes and standards are usually copyrighted and may be purchased from the originating organization or, if they are American National Standards, from the American National Standards Institute, 1430 Broadway, New York, NY 10018. 
NUREG/CR-4914

SAND87-0940

R3, R4

\section{The Influence of Selected Containment Structures on Debris Dispersal and Transport Following High Pressure Melt Ejection from the Reactor Vessel}

Manuscript Completed: July 1988

Date Published: September 1988

Prepared by

M. Pilch, W. W. Tarbell, J. E. Brockmann

Sandia National Laboratories

Albuquerque, NM 87185

Prepared for

Division of Systems Research

Office of Nuclear Regulatory Research

U.S. Nuclear Regulatory Commission

Washington, DC 20555

NRC FIN A1406 


\begin{abstract}
High pressure expulsion of molten core debris from the reactor pressure vessel may result in dispersal of the debris from the reactor cavity. In most plants, the cavity exits into the containment such that the debris impinges on structures. Retention of the debris on the structures may affect the further transport of the debris throughout the containment. Two tests were done with scaled structural shapes placed at the exit of 1:10 linear scale models of the Zion cavity. The results show that the debris does not adhere significantly to structures. The lack of retention is attributed to splashing from the surface and reentrainment in the gas flowing over the surface. These processes are shown to be applicable to reactor scale.

A third experiment was done to simulate the annular gap between the reactor vessel and cavity wall. Debris collection showed that the fraction of debris exiting through the gap was greater than the gap-to-total flow area ratio. Film records indicate that dispersal was primarily by entrainment of the molten debris in the cavity.
\end{abstract}


TABLE OF CONTENTS

$\underline{\text { Page }}$

1. INTRODUCTION

2. THE HIPS-3J EXPERIMENT 16

2.1 Apparatus 6

2.2 Instrumentation $\quad 9$

2.3 Initial Conditions $\quad 15$

2.4 Experiment Results and Analyses 15

2.4.1 Camera Coverage 15

2.4.2 Pressurization and Blowdown History of the Melt Generator

2.4.3 Structure Interactions

3. THE HIPS-7C EXPERIMENT 132

3.1 Apparatus $\quad 32$

3.2 Instrumentation 32

3.3 Initial Conditions $\quad 37$

3.4 Experiment Results and Analyses
3.4.1 Camera Coverage

3.4.2 Pressurization and Blowdown History of the Melt Generator

3.4.3 Structure Interactions

3.4.4 Aerosols

4. THE HIPS-8C EXPERIMENT 59

4.1 Apparatus $\quad 59$

4.2 Instrumentation $\quad 62$

4.3 Initial Conditions $\quad 64$

4.4 Experiment Results and Analyses 64

4.4.1 Camera Coverage $\quad 67$

$\begin{array}{ll}\text { 4.4.2 Pressurization and Blowdown History } & \\ \text { of the Melt Generator } & 67\end{array}$

4.4.3 Structure Interactions $\quad 73$

$\begin{array}{ll}\text { 5. SUMMARY AND CONCLUSIONS } & 77\end{array}$

6. REFERENCES $\quad 79$ 


\section{LIST OF FIGURES}

\section{Figure}

Page

1.1 Containment Building of the Zion Reactor Plant

2.2 Schematic of HIPS Melt Generator

2.3 Photo Detector Locations in the Lower Flange

2.4 Force Cell Location

2.5 X-Ray Cassette Locations

2.7 Pressurization History of the Melt Generator

2.8 Pressure History of the Melt Generator During Melt Ejection and Blowdown

2.9 Predicted Ablation of the Discharge Orifice

2.10 Upstream and Downstream Sides of the Discharge Orifice Compared to an Unused Orifice Plate

2.11 Comparison of Scaled Load Cell Measurements With Model Prediction

2.12 Pyrometer Measurements of Jet Exit Temperatures

3.1 Details of the Excavity Structure for the HIPS-7C Experiment

3.2 Orientation of the Test Apparatus Within the

Test Chamber

3.3 Closeup Photo Sequence Taken From the Rear

(Left Column) and Front (Right Column) of the Structure

3.4 Long Range Photo Sequence

3.5 Pressurization History of the Melt Generator

3.6 Blowdown History of the Melt Generator

3.7 Temperature Measurements Outside the Cavity 
Figure

Page

3.8 Pressure Measurements at Three Locations in the Cavity

3.9 Pretest and Posttest Comparison of Lower Assembly of the Cavity Mockup

49

3.10 Posttest View of the Melt Generator With Frozen Crust on its Surface

3.11 Pretest and Posttest Comparison of the Excavity Structure

52

3.12 Particle Trapping by Excavity Structure

54

3.13 Influence of Containment Structures on Debris

Behavior

3.14 Aerosol Size Distribution

56

3.15 Fraction of Relocated Melt That is Aerosolized

58

4.1 Details of the Melt Generator, Transition Piece, and Cavity Configuration

60

4.2 Arrangement of the Test Apparatus in the Interaction Chamber

4.3 Debris Dispersal Through the Normal Cavity Exit

68

4.4 Debris Dispersal Through the Annular Gap 68

4.5 Pressurization History of the Melt Generator 70

4.6 Blowdown History of the Melt Generator $\quad 71$

4.7 Temperature Measurement Outside the Cavity

Using a Two-Color Pyrometer

4.8 Pressure Measurements in the Cavity 


\section{LIST OF TABLES}

\section{Table}

Page

2.1 Summary of HIPS-3J Instrumentation

2.2 Summary of HIPS-3J Camera Coverage

2.3

HIPS-3J Initial Conditions

2.4

Photo Detector Signal Sequence

3.1 Summary of HIPS-7C Instrumentation

3.2 Summary of HIPS-7C Camera Coverage

3.3

HIPS-7C Initial Conditions

39

3.4

Posttest Debris Inventory

48

4.1 Summary of HIPS-8C Instrumentation

63

4.2 Summary of HIPS-8C Camera Coverage

65

4.3

HIPS-8C Initial Conditions

66 


\section{INTRODUCTION}

The Zion Probabilistic Safety Study, ZPSS, (COMED, 1881) concludes that in over $75 \%$ of the accident sequences considered, failure of the reactor pressure vessel (RPV) occurs while the primary system remains at some elevated pressure. The point of failure is predicted to occur at one or more of the RPV instrument tube penetrations, resulting in a small orifice through which the molten core material can be ejected. Substantial ablation of the initially small orifice is predicted. As the molten material enters the cavity region beneath the RPV, it forms a pool of core debris that flows radially outward and into the tunnel region. The analysis suggests that this initial movement of debris coupled with the subsequent blowdown of the primary system will cause virtually all of the expelled core material to be dispersed into the containment regions. These processes are now termed High Pressure Melt Ejection (HPME).

High pressure accidents of this type are identified with either transient (T) or small-break loss-of-coolant (S) initiating events accompanied with failure of recirculation or upper head ejection, loss of feedwater, or station blackout. Based upon a number of probabilistic risk assessments, these accident initiators dominate the core damage frequency (IDCOR, 1984). For 14 reference plants, the estimated core melt frequency for $S$ and $T$ events is over $80 \%$ for pressurized water reactors (PWR) and over $90 \%$ for boiling water reactors (BWR).

The ZPSS assumes that debris dispersal from the reactor cavity will result in the formation of a relatively shallow bed of debris that is coolable by water located on the floor of the containment. This scenario eliminates the possibility of an extended interaction between the core debris and concrete basemat, thus eliminating the resulting gas and aerosol production that is associated with such interactions. Steam generated by quenching the debris bed is not sufficient to cause containment failure by overpressurization. The ZPSS methodology assumptions have also been used for other plants with essentially the same benign termination of the accident (CONED, 1982).

Study of the ZPSS and other similar documents shows that much of the information presented is conjectural with little experimental support. Many of the assumptions regarding debris dispersal are made without the benefit of appropriate test data. For this reason, research was initiated at Sandia National Laboratories (SNL) to perform an experimental and analytical investigation of the phenomena associated with this type of accident scenario, particularly the dispersal of debris from the reactor cavity. The ensuing effort was termed the High-Pressure Melt Streaming Program, HIPS, (Tarbell, Brockmann, and Pilch, 1984).

A number of scaled cavity experiments (Tarbell et al. 1986) conducted by the HIPS program have shown that debris is indeed 
forcibly removed from the cavity. Unlike the film-like flow portrayed in the ZPSS, the debris emerged as fine particulate interspersed in a high-velocity gas stream. In all experiments utilizing concrete cavity models, over $85 \%$ of the debris ejected from the melt generator was also dispersed from the cavity. Flash X-ray images and samples of the debris collected following the tests reveal that the mass mean diameter of the dispersed debris particles is approximately $0.5 \mathrm{~mm}$. High speed film records showed that the unimpeded flight of the debris was over 40 meters in elevation with impact on the ground nearly 60 meters downrange.

In some reactor containments, a significant portion of the material that would be swept from the reactor cavity could be carried into portions of the containment atmosphere where the debris might liberate its thermal and chemical (oxidation of metallic constituents) energy. This airborne energy exchange may significantly increase the containment pressure by heating the atmosphere or by boiling of codispersed water (thus increasing the mass of the containment atmosphere). The HIPS experiments and the earlier SPIT experiments have also shown that the energy exchange process is accompanied by intense generation of aerosols (Brockmann \& Tarbell, 1984; Tarbell, et al., 1986). This is an important potential contributor to radionuclide release that has not been previously identified. The processes of containment heating and aerosol production have been termed Direct Containment Heating (DCH).

The CONTAIN code (Bergeron, et al., 1985), using an interim $\mathrm{DCH}$ model (Williams, et al., 1986), predicts that pressures sufficient to threaten some containments can be generated as a result of these airborne energy exchange processes. These calculations couple DCH with all other forms of exvessel severe accident phenomena. Modeling the influences of plant specific geometry is currently beyond the state-of-the art. Key uncertainties in these calculations are the amount of debris that interacts with the atmosphere and the length of time that the debris interacts with the atmosphere. Both these quantities may be strongly influenced by the plant specific structures near the cavity exit and throughout the plant.

The disparate opinions of the various researchers leads to several major unresolved issues associated with HPME and DCH: (1) the amount of debris dispersal from various cavity configurations, (2) the extent of debris transport beyond the cavity including interaction of the debris with containment structures, (3) the debris/atmosphere energy transfer processes, (4) the production of aerosols, and (5) rapid production and combustion of hydrogen. This report discusses the results of three HIPS experiments that focus on phenomena associated with the issue of debris dispersal and transport in the presence of 'structures.' 


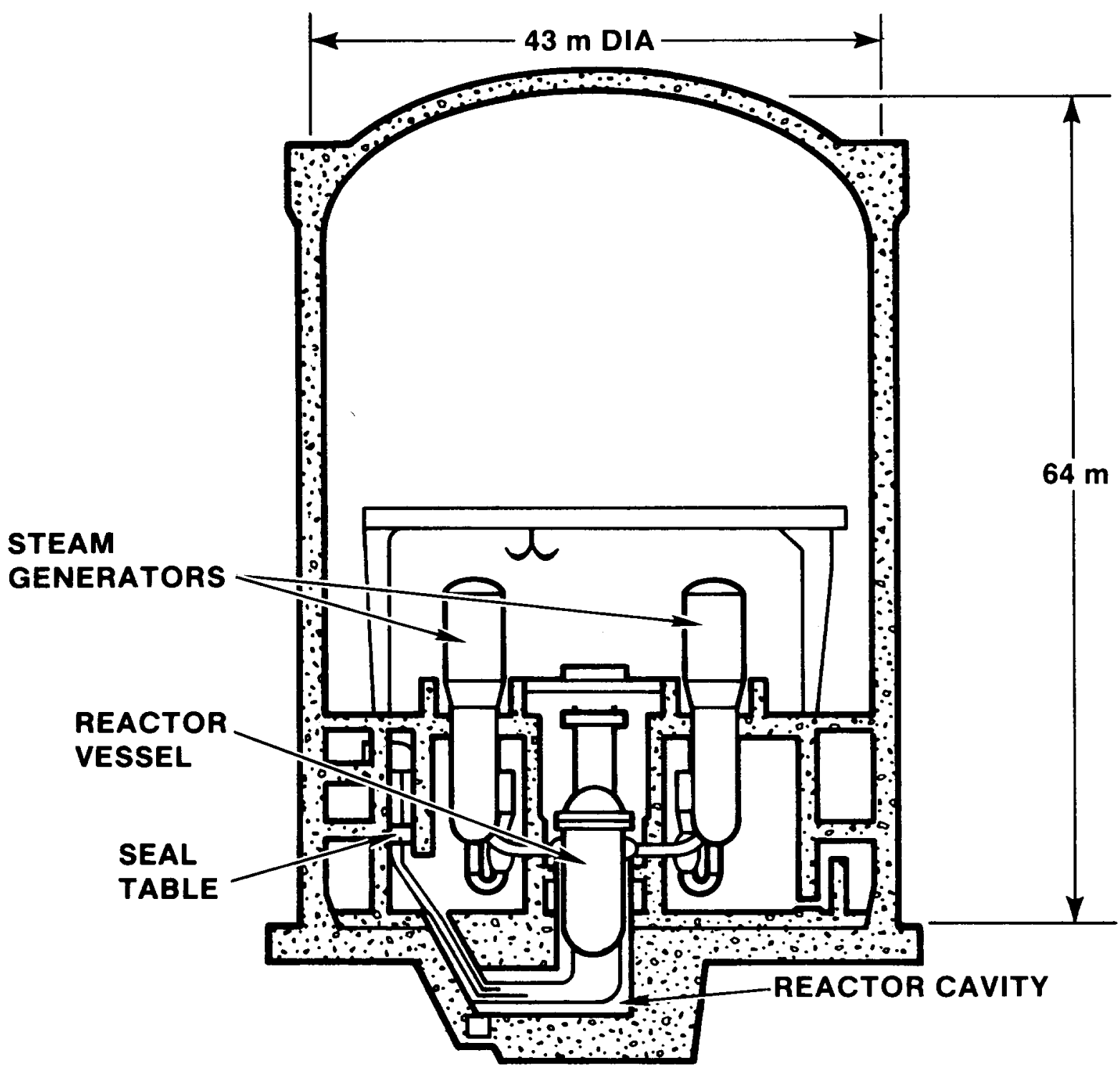

Figure 1.1: Containment Building of the Zion Reactor Plant 
While agreeing that blowdown gases can sweep most of the core melt from some reactor cavities, some researchers (Squarer, 1984; Fauske, 1985) argue that obstructions outside the cavity will mitigate the direct heating problem by trapping a significant portion of the melt before it can interact with the containment atmosphere. Figure 1.1 depicts the containment building of the Zion reactor plant illustrating the compartmentalization of the building and a few of the structures and obstacles that could trap debris and thus potentially mitigate the DCH problem.

The angle of inclination of the instrument tube shaft will cause the gas and debris exiting the cavity to be directed into an enclosure beneath the seal table. It has been suggested (Squarer, 1984; Fauske, 1985) that this enclosure will trap the bulk of debris exiting the cavity. The HIPS-7C test, which is described in this report, used a 1:10 linearly scaled concrete model of the reactor cavity and structure beneath the seal table to determine how much debris is trapped by the enclosure. Debris that exits the cavity through the instrument tube shaft and escapes the intervening structure enters an annular room that is bounded by the operating floor, crane wall, and refueling canal wall. This annular room houses the steam generators, coolant pumps, pressurizer, and a large amount of piping associated with these devices. Critics of DCH have argued that debris will freeze on these structures thus depleting the quantity of debris mass that can interact with the atmosphere. The HIPS-3J test, which is described in this report, was the first attempt at understanding how debris interacts with the concrete slabs and steel pipes that are expected to intercept debris.

In many reactor plants, there is an annular gap around the RPV that could allow debris to be transported directly into the refueling canal which in turn is open to the upper dome of the containment building. Debris exiting the cavity by this route will completely bypass structures in the lower part of the containment that might potentially trap debris. The HIPS-8C test, which is described in this report, investigated the potential for debris to escape the cavity via this annular gap. The experiment used the same 1:10 linearly scaled model of the Zion cavity from previous tests except that a simulated annular gap was placed at the scaled height of the RPV.

The experiments discussed in this report are not intended to directly simulate all aspects of HPME accidents. It becomes nearly impossible to scale integral tests that simultaneously simulate complicated processes involving a broad spectrum of rate-dependent processes. The experiments are intended to provide insight into relevant physical processes and to support development of models for specific phenomena relevant to HPME and 
DCH. Realistic assessment of plant performance during severe accidents can only be made by integrating phenomenological models into system leel codes (e.g., MELPROG and CONTAIN), which couple all the relevant phenomena associated with a severe accident. 
The primary objective of HIPS-3J was to determine the potential for simple structures, such as walls and pipes, to trap and retain debris that would be dispersed from the reactor cavity. To achieve this objective, an $80 \mathrm{~kg}$ mass of molten iron and alumina was created and forcibly expelled from a pressurized melt generator. The melt stream was directed at a canted slab of concrete that redirected the melt at a steel pipe.

A secondary objective of the test was to obtain direct and indirect measurements of the transient diameter of the discharge aperture in the melt generator. The oriface size determines the rate at which melt and blowdown gases are discharged into the cavity.

\subsection{Apparatus}

The apparatus for this experiment consisted of a melt generator, a concrete slab, and a steel pipe. The orientations of the components are shown in Figure 2.1.

The melt generator (Figure 2.2) was intended to produce and deliver a mixture of molten iron and alumina which was produced by the metalothermic reaction:

$$
8 \mathrm{Al}+3 \mathrm{Fe}_{3} \mathrm{O}_{4} \rightarrow 9 \mathrm{Fe}+4 \mathrm{Al}_{2} \mathrm{O}_{3} .
$$

The melt generator consists of a crucible, a pressure vessel, and a fusible melt plug. The aluminum and iron oxide powders were ignited in the crucible where the reaction progresses from top to bottom. The entire crucible was placed inside a second vessel that is pressurized prior to ignition of the reaction. Pressure-driven ejection of melt was initiated when a fusible plug, which mounted in the lower flange over of the pressure vessel, melts after the reaction progresses to the bottom of the crucible. Additional details of the melt generator are reported elsewhere (Tarbell et al., 1986).

The concrete slab was centered approximately $0.56 \mathrm{~m}$ (22 in) below the melt generator and was canted $45^{\circ}$ from the horizontal to redirect the melt towards the steel pipe. The slab was a square, $0.46 \mathrm{~m}$ (18 in) on a side and $0.10 \mathrm{~m}$ (4 in) thick, made from limestone common sand concrete. The slab was intended to represent one of the many concrete walls that exist in reactor containments.

The steel pipe was placed approximately 1 m (36 in) from the concrete $s$ lab in the anticipated path of the redirected melt. The pipe was $0.10 \mathrm{~m} \mathrm{(4} \mathrm{in)} \mathrm{in} \mathrm{diameter,} 0.46 \mathrm{~m}$ long, and had a wall thickness of $6 \mathrm{~mm}$. The pipe represented the many steel structures (pipes, steam generators, gratings, etc.) located outside the reactor cavity of most plants.

In the HIPS-2C test (Tarbell et al., 1986), the diameter of the orifice in the lower flange cover increased by nearly a 


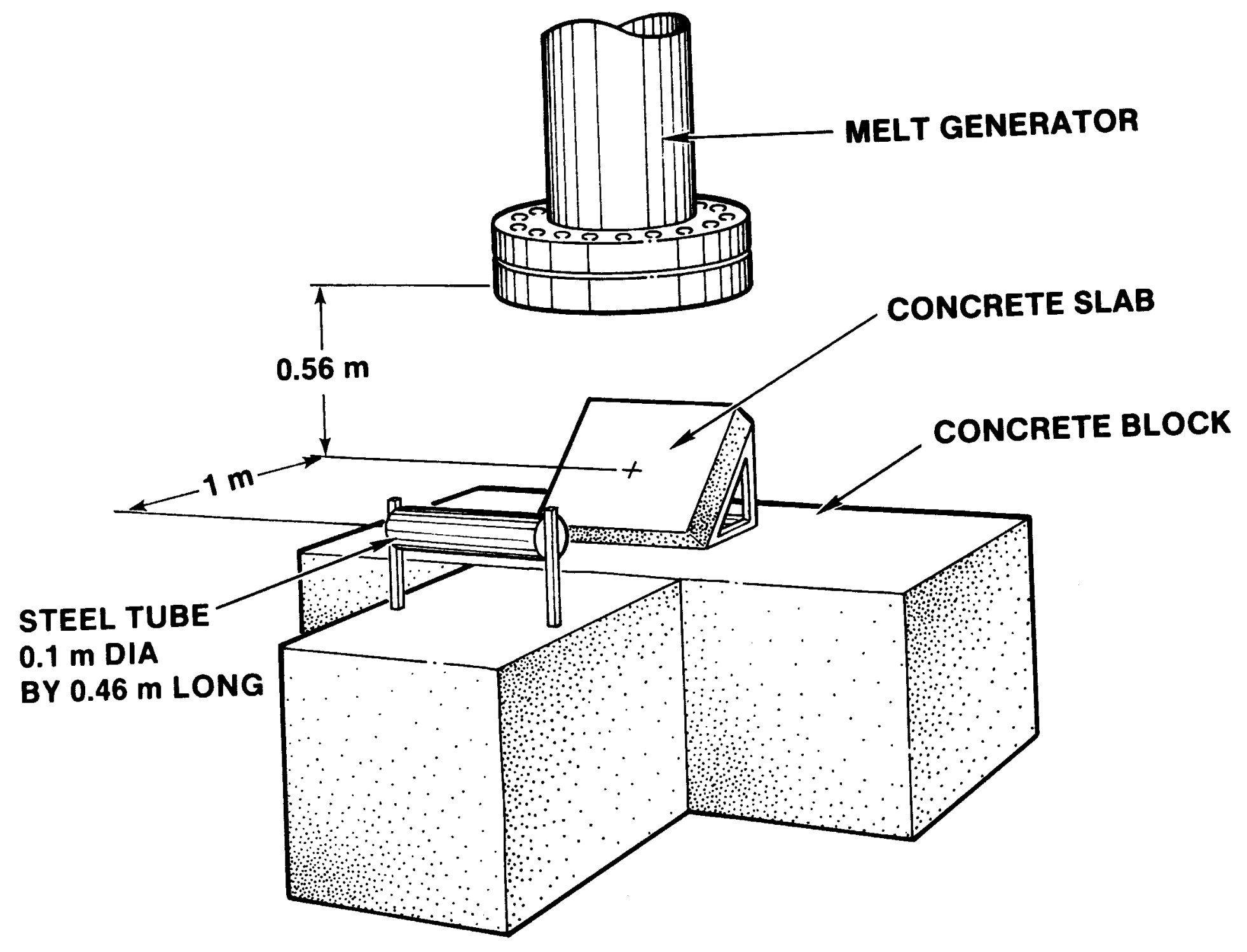

Figure 2.1: HIPS-3.J Test Configuration 


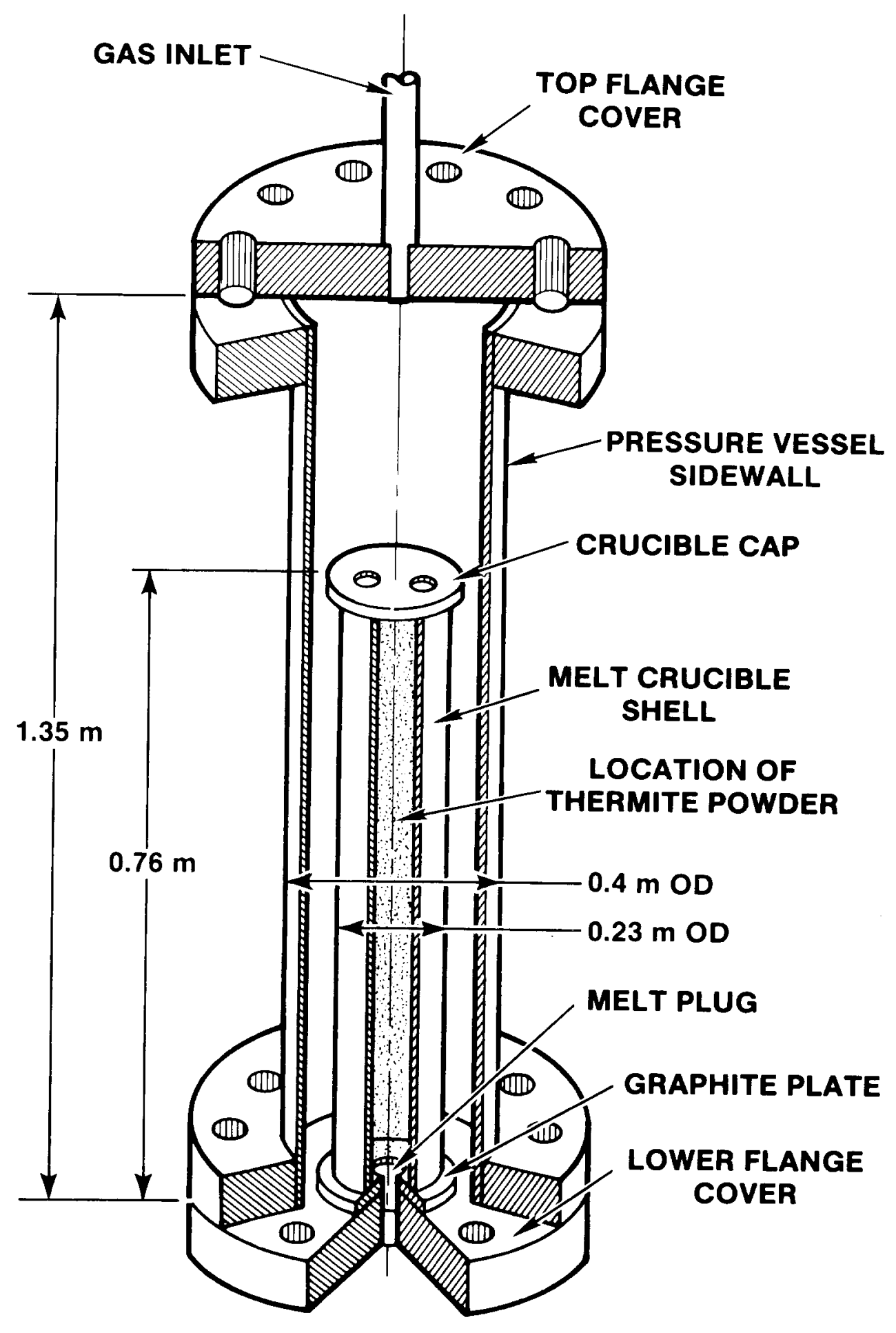

Figure 2.2: Schematic of HIPS Melt Generator 
factor of three due to ablation during discharge of melt from the generator. In HIPS-3J, photodetectors were placed at various radial positions in the flange cover in an attempt to measure the rate of hole ablation. It was anticipated that the detectors would record a sharp increasing in light intensity as the ablation process uncovered the end of the detector.

Four pairs of phototransistors (Motorola type MRD310) were embedded in the flange cover, as depicted in Figure 2.3. Each pair was located at increasing radial positions of $0.0222 \mathrm{~m}$ $(7 / 8 \mathrm{in}), 0.0254 \mathrm{~m}(1 \mathrm{in}), 0.0381 \mathrm{~m}(1.5 \mathrm{in})$, and $0.0444 \mathrm{~m}$ ( 1.75 in) respectively. The detectors of each pair were placed $90^{\circ}$ apart in order to provide data on the symmetry of the ablation process.

The photo detectors were placed in the end of slots, $13 \mathrm{~mm}$ $(1 / 2$ in) deep, cut in the bottom surface of the flange cover from the outside edge. The slots were angled radially so as not to interfere with other detectors located along the same radial line. The photo detectors were held in place with high alumina cement; so that as the hole ablated, the detector would be uncovered and exposed to the luminous melt stream.

\subsection{Instrumentation}

A summary of the HIPS-3J instrumentation is given in Table 2.1. Pressure gauges were placed in the top flange cover of the melt generator to obtain the pressurization and blowdown histories. The primary device was a water-cooled gauge (Precise Sensors Model 111-2) placed in a machined recess filled with steel turnings to protect the sensing element. Another gauge (Kulite Model XT-190) was located in a less hostile position in the gas line near the melt generator. The second device provided a backlip in the event that the primary device was affected by the heat flux from the molten pool formed during the thermite reaction.

Two thermocouples were inserted through the flange cover to a depth of approximately $0.30 \mathrm{~m}$ to monitor the temperature of the gas above the melt. One sensor had a 3.2-mm diameter stainless steel sheath while the other was a $1.7-\mathrm{mm}$ diameter sheath unit inserted into a $6-\mathrm{mm}$ diameter stainless steel tube. Small diameter holes (0.5-mm diameter) drilled in the steel tube allowed the hot gases to reach the sensor while protecting against possible contact with debris.

Three pyrometers were used to provide temperature data on the melt as it emerged from the melt generator. The first pyrometer was a single-wavelength device using a photodetector for the sensing element (Thermogage Inc.-Serial Number 2589). The response of this unit was on the order of $1 \mu \mathrm{s}$, which is significantly shorter than $100 \mathrm{~ms}$ exposure the unit had to melt. The device was incorporated into the test to determine if rapid 


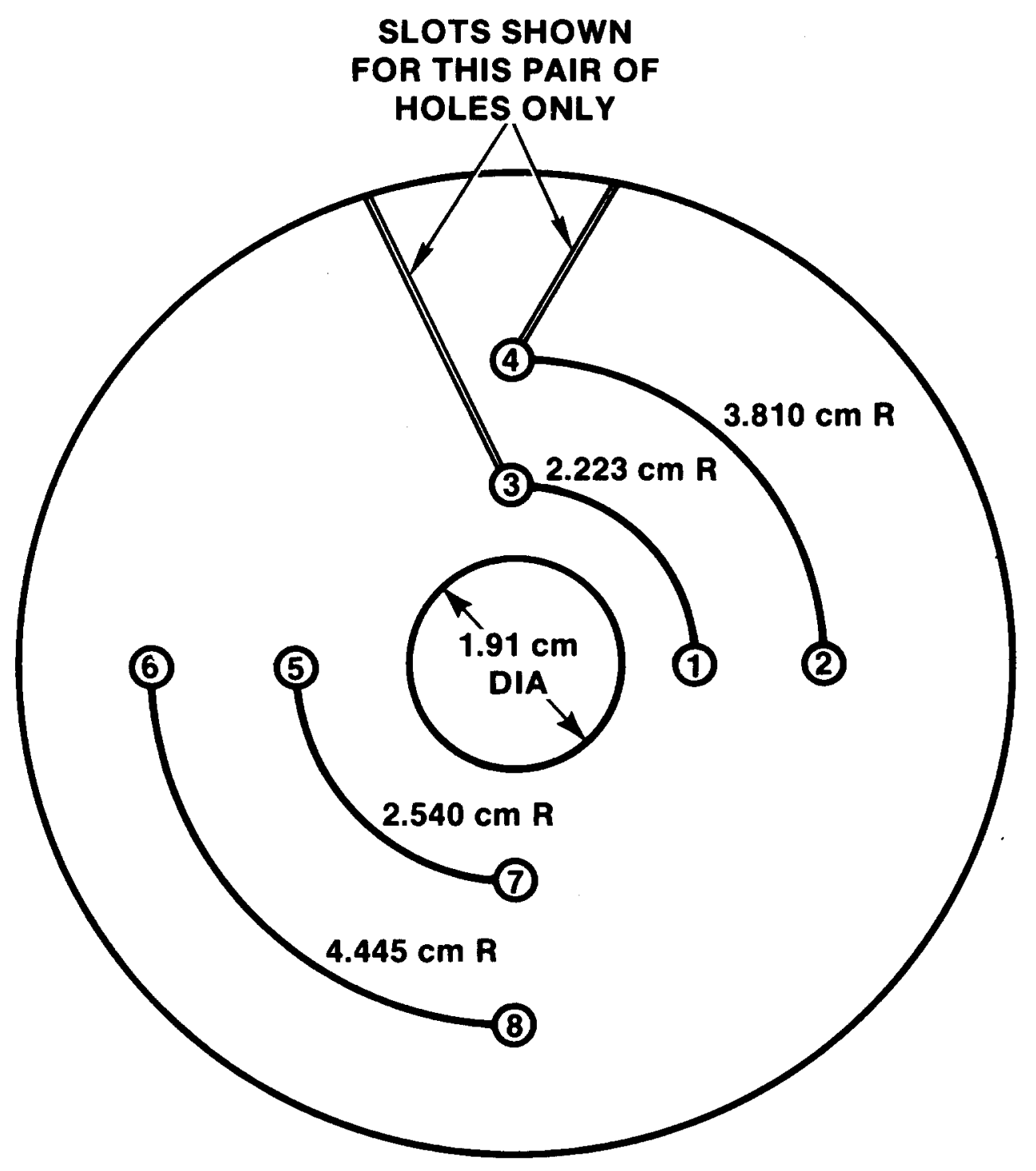

Figure 2.3: Photo Detector Locations in the Lower Flange 
Table 2.1

Summary of HIPS-3J Instrumentation

\begin{tabular}{|c|c|c|c|c|}
\hline \multicolumn{2}{|c|}{ Device } & \multirow[b]{2}{*}{ Range } & & \multirow[b]{2}{*}{ Purpose } \\
\hline Type & No. & & Location & \\
\hline Pressure & 1 & $0-34.5 \mathrm{MPa}$ & Gas Line & Reference \\
\hline Pressure & 1 & $0-41.4 \mathrm{MPa}$ & Melt Generator & Blowdown \\
\hline $\mathrm{TC}$ & 2 & $0-1500 R C$ & Melt Generator & Expansion Chamber \\
\hline Photo Detectors & 8 & & Flange Cover & Transient Hole Diameter \\
\hline Pyrometer & 1 & $1700-4000 R C$ & Jet & Melt Temperature \\
\hline Pyrometer & 1 & $1500-3500 R C$ & Jet & Melt Temperature \\
\hline Pyrometer & 1 & 1500-3000RC & Jet & Melt Temperature \\
\hline Force Cell & 1 & $-8900-8900 \mathrm{NT}$ & Concrete Slab & Reaction Force \\
\hline Cameras & 7 & $30-2000 \mathrm{fps}$ & -- & Observation \\
\hline Flash X-Ray & 4 & & Structures & Structure Interactions \\
\hline
\end{tabular}


variations in the debris temperature occurred during discharge of the melt. Because the emissivity of the molten material is uncertain, the temperature data from this device are somewhat uncertain in magnitude. The pyrometer was focused on the jet $2.5 \mathrm{~cm}$ below the melt generator. The circular target area at the jet was approximately $1.2 \mathrm{~cm}$. The second device was also a single-wavelength device (Ircon Model 22B30) incorporating optics to allow placement several meters from the target. The useful range of this instrument was $1500^{\circ}-3000^{\circ} \mathrm{C}$ with a response time constant of $30 \mathrm{~ms}$. For this experiment, the device was placed approximately $5 \mathrm{~m}$ from the melt generator. At this distance, the spot size of the image was $1.7 \mathrm{~cm}$ in diameter.

The other pyrometer (Incon Model R-35C10) was a two-color unit. For this unit, the target material was assumed to behave as a gray body, so that the ratio of transmitted energies at the two different wave-length yields temperature directly without need for emissivity corrections. This feature also reduces the influence of intervening, semitransparent materials, such as aerosols, known to accompany melt discharge.

The two-color pyrometer has a useful range of $1500^{\circ}-3500^{\circ} \mathrm{C}$ and a time constant of $10 \mathrm{~ms}$. This time constant is significantly greater than that of one-color pyrometer but still an order of magnitude less than the expected melt discharge time. The pyrometer was focused on the jet $0.5 \mathrm{~m}$ below the melt generator, and the circular target area at the jet was approximately $2.5 \mathrm{~cm}$.

The reaction force on the concrete slab resulting from the impinging jet was measured by mounting a single force cell on the frame supporting the slab as depicted in Figure 2.4. The device (Kulite Model TC-2000) uses semiconductor strain gauges to form a balanced 4-arm bridge circuit and a rated capacity of $20001 \mathrm{~b}$ in both tension and compression. The support frame was constructed so that the front edge pivoted about a pin while the back was attached to the gauge. Both the pivot and the load cell were placed on a steel plate laid on the massive concrete block. In this manner, forces exerted on the center of the concrete surface were carried equally by the pivot and the gauge.

Six high-speed photographic film cameras and one video camera were employed to record the test; Table 2.2 summarizes the camera coverage for this test. The 2000 fps cameras (HyCam manufactured by Redlake Corp.) were triggered by a shielded photo detector embedded in the thermite powder near the bottom of the melt crucible. These cameras provided closeup coverage of the melt/structure interactions. The remaining cameras provided overall coverage of the test. These latter cameras were triggered by the signal that initiated ignition of the thermite burn with each camera delayed a predetermined length of time. The entire test was recorded in real time with a video camera. 


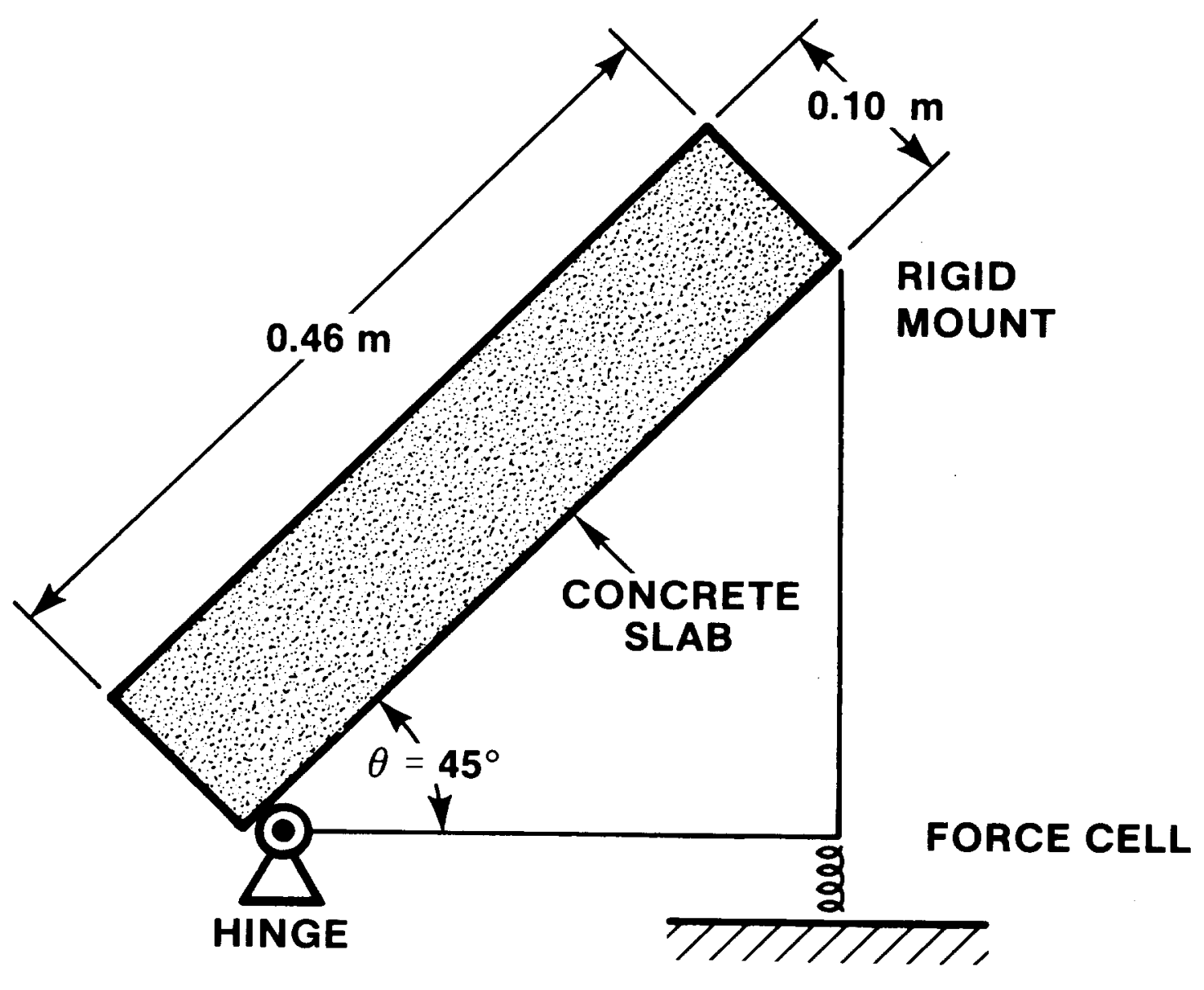

Figure 2.4: Force Cell Location 
Table 2.2

Summary of HIPS-3J Camera Coverage

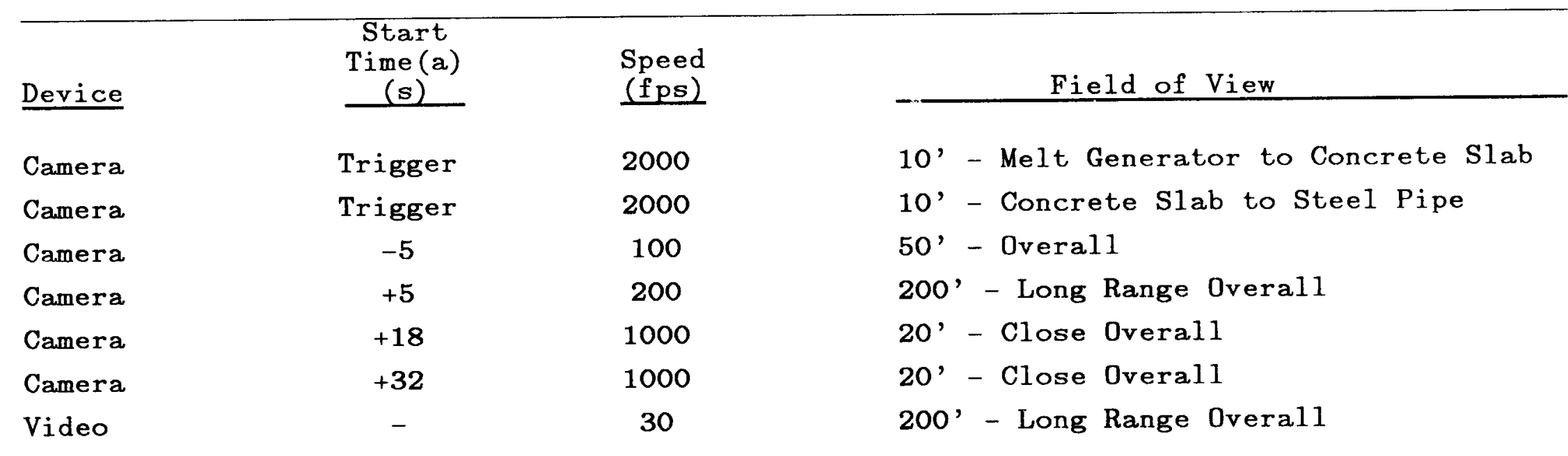

- Relative to Ignition of Thermite Powder 
Previous experiments have shown that an intense cloud of aerosols is produced during melt discharge from the melt generator. It seemed likely that these aerosols would obscure the nature of melt/structure interactions, thus reducing the value of photographic film as a diagnostic tool. Under these conditions, radiographs are useful because they are not hindered by aerosols or blinded by radiated light from the melt stream. The flash X-ray (Hewlett Packard Model KC-150, $150 \mathrm{keV}$ ) technique should be particularly useful because the inherent short exposure times (70 ns) essentially freezes the motion of even the fastest particles.

Figure 2.5 shows the position of the four X-ray film cassettes in relation to the apparatus. The $\mathrm{X}$-ray generators and film cassettes were positioned to give a view parallel to the pipe and orthogonal to the direction of flowing debris. The first cassette looks at the melt stream as it emerges from the melt generator, while the second cassette looks at the point where the melt stream strikes the concrete slab. The third and fourth cassettes look at melt/pipe interactions at the front and rear of the steel pipe respectively.

The aluminum cassettes and $\mathrm{X}$-ray generators were insulated with a refractory blanket to protect them from the splatter of hot melt. The X-ray units (located $4 \mathrm{~m}$ from the cassettes) were triggered as sequenced by photo detectors placed at the exit of the melt generator, the surface of the concrete slab, and the pipe surface. It was estimated that the resolution of the X-ray system was no better than $0.3 \mathrm{~mm}$ due to the combined effects of film and geometric unsharpness.

\subsection{Initial Conditions}

The initial conditions for HIPS-3J are summarized in Table 2.3. The gas volume, pressure, and temperature are all values at the onset of melt ejection.

\subsection{Experiment Results and Analysis}

This section presents the results obtained from the HIPS- $3 J$ experiment. Analysis of the test is also presented where appropriate to aid in the understanding and interpretation of the experiment observations.

\subsubsection{Camera Coverage}

Figure 2.6 summarizes the sequence of events as recorded by the cameras. X-ray coverage of this test, which was focused on melt/structure interactions, failed to provide useful information because a faulty trigger signal caused all X-ray heads to improperly synchronize with melt ejection.

Prior to impact with the slab, the jet appears as a luminous cone. Flash X-rays of similar jets from other tests (Brockmann \& 


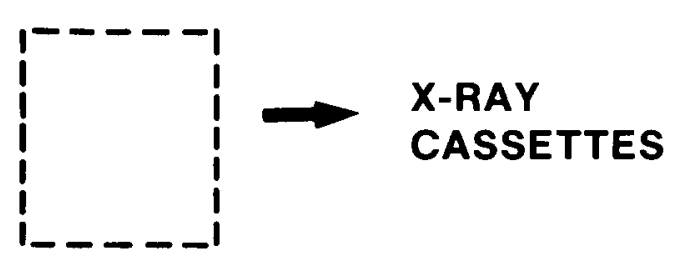

(NOT TO SCALE)

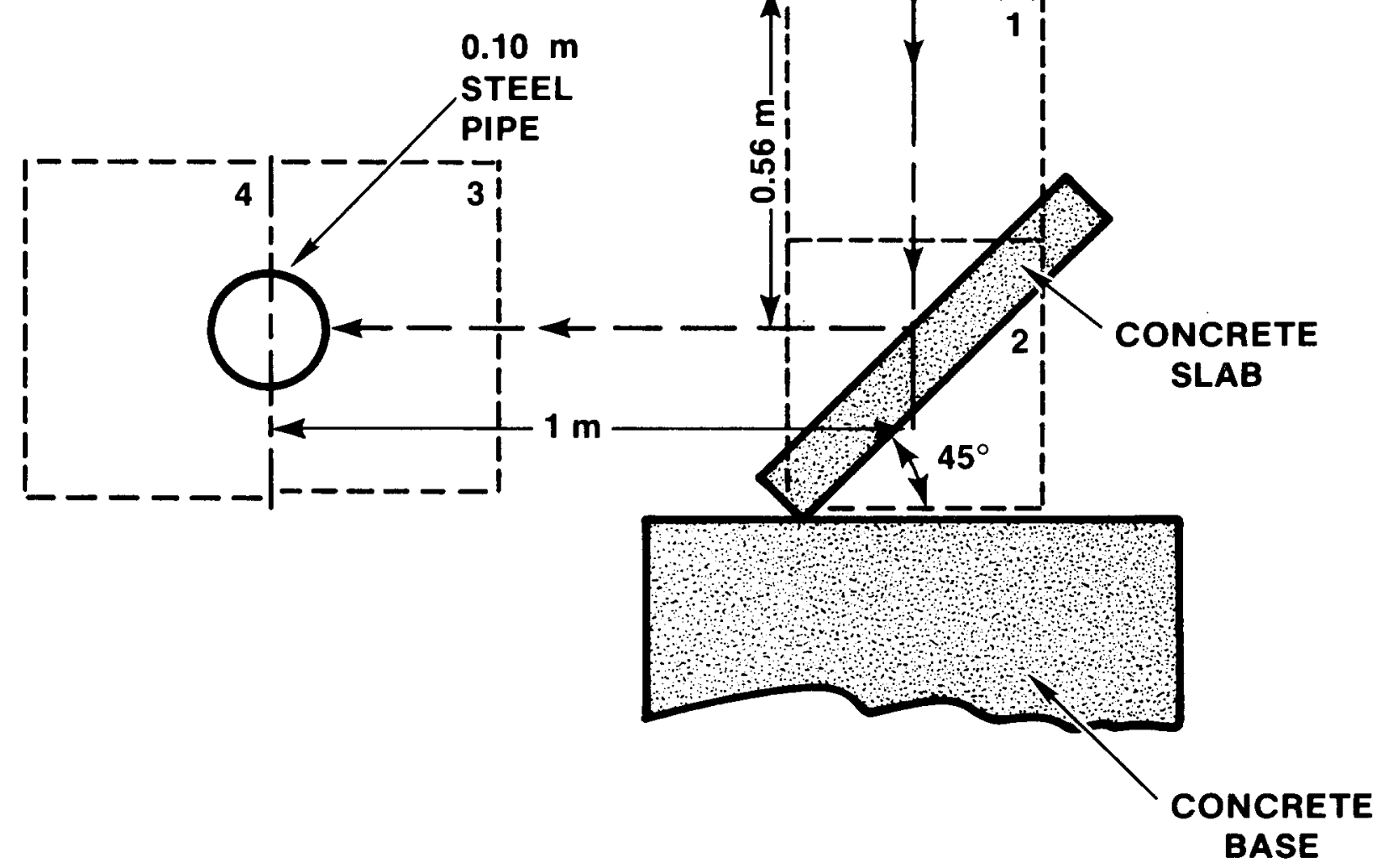

Figure 2.5: X-Ray Cassette Locations 
Table 2.3

HIPS-3J Initial Conditions

\begin{tabular}{|c|c|}
\hline Melt Mass & $80 \mathrm{~kg}$ \\
\hline Thermite Composition & $\begin{array}{l}\text { Iron Dxide }\left(\mathrm{Fe}_{3} \mathrm{O}_{4}\right) \\
\text { Aluminum (AI) }\end{array}$ \\
\hline Melt Compositions & $\operatorname{Iron}(\mathrm{Fe})+\mathrm{Alumina}\left(\mathrm{Al}_{2} \mathrm{O}_{3}\right)$ \\
\hline Dopants & None \\
\hline Gas & Carbon Dioxide $\left(\mathrm{CO}_{2}\right)$ \\
\hline Gas Volume & $0.118 \mathrm{~m}^{3}$ \\
\hline Initial Pressure & $4.18 \mathrm{MPa}$ \\
\hline Ambient Temperature & $423 \mathrm{~K}$ \\
\hline Orifice Diameter & $0.0191 \mathrm{~m}$ \\
\hline
\end{tabular}




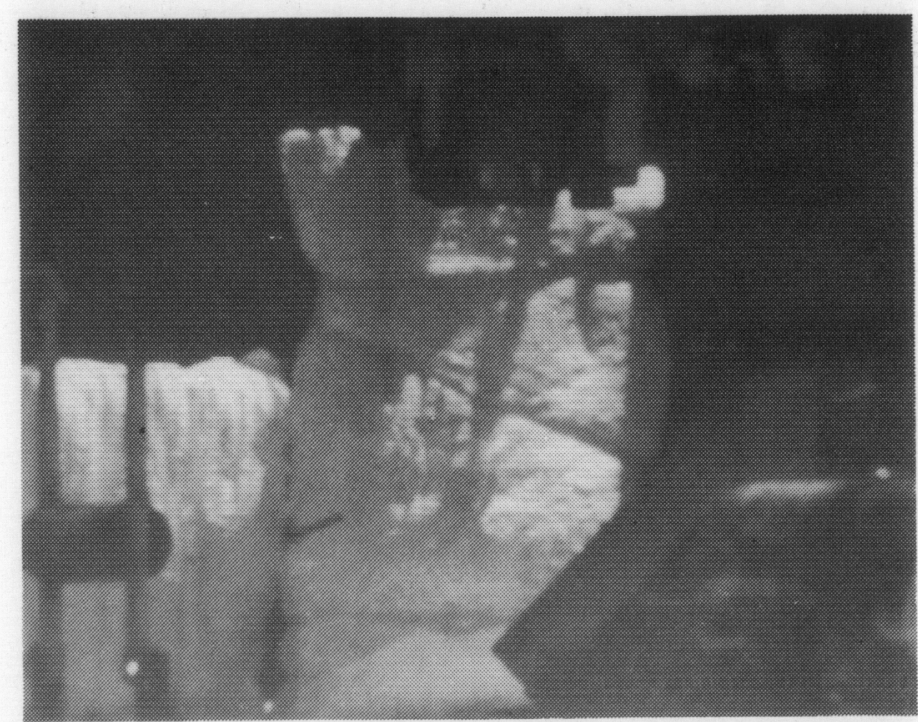

a) TIME $=\mathbf{5} \mathrm{ms}$

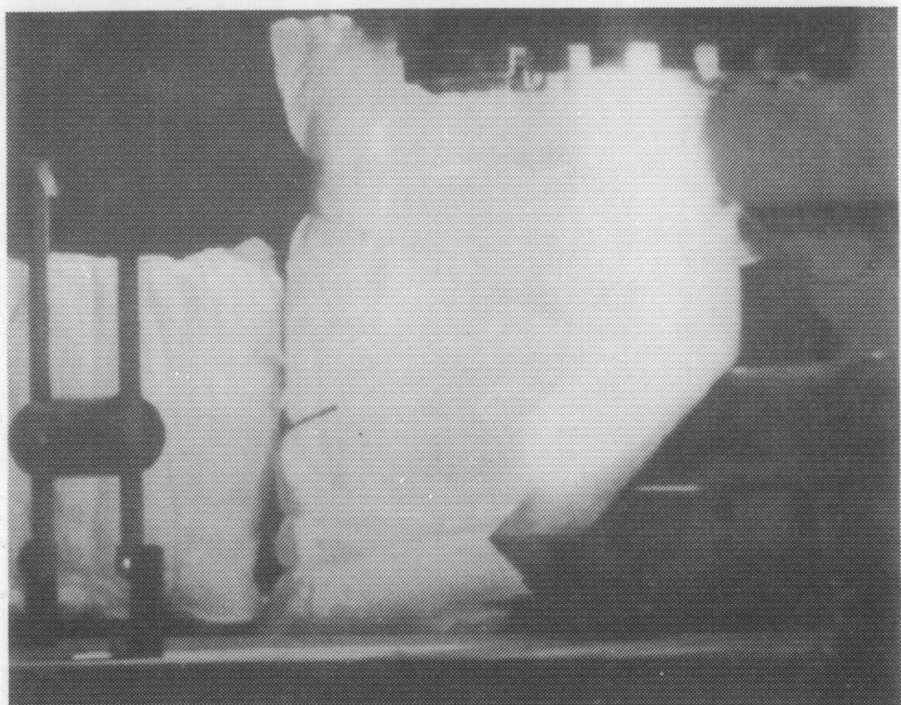

c) TIME $=15 \mathrm{~ms}$

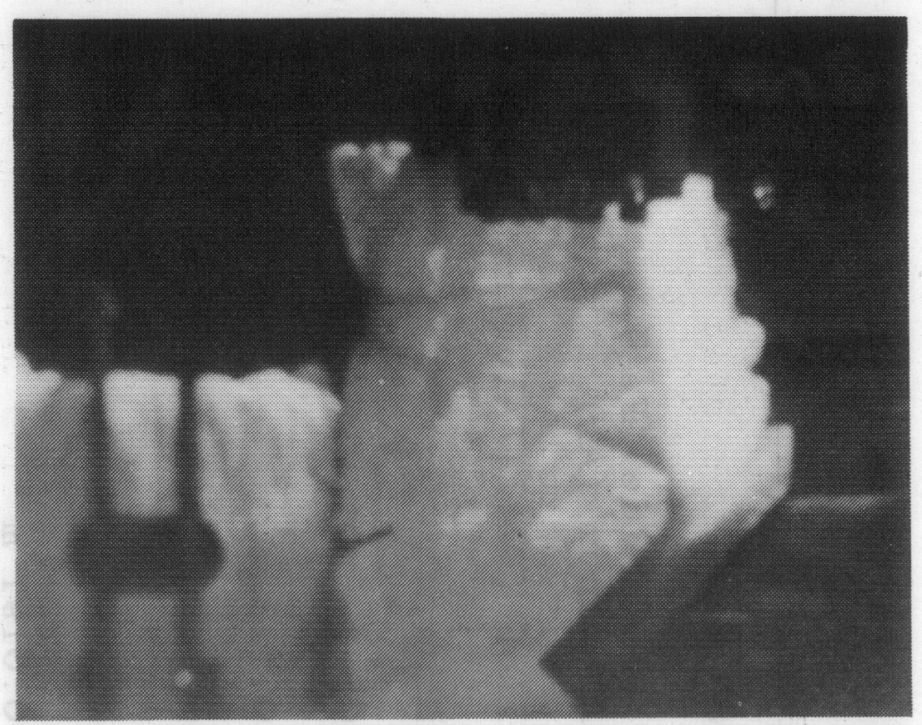

b) TIME $=10 \mathrm{~ms}$

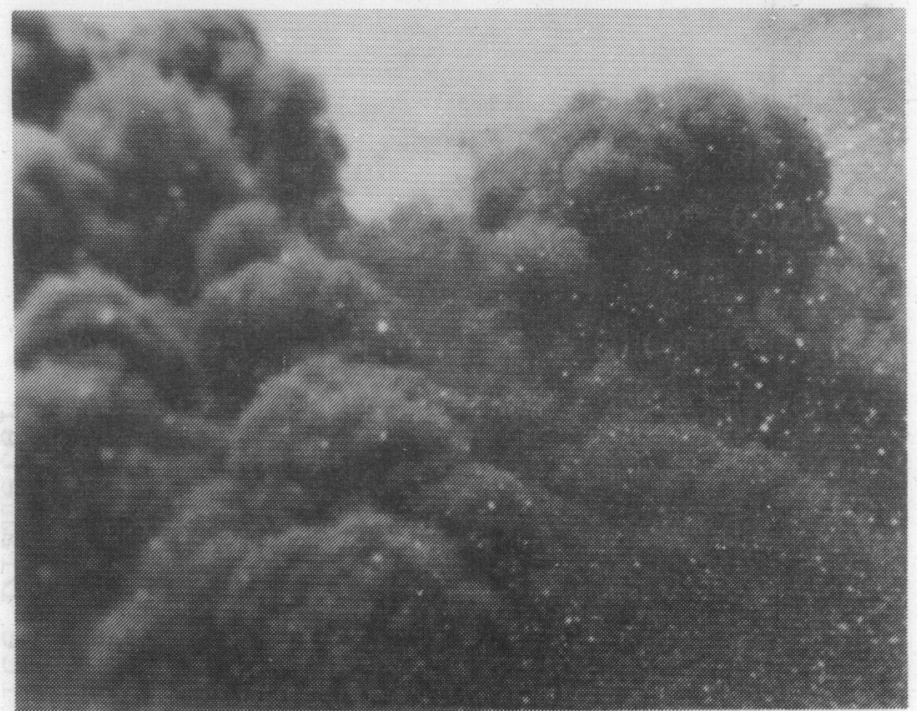

d) LATE TIME, FAR VIEW

Figure 2.6: Camera Coverage 
Tarbell, 1984) where $\mathrm{CO}_{2}$ was the pressurizing gas indicated that there is a coherent core of melt surrounded by luminous gas and aerosol. As Figure 2.6 indicates, the jet appears to travel about $75 \%$ of the distance to the slab in two frames of the film record ( $10 \mathrm{~ms}$ ), thus indicating that the initial jet velocity was approximately $42 \mathrm{~m} / \mathrm{s}$. This visual estimate of the jet velocity exceeded the predicted value of $28 \mathrm{~m} / \mathrm{s}$, assuming liquid discharge and an orifice coefficient of 0.6 . The predicted value, as will be discussed later, is consistent with the measured depressurization history of the melt generator during melt discharge. The visual estimate is more closely comparable to the maximum possible liquid discharge velocity of $46.6 \mathrm{~m} / \mathrm{s}$, which occurs for a discharge coefficient of unity. It should be noted, however, that the visual estimate of the initial jet velocity suffers from a lack of resolution in the space and time measurements. The predicted values of the jet velocity, which are consistent with other data over the entire duration of melt discharge, are thought to be a more accurate measure of the quasi-steady jet velocity.

Upon impact with the slab, vigorous splashing was observed with the bulk of the material being deflected at a shallow angle relative to the slab. Only a negligible amount of melt was retained on the surface of the concrete slab. Far field photos taken late in the sequence show melt particles propagating in all directions with an intense cloud of aerosols obscuring the entire test apparatus.

Interaction of the redirected melt particles with the steel pipe was completely obscured by the aerosol cloud, which begins to form shortly after the jet struck the slab. Only a small quantity of melt was retained by the pipe in the form of a thin crust on the forward surface of the pipe.

Aerosol instrumentation was not employed on this test so that the quantity and size distribution of the aerosols were not determined. However, the mechanisms of aerosol production, which were identified by Brockmann \& Tarbell (1984) for other tests, are believed to be operable in the HIPS-3J test also. Of those mechanisms identified, vaporization (not boiling) from the highly fragmented melt (after splashing) followed by subsequent condensation of the vapors in the cool atmosphere is thought to be the dominant source of the aerosols.

\subsubsection{Pressurization and Blowdown History of the Melt Generator}

Figure 2.7 summarizes the pressure history of the melt generator. The start of melt discharge is taken as the reference time. Gradual charging of the melt generator with $\mathrm{CO}_{2}$ gas began at $-175 \mathrm{~s}$. Prior to ignition of the thermite at $-15 \mathrm{~s}$, the melt generator was isolated from the gas source. The thermite reaction time was $15 \mathrm{~s}$. 


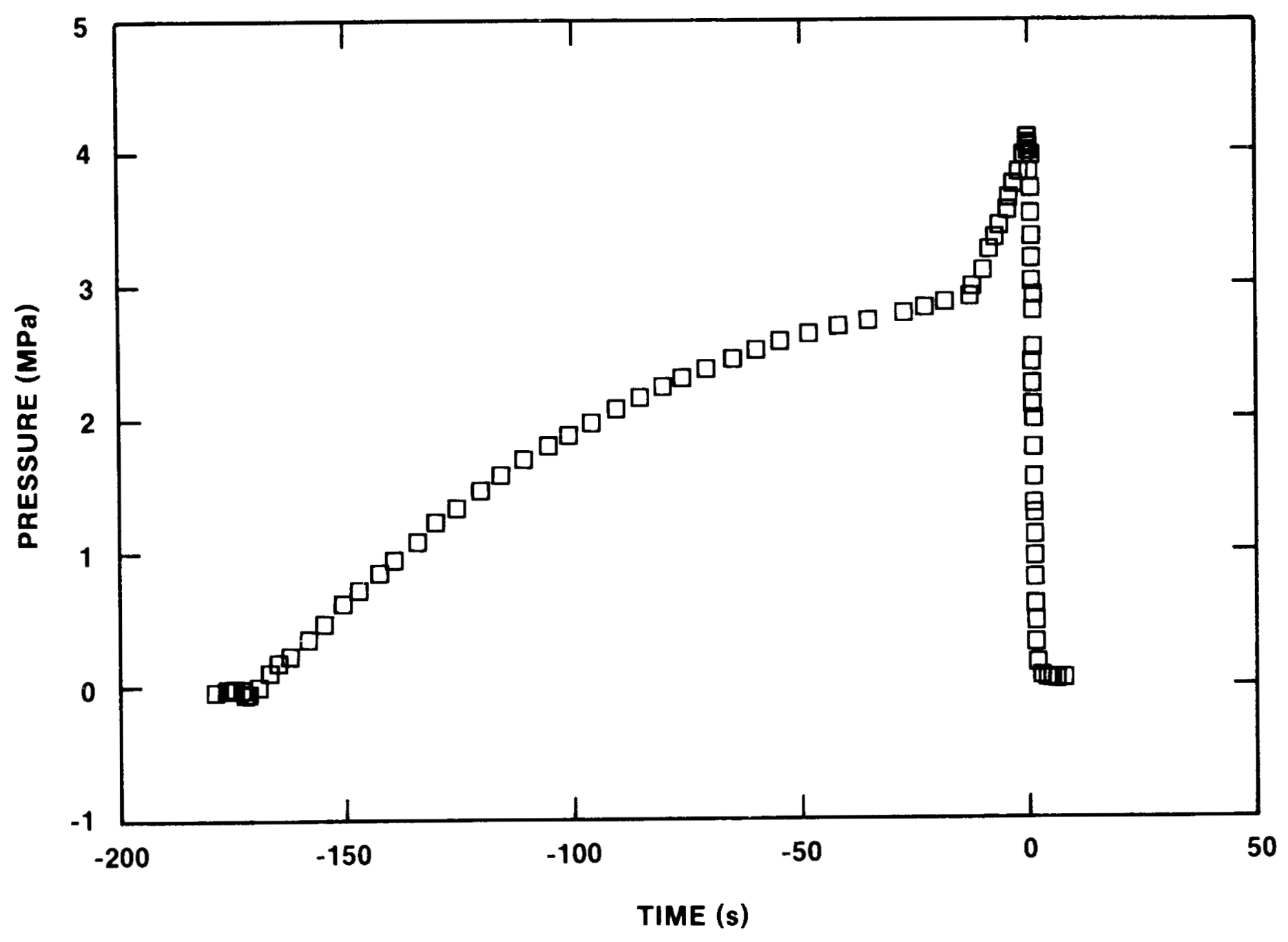

Figure 2.7: Pressurization History of the Melt Generator 
Both the temperature and pressure were observed to increase during the thermite reaction. The pressure increase occurred partly because contaminants in the charge powders produced gas during the burn, so it was useful to estimate the magnitude of the effect. By applying the ideal gas law to the gas before and after the burn (subscripts 0 and 1 , respectively), the relative change in the gas mass and composition is given by:

$$
\frac{\Delta(\mathrm{mR})}{\mathrm{mR}}=\frac{\mathrm{T}_{0}}{\mathrm{~T}_{1}} \frac{\mathrm{P}_{1}}{\mathrm{P}_{\mathrm{O}}} \frac{\mathrm{V}_{0}}{\mathrm{~V}_{1}}-1 .
$$

Here $m, R, T, P$, and $V$ are the mass, gas constant, temperature, pressure, and free volume of the cover gas.

Composition and density changes of the thermite reaction alters slightly the free volume in the melt generator. The ratio $\mathrm{V}_{1} / \mathrm{V}_{0}$ is estimated to be 0.91 . The measured ratios of pressure $\left(\mathrm{P}_{1} / \mathrm{P}_{0}\right)$ and temperature $\left(\mathrm{T}_{1} / \mathrm{T}_{\mathrm{O}}\right)$ of the gas are about 1.36 and 1.42 , respectively. Using these values,

$$
\frac{\Delta \mathrm{mR}}{\mathrm{mR}}=.052
$$

indicating that contaminant gases contributed only slightly to the pressurizing gas.

Figure 2.8 shows an expanded version of the depressurization history of the melt generator following the onset of melt ejection. Two phases can be distinguished; the first phase, lasting about $475 \mathrm{~ms}$, corresponds to liquid phase discharge during which the pressure decreases because the free volume increases as melt is expelled from the generator. The onset of gas flow out the orifice marked the beginning of the second phase. Gas discharge is accompanied by continued, but reduced, discharge of melt (Pilch \& Tarbell, 1985). The second phase lasts $1.5-2 \mathrm{~s}$ at which time the blowdown of the generator is complete.

Figure 2.8 also shows a model prediction (Pilch \& Tarbell, 1985) for the blowdown history. During the first phase, the model couples melt discharge (sharp-edged orifice discharge coefficient of 0.6 ) with a transient orifice diameter that is calculated to increase in size due to ablation. The excellent agreement between experiment data and model predictions lends confidence in the model's ability to predict ablation rates and time dependent hole sizes prior to the onset of gas blowdown.

Figure 2.9 shows the time-dependent orifice diameter as predicted by the model of Pilch \& Tarbell (1985). During the first phase, the ablation rate (based on diameter) is constant and equal to $9.25 \mathrm{~cm} / \mathrm{s}$. The predicted ablation rate rapidly approaches zero when gas discharge begins. The final orifice size is predicted to be $6.5 \mathrm{~cm}$, which is in excellent agreement 


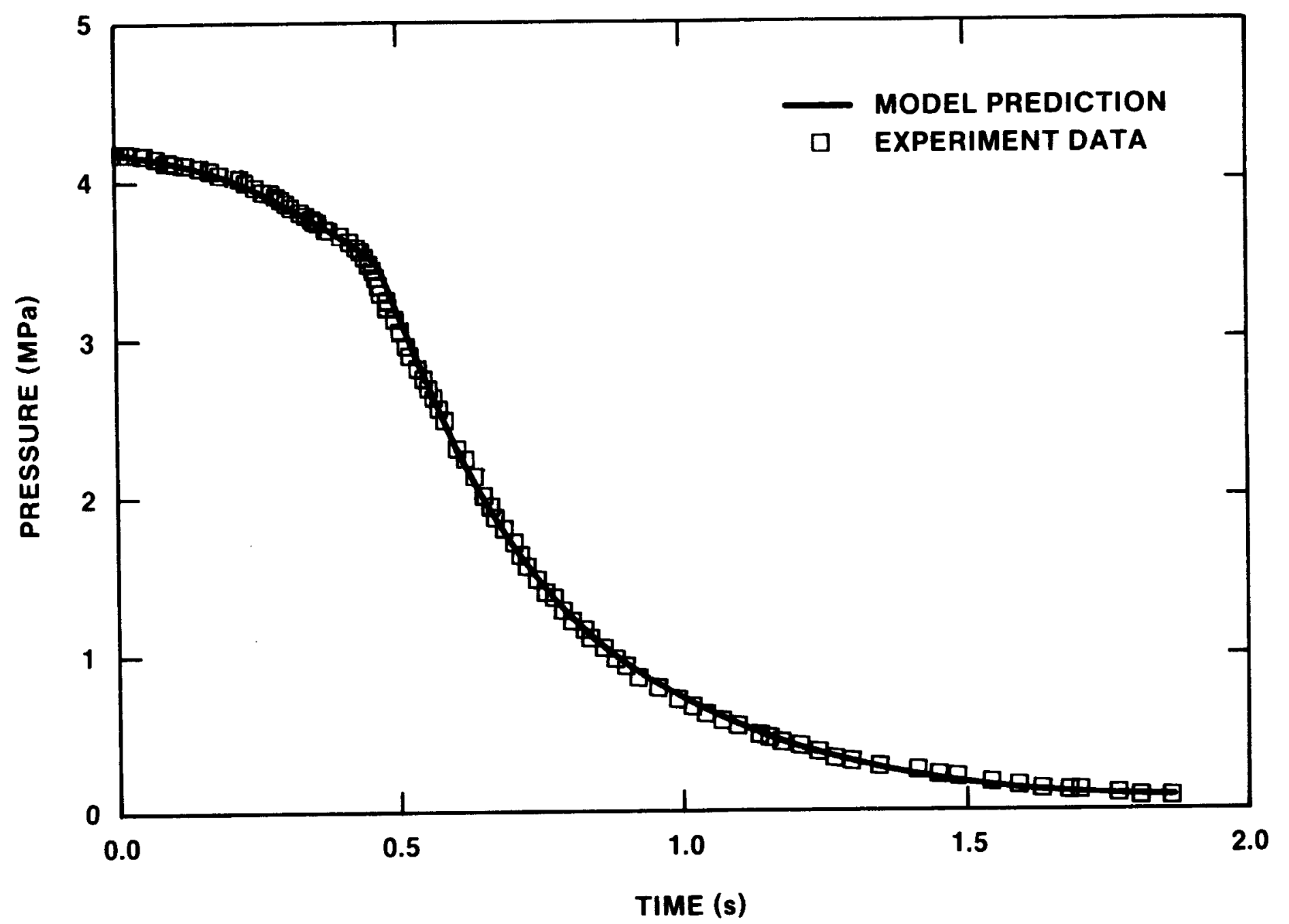

Figure 2.8: Pressure History of the Melt Generator During Melt Ejection and Blowdown 


$$
\sqrt{2}
$$


with the posttest observation of $6-7 \mathrm{~cm}$. Figure 2.10 compares an unused discharge orifice with the one removed from the HIPS-3J apparatus to show that the erosion pattern is not exactly symmetric. Notice that the upstream side of the discharge orifice has taken on a bellmouth shape.

In the above discussion, the ablation rate and transient hole diameter were obtained from model predictions that were validated by pressure measurements during the blowdown process. Phototransistors were imbedded in the lower flange at varying distances from the orifice surface in anticipation of directly measuring the transient hole size. Unfortunately, this technique did not provide useful data on hole ablation because of unexplained signal noise.

Figure 2.3 shows the locations of the detectors in the lower flange, and Table 2.4 summarizes the experiment data. Eight combinations of sensors or sensors and initial orifice size were available. Those pairs involving the initial orifice size must be discarded because there was a fajlure to synchronize the detector signal with the onset of melt discharge. Four detectors signaled melt at their locations when the thermite was ignited, which occurred about $15 \mathrm{~s}$ prior to melt discharge. Thus, signal noise dictated that the $3 ; 4,5 ; 6$, and $7 ; 8$ pairs also be discarded. Only the 1;2 pair of detectors had complete timing information, and this pair suggested that the ablation rate (based on diameter) is $1058 \mathrm{~cm} / \mathrm{s}$. This is two orders of magnitude greater than model predictions, implying a final hole diameter of $503 \mathrm{~cm}$ if the ablation rate were constant over the discharge interval. This clearly was not observed.

Based on the slope of the melt generator pressure record, gas blowthrough (Pilch \& Tarbell, 1985) occurs at approximately 475 ms after melt discharge was initiated. Following gas blowthrough, there is a simultaneous discharge of melt and gas with pneumatic atomization of the melt occurring in the orifice. Model predictions (Pilch \& Tarbell, 1985) for this second phase are compared with experiment data on Figure 2.8. The model assumes that the gas in the melt generator expands isentropically during blowdown. The model assumes that choked, adiabatic, and separated flow occurs in the orifice. The figure shows excellent agreement between model predictions and experiment data for this second, predominantly gas discharge, phase.

As depicted in Figure 2.4, a load cell was centered along the back edge of the rack supporting the concrete slab. Because of the geometry, the load cell measured one-half the force required to deflect the jet downwards along the slab:

$$
F=\frac{1}{2}\left(V_{j} \dot{\mathrm{m}}_{j}+\mathrm{V}_{\mathbf{g}_{\mathrm{g}}}\right)\left(1-\sin ^{2} \theta\right),
$$

where the velocities (V) and the mass flow rates ( $\dot{m}$ ) of the melt and gas are taken from the model by Pilch \& Tarbell (1985). 


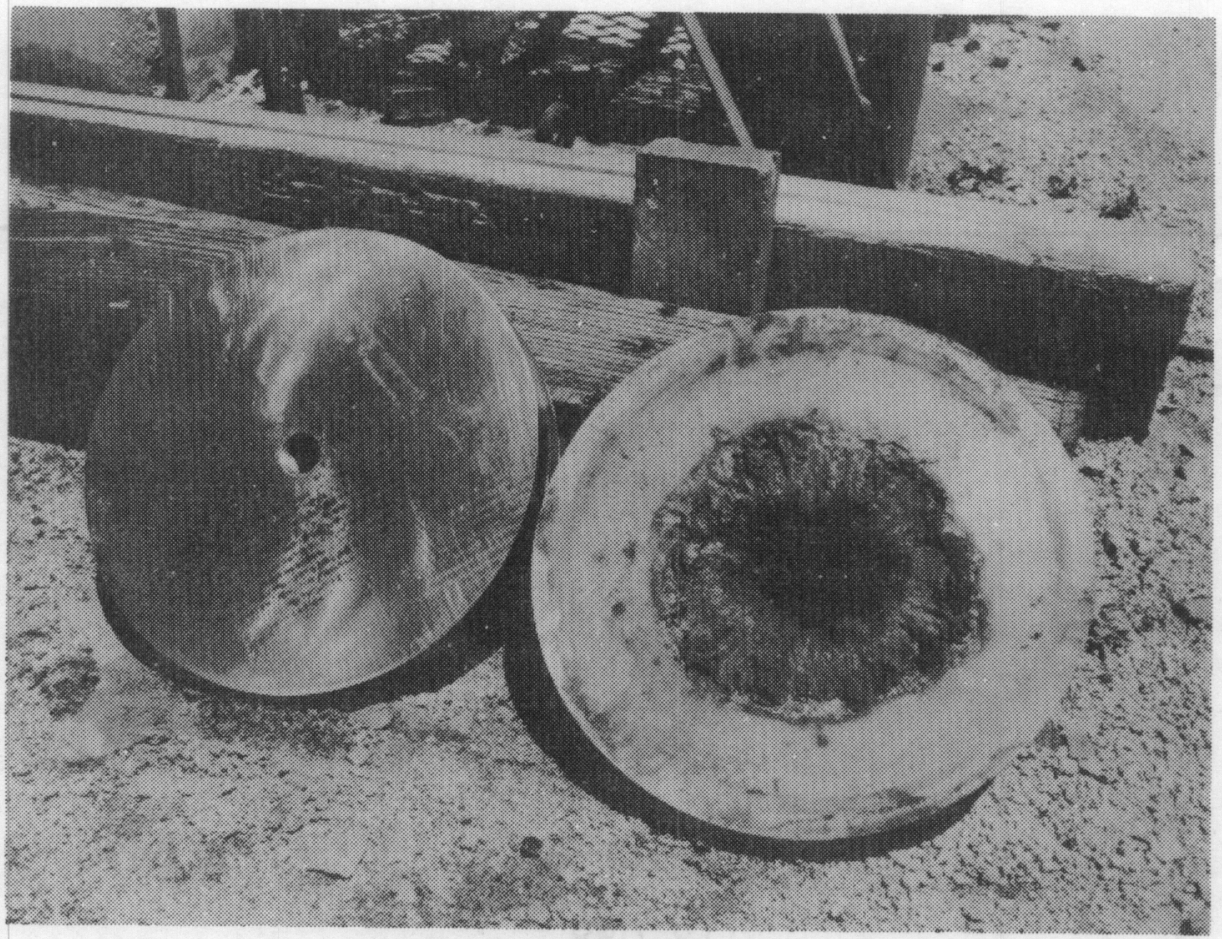

UPSTREAM SIDE

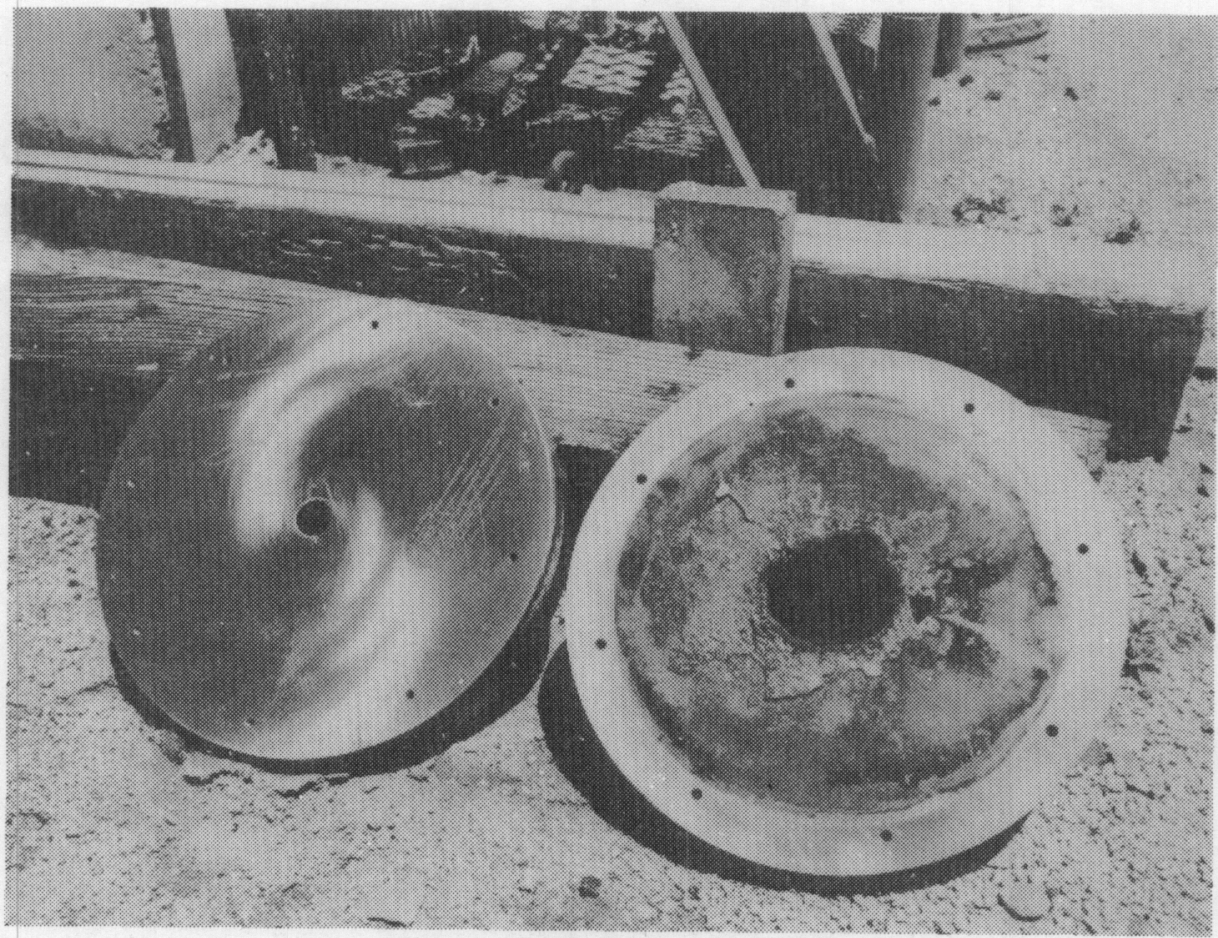

DOWNSTREAM SIDE

Figure 2.10: Upstream and Downstream Sides of the Discharge Orifice Compared to an Unused Orifice Plate 
Table 2.4

Photo Detector Signal Sequence

Pair Number

0

1

0

3

0

5

0
7

1

2

3

4

5

6

7

8
Time of

Signal (s)

$13 . \overline{0} 58$

13.063

$13 . \overline{0}$.

Ignition

13. 058

13.061

13.063

Ignition

13.063

Ignition

Ignition

Ignition
$\Delta \mathrm{R}(\mathrm{cm})$

2.223

2.223

2.540

2.540

1.587

1. 587

1.905

1.905 
As discussed previously, this model successfully predicts the melt ejection and blowdown phases of the discharge process.

Load cell measurements exceeded the predicted forces by about an order of magnitude, which is physically impossible given the initial conditions of the experiment. This suggests a sensitivity error in interpreting the data, but the source of any possible error of this type could not be identified with certainty.

Figure 2.11 compares model predictions with experiment data that are arbitrarily scaled downwards by a factor of ten. Model predictions and experiment data show that the reaction force increases during the melt ejection phase. The reaction force increases because the orifice increases in size thus allowing more melt to impinge on the slab as time increases. The reaction force is seen to drop off rapidly once gas discharge begins. This is because the low density gas does not carry the same momentum as the higher density melt despite the fact that gas velocities are much higher. The experiment data also exhibit a low frequency oscillation, with the time constant ( 0.21 s) is comparable to the the time scale of melt discharge. This oscillation is much slower than the natural frequency of the slab/load-cell system, and it most likely results from oscillations of the support structure.

Three pyrometers were used to measure the temperature of the melt jet: 1 one-color pyrometer and 2 two-color pyrometers. The one-color pyrometer was placed in close proximity to the melt stream where its function was compromised shortly after it was struck by the melt. The one-color pyrometers require an emissivity value for the melt in order to quantify the temperature, and a constant value of 0.3 (Touloukian, 1967), which is appropriate for the alumina phase (by volume), was used in the calculations. The two-color pyrometers require no such correction.

Figure 2.12 compares the measured temperatures from the three pyrometers. Peak temperatures range from $2170 \mathrm{~K}$ to $2470 \mathrm{~K}$. These temperatures are well below the theoretical value of $3200 \mathrm{~K}$ for a complete and adiabatic reaction, thus suggesting that the reaction was neither complete nor adiabatic. The measured temperatures are well above the freezing point (1700 K) and well below the boiling point $(3200 \mathrm{~K})$ of the iron phase of the melt. However, the peak temperatures straddle the freezing point $(2300 \mathrm{~K})$ of the alumina phase of the melt.

\subsubsection{Structure Interactions}

The film records reveal that splashing is a significant interaction when high velocity jets and particle streams strike simple structures. Only a small amount of material was retained by the surfaces (including the steel surface), with the retained 


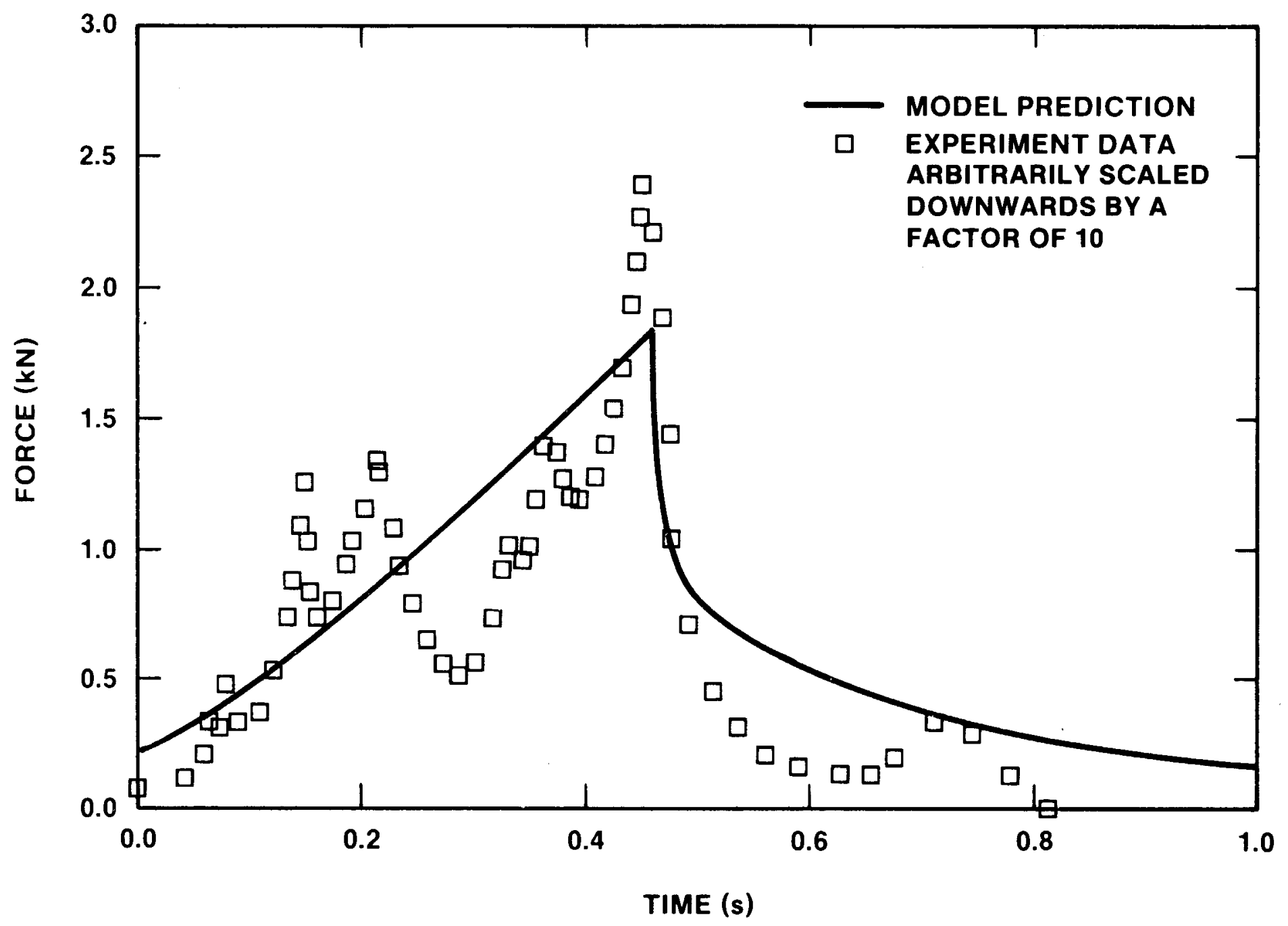

Figure 2.11: Comparison of Scaled Load Cell Measurements With Model Prediction 


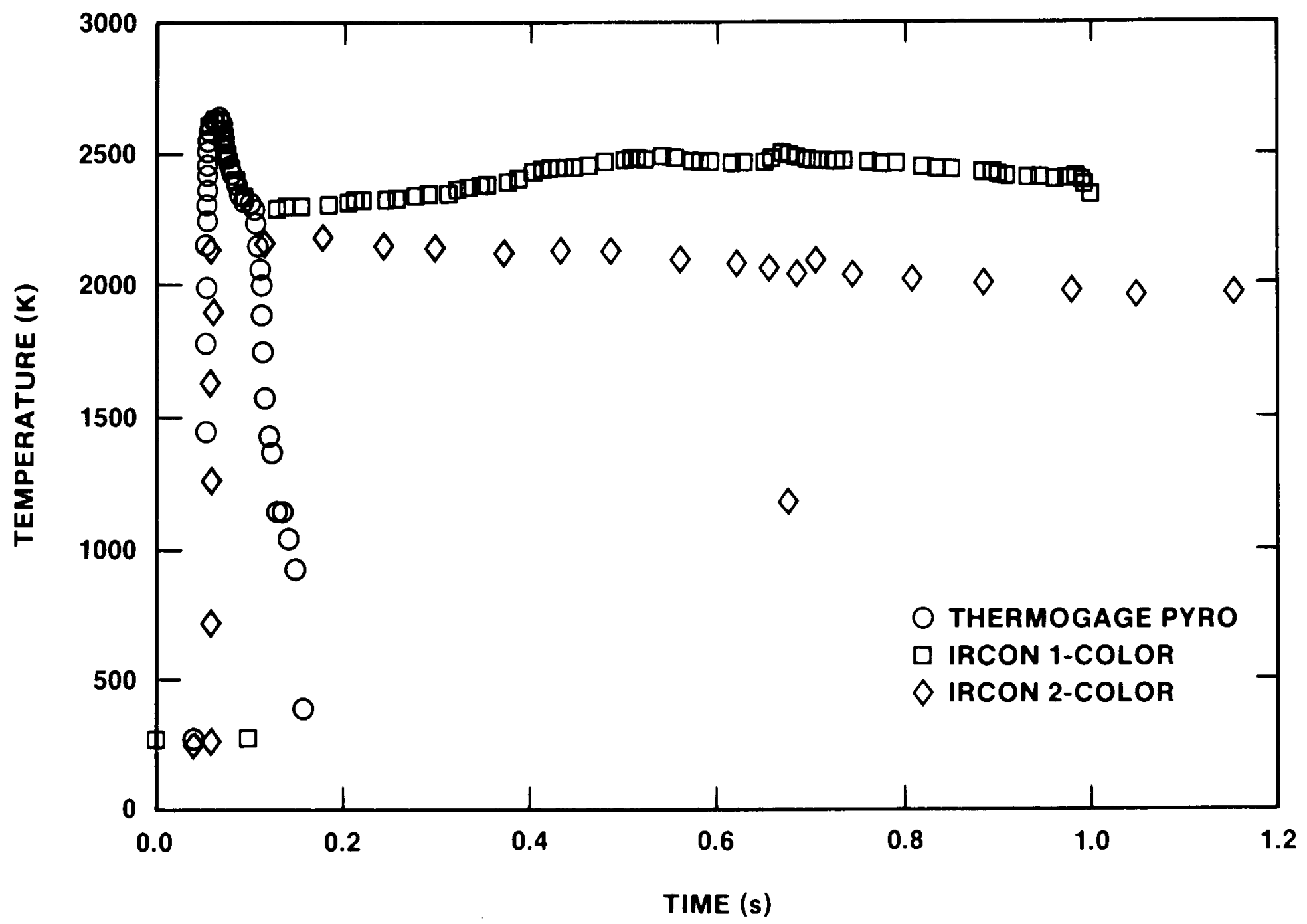

Figure 2.12: Pyrometer Measurements of Jet Fxit Temperatures 
material in the form of a thin crust. The impact of melt streams with structures does not guarantee that the melt will be trapped or retained by the structure.

The interaction of melt streams with structures alters the direction and character of the stream. Figure 2.6 shows that the bulk of the deflected material skids along the surface of the slab. This is consistent with observations of Tarbell et al. (1984) in the SPIT-19 experiment. The film records clearly show that the melt jet fragments when it impacts the concrete slab, thus greatly increasing the surface area of the melt stream. Thus the structure interaction may also promote mixing of the melt with the atmosphere since splashed particles are observed to propagate in many directions.

Crust formation was the only observed mechanism for retaining material on the simple structures used in this test. However, only limited and somewhat isolated crust formation was observed on the concrete slab, with the surface appearing slightly eroded $(<1 \mathrm{~cm})$. This observation is consistent with reported observations from other tests (Tarbell et al., 1986). It is speculated that decomposition of the concrete surface under the applied heat load prevents a stable crust from adhering to the concrete. Concrete is an ineffective material for retaining melt by crust formation.

A more uniform crust, approximately $0.5 \mathrm{~mm}$ thick, was observed on the forward-facing surface of the steel pipe. No crust was observed on the rear surface, which was shadowed from the debris stream. Thus, when extrapolating to reactor geometry, it must be recognized that melt can be retained as a crust only on those steel surfaces that are exposed to the melt.

The maximum quantity of material that might be retained as a crust can be estimated by assuming conduction freezing of an infinite supply of melt on an infinitely thick surface. The crust thickness $(\delta)$ after a period of time ( $t$ ) is given by

$$
\delta=2 \lambda \sqrt{\alpha t},
$$

where $\lambda$ is a growth rate parameter for a superheated melt and is determined by a transcendental equation (Carslaw \& Jaegar, 1959), and $\alpha$ is the thermal diffusivity of the frozen crust. The values for $\lambda$ and $\alpha$ are 0.5 and $2.8 \times 10^{-6}$, respectively, for iron/alumina thermite on room temperature steel.

The predicted thickness of crust that could develop during the melt relocation time $(0.5-1.0 \mathrm{~s})$ is $1.1-1.7 \mathrm{~mm}$. This predicted thickness is a factor of 2 - 3 greater than the observed crust thickness. This suggests that the freezing process was limited by the supply of melt to the surface. Indeed, Figure 2.6 shows that a large portion of the melt skids along the slab surface and is not redirected towards the pipe. An upper bound to the fraction of melt splashed into a conceptual 
hemisphere above the slab can be estimated by assuming that all splashing melt is retained as a uniform crust $0.5 \mathrm{~mm}$ thick on the surface of the hemisphere. Approximately $30 \mathrm{~kg}$, representing $37 \%$ of all the melt, would be retained in this fashion. 
The objective of the HIPS-7C experiment is to determine if a specific excavity structure, such as that found in the Zion plant, would be effective in trapping melt that is dispersed from the reactor cavity. To achieve this objective, an $80 \mathrm{~kg}$ mass of molten iron and alumina was expelled from a pressurized melt generator into a scaled model of the $\mathrm{Zion}$ reactor cavity. Melt dispersed from the cavity then impacted on a scaled model of the excavity structure found in the Zion plant. The entire apparatus was placed in a large open-ended steel box in order to facilitate posttest recovery of the debris.

\subsection{Apparatus}

In the HIPS-7C test, $80 \mathrm{~kg}$ of molten iron and alumina, doped with $1.5 \mathrm{~kg}$ of fission product mocks, was ejected from a pressurized melt generator through an ablating orifice. The melt generator is essentially the same fixture as used in the HIPS-3J test (Figure 2.2) and other HIPS tests (Tarbell et al. 1986). The jet of melt was directed into a $1: 10$ linearly-scaled concrete model of the $\mathrm{Zion}$ reactor cavity. The cavity model is the same one used in previous tests (HIPS-2C, HIPS-5C) and details can be found in Tarbell et al. (1986).

Just outside the cavity was a $1: 10$ linearly scaled model of a structure which, in the Zion containment (Figure 1.1), allows instrument tubes to pass from the reactor cavity into the seal table room. The structure was made from three slabs (0.1 m thick) of 1 imestone common-sand concrete. This structure is essentially a three-sided room with a roof and a short overhang on the open side. Details of the structure are given in Figure 3.1 The structure and cavity exit are oriented in such a way that all debris exiting the cavity will impact the structure unless it is redirected by the deflected gas stream.

The entire apparatus (melt generator, cavity, and excavity structure) was placed in a large steel chamber ( $45 \mathrm{~m}^{3}$ ) that was open on one end. The apparatus was oriented such that the open side of the structure faced the closed back of the chamber. Details of the apparatus and the chamber are given in Figure 3.2.

\subsection{Instrumentation}

A summary of the HIPS-7C instrumentation is given in Table 3.1. The melt generator was instrumented with two pressure transducers and one thermocouple to determine the gas pressure and temperature, respectively. One pressure gauge (Kulite model H19S-375) was placed in a machined recess in the top flange cover. Stainless steel metal turnings in front of the gauge face protected the device from damage by melt particles. A similar gauge was mounted in a tee fitting in the gas line heading to the 


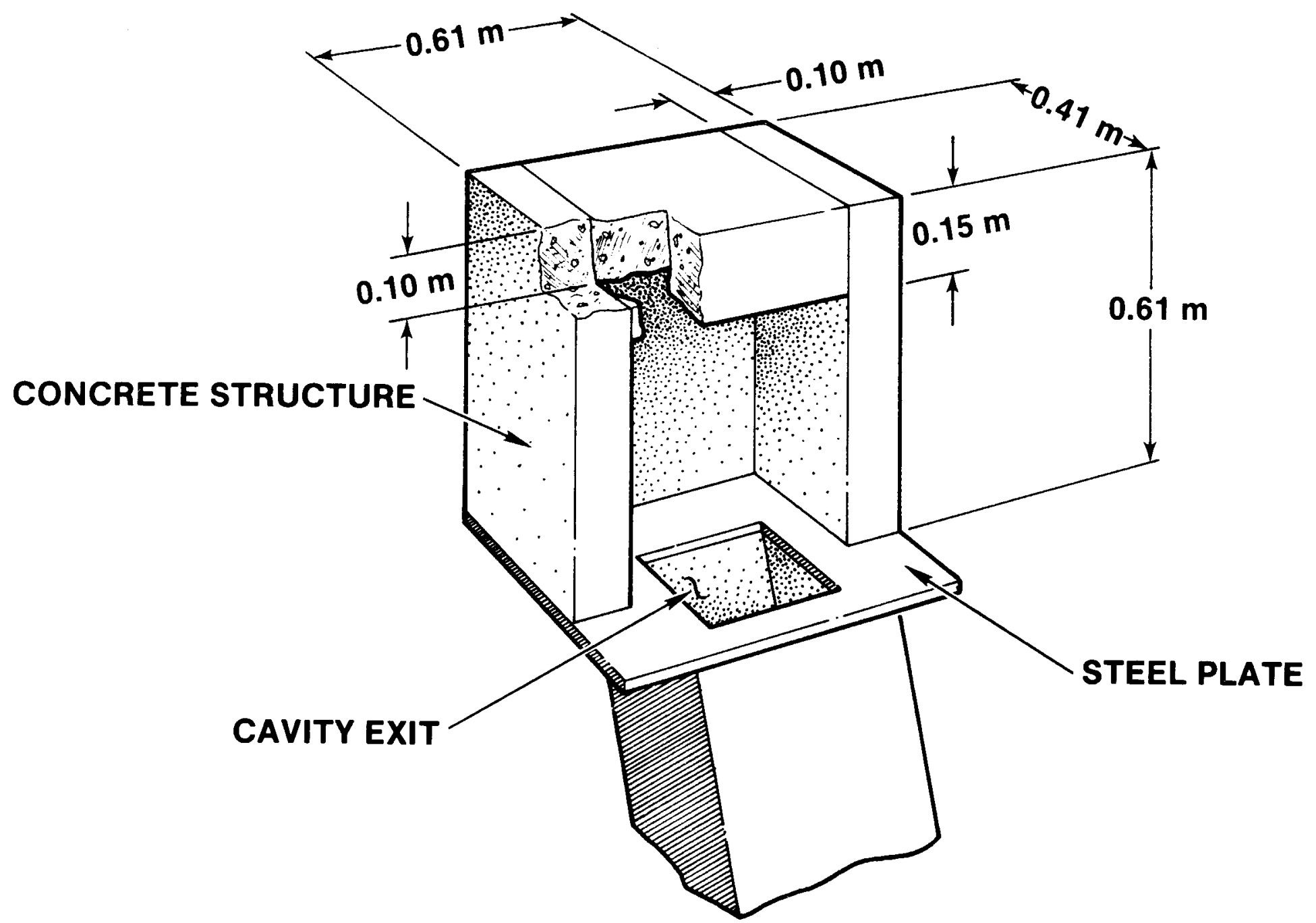

Figure 3.1: Details of the Excavity Structure For HIPS-7C 


\section{HIPS-7C EXPERIMENTAL APPARATUS}

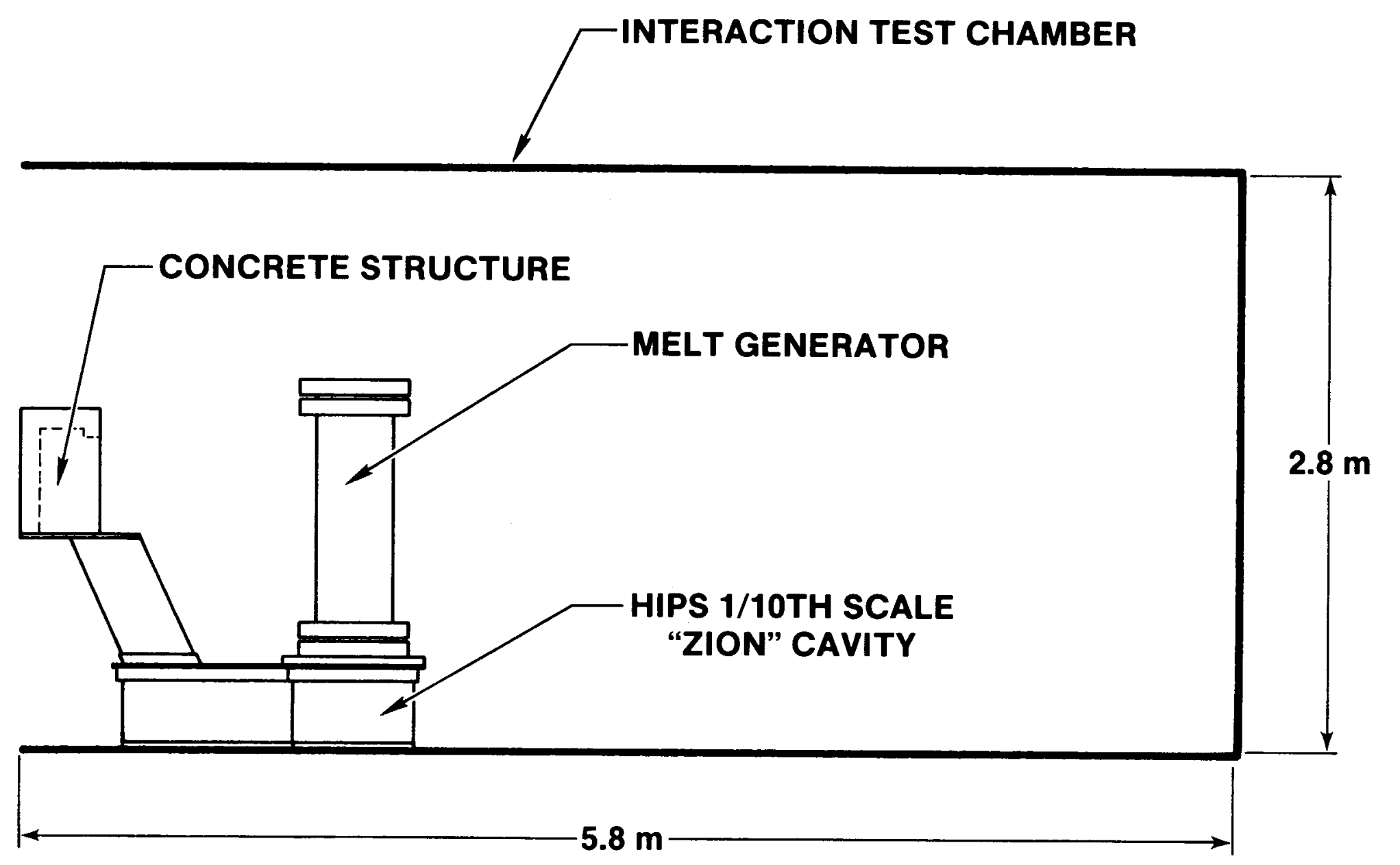

6andia National Laboratories

Figure 3.2: Orientation of the Test Apparatus Within the Test Chamber 
Table 3.1

Summary of HIPS-7C Instrumentation

\begin{tabular}{|c|c|c|c|c|}
\hline Type & No. & Range & Location & Purpose \\
\hline Pressure & $\overline{1}$ & $0-6.9 \mathrm{MPa}$ & Melt Gen & MG Blowdown \\
\hline Pressure & 1 & $0-6.9 \mathrm{MPa}$ & Gas Line & MG Reference \\
\hline Pressure & 3 & $0-2.1 \mathrm{MPa}$ & Cavity & Cavity Pressure \\
\hline Pressure & 2 & $0-0.7 \mathrm{MPa}$ & Chamber & Chamber Pressure \\
\hline Pyrometer & 1 & $1500-3500 \mathrm{RC}$ & Cavity Exit & Chamber Temperature \\
\hline $\mathrm{TC}$ & 1 & $0-1100 R C$ & Melt Gen & Gas Temperature \\
\hline Photo Detector & 1 & -- & Melt Plug & Timing \\
\hline Photo Detector & 1 & -- & Cavity & Timing \\
\hline Cameras & 6 & $10-400 \mathrm{fps}$ & & Observation \\
\hline Filters & 2 & -- & Chamber & Aerosol Concentration \\
\hline Impactors & 3 & -- & Chamber & Aerosol Size Distribution \\
\hline
\end{tabular}


melt generator. The location was selected to isolate the device from the high-temperature environment inside the melt generator.

The thermocouple was a Type-K unit with a stainless-steel sheath. The sheath (3.2 $\mathrm{mm}$ in diameter) was inserted through the flange cover into the gas volume (46 cm distance) above the thermite reaction crucible.

Three pressure transducers (Kulite XT-190) were attached to the cavity to measure pressure changes caused by the ejected melt. The location of the gauges were in the circular cavity opposite the tunnel opening, halfway along the tunnel, and on the inclined tunnel section. In all cases, the gauge was connected to the internal cavity by a $9.5 \mathrm{~mm}$ diameter steel tube through the concrete placed flush with the inner surface. This arrangement has been shown to not significantly degrade the frequency response for the phenomena considered (Tarbell, et al. 1987).

Transient overpressure in the box housing the experiment was measured with two low-range devices (Kulite Model XT-190). These were placed directly through the 6-mm thick steel wall of the box, one along the long side and the second in the closed end opposite the position of the apparatus. The gauge faces were positioned flush with the inner surface of the steel without any external protection.

A two-color pyrometer (Ircon Model $\mathrm{R}-35 \mathrm{C} 10$ ) was mounted to a bracket on the melt generator and aimed at the cavity opening. The spot size at the cavity opening was nominally $2.5 \mathrm{~cm}$ in diameter. The placement was designed to monitor the debris just outside the cavity, but before interaction with the structure model.

The two photodetectors were designed to give a sharp signal output when exposed to the light emanated by the melt. The first was positioned just under the fusible plug to detect the melt just after plug failure. The second was placed on the cavity floor directly under the melt generator. This latter device was shielded so that only light emitted directly into the device would cause a signal output. By comparing the output of the two devices, the average jet velocity from the melt generator to the cavity floor was determined.

The aerosol filters (Millipore Type L5, $47 \mathrm{~mm}$ in diameter) and cascade impactors (Anderson Mk-II) were placed outside the chamber and sampled the atmosphere by 12.5-mm diameter steel tubing probes. Each device was controlled by a remotely operated valve on the outlet to isolate the device from a vacuum suction system. By cycling the valve for a set time interval, a critical orifice controlled the volume of gas flowing through the sampler. The aerosol concentration was then determined following the test 
by weighing the collected mass in the filter and dividing by the total gas flow through the device. The cascade impactors were actuated in a similar manner with the size distribution determined from the material collected on each sampling stage. A more extensive discussion of these devices can be found in Tarbell et al. (1987).

Table 3.2 summarizes the camera coverage for this test. Six high-speed film cameras plus one video camera recorded the test. In addition, two Hulcher cameras, using $70 \mathrm{~mm}$ film, provided high quality still pictures.

\subsection{Initial Conditions}

The initial conditions for HIPS-7C are summarized in Table 3.3. The gas volume, pressure, and temperature are values at the onset of melt ejection. Direct measurement of the gas temperature failed during this test because the noise level of the thermocouple signal was comparable to the absolute signal itself. The temperature reported in Table 3.3 was determined from the measured pressure rise, estimated volume change (of melt), and the estimated increase in gas mass (from HIPS-3J) during the thermite burn.

\subsection{Experiment Results and Analysis}

This section presents the results obtained from the HIPS-7C experiment. Analysis of the test is also presented where appropriate to aid in the understanding and interpretation of the experiment observations.

\subsubsection{Camera Coverage}

Figure 3.3 presents a close-up photo sequence of the test. Photos in the left column were taken looking into the interaction chamber and at the outside back face of the structure mockup. Photos in the right column were taken looking through a plexiglass port on the back wall of the chamber. The structure mockup is mostly hidden behind the melt generator. Melt primarily deflects of the structure in the direction of the back wall. Each photo in the pair (left column and right column) were taken at the same instant in time.

The photo sequence in Figure 3.3 shows that a great deal of melt appears to splash off the structure. Melt is directed downwards, upwards, and to the sides (taken through the port in the back door of the chamber). Late time camera records show a large quantity of material raining down as particles from the ceiling and along the back wall.

Figure 3.4 shows the sequence of events taken from a longrange camera placed outside the interaction chamber. The most striking feature is the intense cloud of aerosols that accompanies the process. The second notable feature is the appearance of melt particles coming out the open side of the 
Table 3.2

Summary of HIPS-7C Camera coverage

\begin{tabular}{|c|c|c|c|}
\hline Device & $\begin{array}{c}\text { Start } \\
\text { Time(a) } \\
(\mathrm{s}) \\
\end{array}$ & $\begin{array}{l}\text { Speed } \\
\text { (fps) }\end{array}$ & Field of view \\
\hline Camera & -5 & 100 & $50^{\prime}$ Head on \\
\hline Camera & -5 & 100 & 50 ' side on \\
\hline Camera & +5 & 400 & $20^{\prime}$ Head on \\
\hline Camera & +5 & 400 & $20^{\prime}$ side on \\
\hline Camera & +5 & 400 & $10^{\prime}$ Chamber Rear \\
\hline Camera & -5 & 100 & 100' Hilltop Rear \\
\hline Hulcher & -5 & 10 & Hilltop Rear \\
\hline Hulcher & -5 & 20 & $45^{\circ}$ \\
\hline Video & & 30 & \\
\hline
\end{tabular}

a Relative to ignition of Thermite Powder. 
Table 3.3

HIPS-7C Initial Conditions

\section{Melt Mass}

Thermite Composition

Iron Oxide $\left(\mathrm{Fe}_{3} \mathrm{O}_{4}\right)$

Aluminum (AI)

$\frac{\operatorname{Mass}(\mathrm{kg})}{81.50}$

Melt Composition

Iron $(\mathrm{Fe})+$ Alumina $\left(\mathrm{Al}_{2} \mathrm{O}_{3}\right)$

Dopants

$\mathrm{ZrO}$

$\mathrm{La}_{2} \mathrm{O}_{3}$

0.25

0.25

0.50

$\mathrm{Nb}$

0.50

Gas

Carbon Dioxide $\left(\mathrm{CO}_{2}\right)$

Melt Generator

Gas Volume

$0.118 \mathrm{~m}^{3}$

Pressure

$5.58 \mathrm{MPa}$

Temperature

$526 \mathrm{~K}$

Melt Plug Diameter

$0.0191 \mathrm{~m}$ 


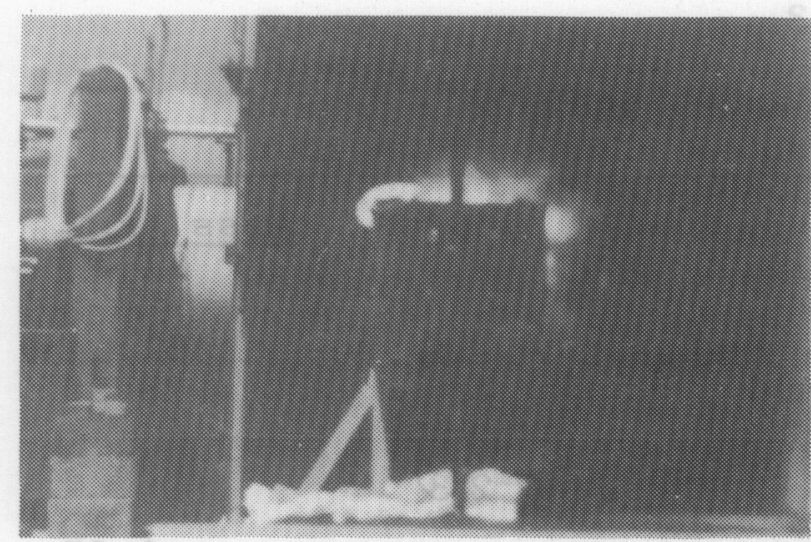

TIME = $5 \mathbf{m s}$

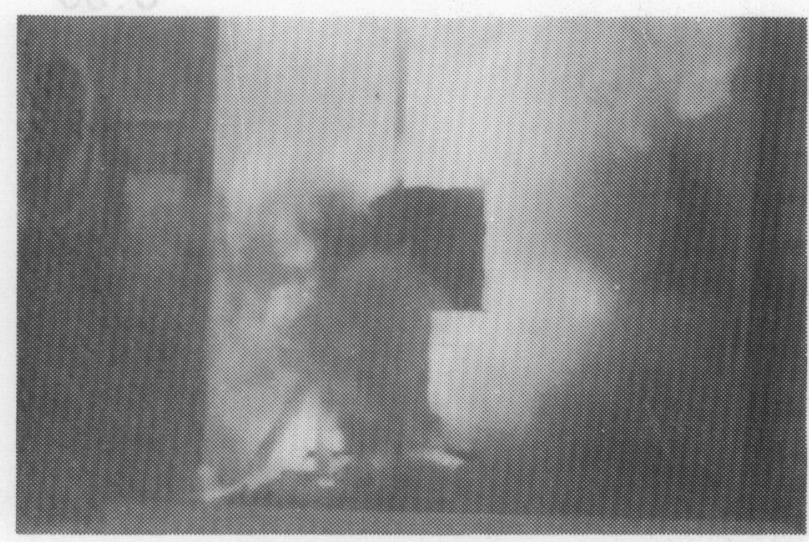

TIME = $180 \mathrm{~ms}$

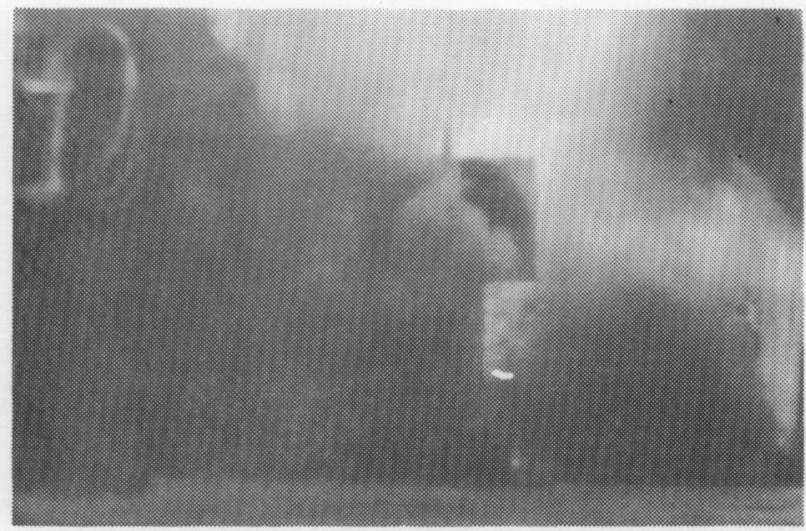

TIME $=\mathbf{3 0 0} \mathrm{ms}$

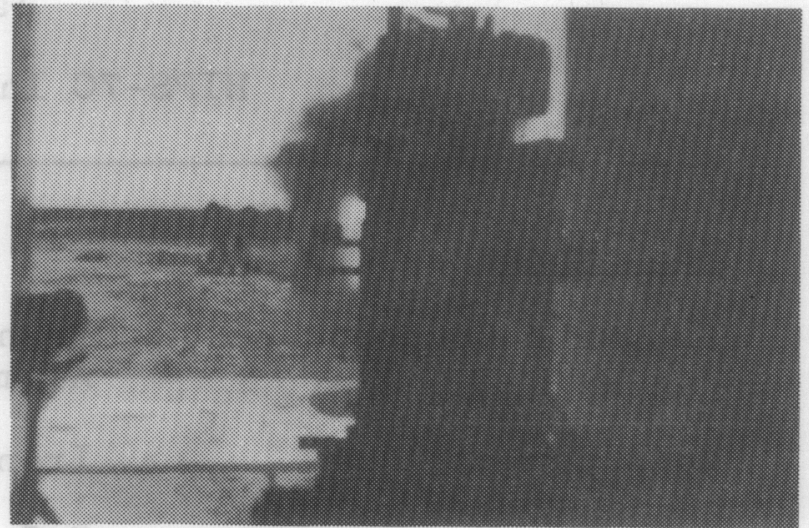

TIME = $5 \mathrm{~ms}$

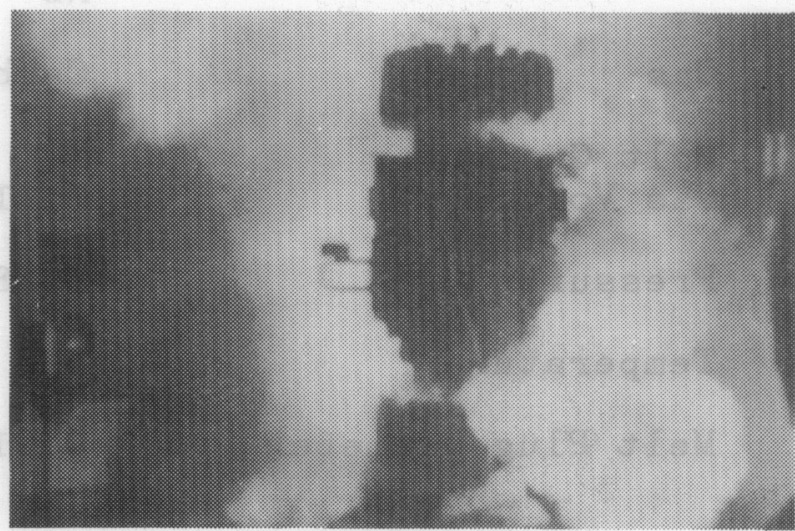

TIME = $180 \mathrm{~ms}$

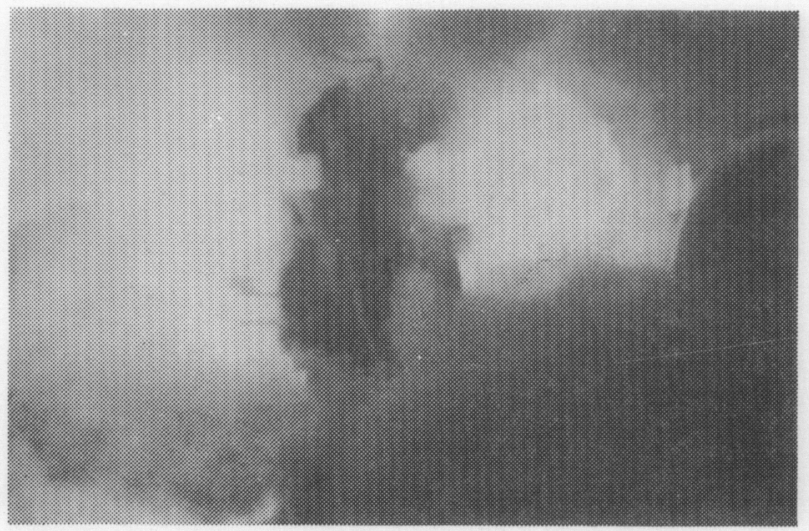

TIME $=\mathbf{3 0 0} \mathrm{ms}$

Figure 3.3: Closeup Photo Sequence Taken From the Rear (Left Column) and Front (Right Column) of the structure. 


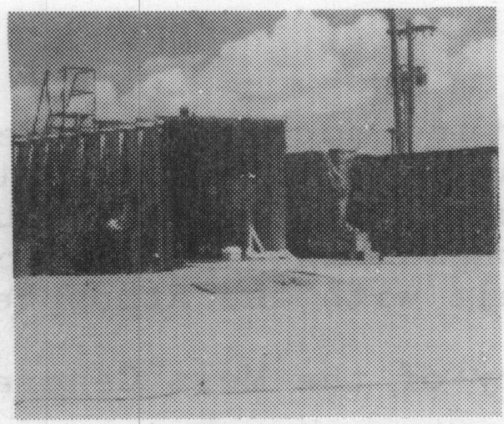

$$
\mathbf{t}=\mathbf{0}
$$

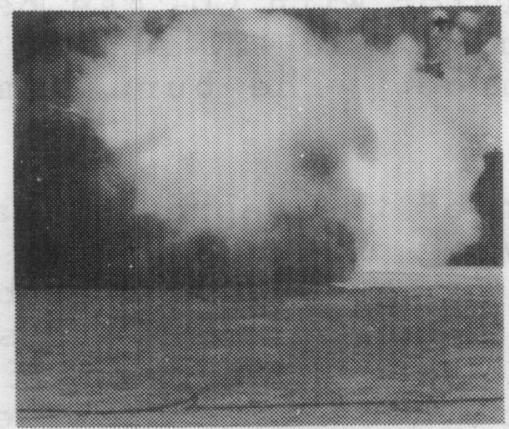

$\mathrm{t}=\mathbf{0 . 7 \mathrm { s }}$

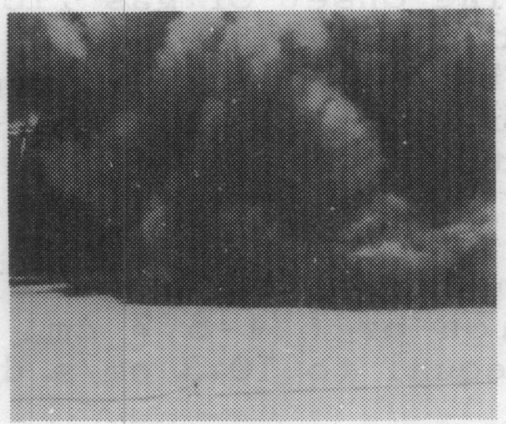

$t=1.7 \mathrm{~s}$

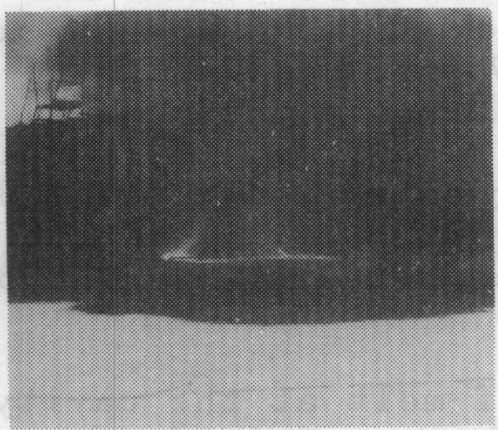

$t=2.7 \mathrm{~s}$

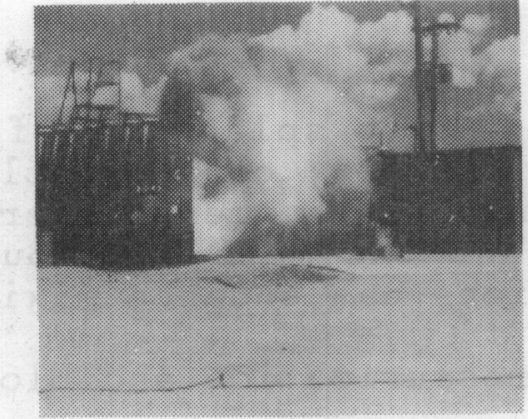

$t=0.4 \mathrm{~s}$

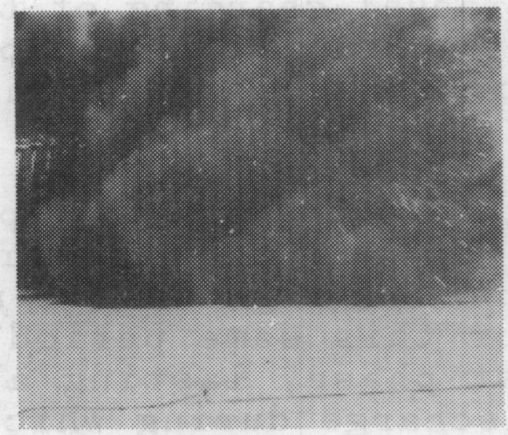

$t=1.2 \mathrm{~s}$

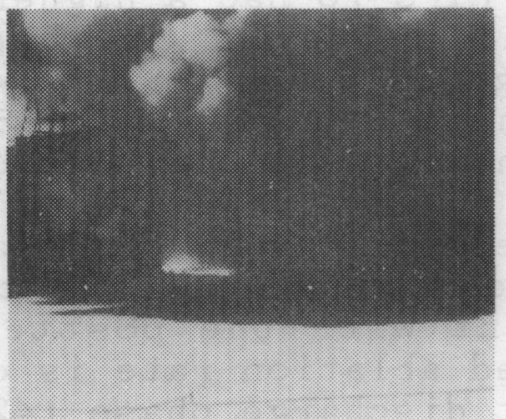

$t=2.2 \mathrm{~s}$

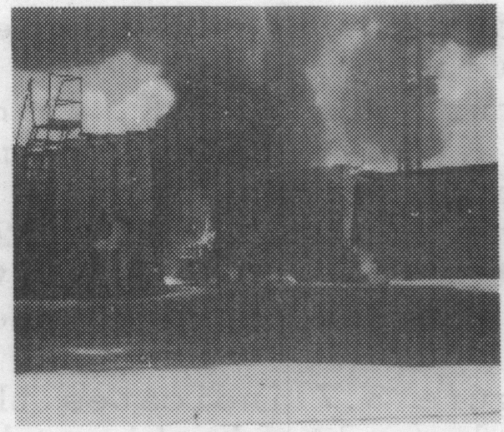

$\mathrm{t}=\mathbf{3 . 2 \mathrm { s }}$

Figure 3.4: Long Range Photo Sequence 
chamber. Melt splashing off the structure mockup is directed into the chamber; consequently, additional structure interactions (splashing off the melt generator or chamber walls) are required to redirect the melt back out the opening. Vigorous structure interactions can enhance mixing of the melt with the atmosphere.

\subsubsection{Pressurization and Blowdown History of the Melt Generator}

Figure 3.5 summarizes the pressurization history of the melt generator. Start of melt discharge is taken as the reference time. Gradual charging of the melt generator with $\mathrm{CO}_{2}$ gas begins at $-330 \mathrm{~s}$. Prior to ignition of the thermite at $-20 \mathrm{~s}$, the melt generator is isolated from the gas source. The burn time is $20 \mathrm{~s}$.

Figure 3.6 shows an expanded version of the depressurization history of the melt generator following the onset of melt ejection. Also shown are model predictions (Pilch \& Tarbell, 1985) for this same period. Two phases can be distinguished. The first phase, lasting about $425 \mathrm{~ms}$, corresponds to liquid phase discharge during which the pressure decreases because the free volume is increasing as melt is expelled from the generator. This phase is about $50 \mathrm{~ms}$ shorter than observed in HIPS-3J because HIPS-7C had a higher pressure. The onset of gas flow out the orifice marks the beginning of the second phase. Gas discharge is accompanied by continued, but reduced discharge of melt (Pilch \& Tarbell, 1985). The second phase lasts $1.5-2 \mathrm{~s}$ at which time the blowdown of the generator is complete.

The model of Pilch \& Tarbell (1985) predicts the final size of the discharge orifice to be $6.48 \mathrm{~cm}$, which is in excellent agreement with the posttest observation of $6.1-6.7 \mathrm{~cm}$. The predicted ablation rate is constant and equal to $10.3 \mathrm{~cm} / \mathrm{s}$ during the melt discharge phase (425 ms).

A two-color pyrometer was placed near the cavity exit to measure the temperature of the dispersed melt. The two-color pyrometer measures temperature directly and requires no emissivity correction. Figure 3.7 shows that the peak temperature was $2350 \mathrm{~K}$, which is well below the theoretical value of $3200 \mathrm{~K}$ for a complete and adiabatic reaction. The measured temperatures are well above the freezing point ( $1700 \mathrm{~K}$ ) and well below the boiling point $(3200 \mathrm{~K})$ of the iron phase of the melt. The peak temperature is virtually at the freezing point (2300 K) for the alumina phase of the melt.

Figure 3.7 indicates the presence of melt at the cavity exit during the melt ejection phase $(0-0.425 \mathrm{~s})$. This implies that some melt is leaving the cavity under its own momentum because blowdown gases have not yet entered the cavity. There is an abrupt, but temporary, drop in output at $0.825 \mathrm{~s}$, which might indicate when most of the melt is dispersed from the cavity. The final drop in output occurs at $1.2 \mathrm{~s}$, which corresponds closely to the end of the blowdown phase (see Figure 3.5). 


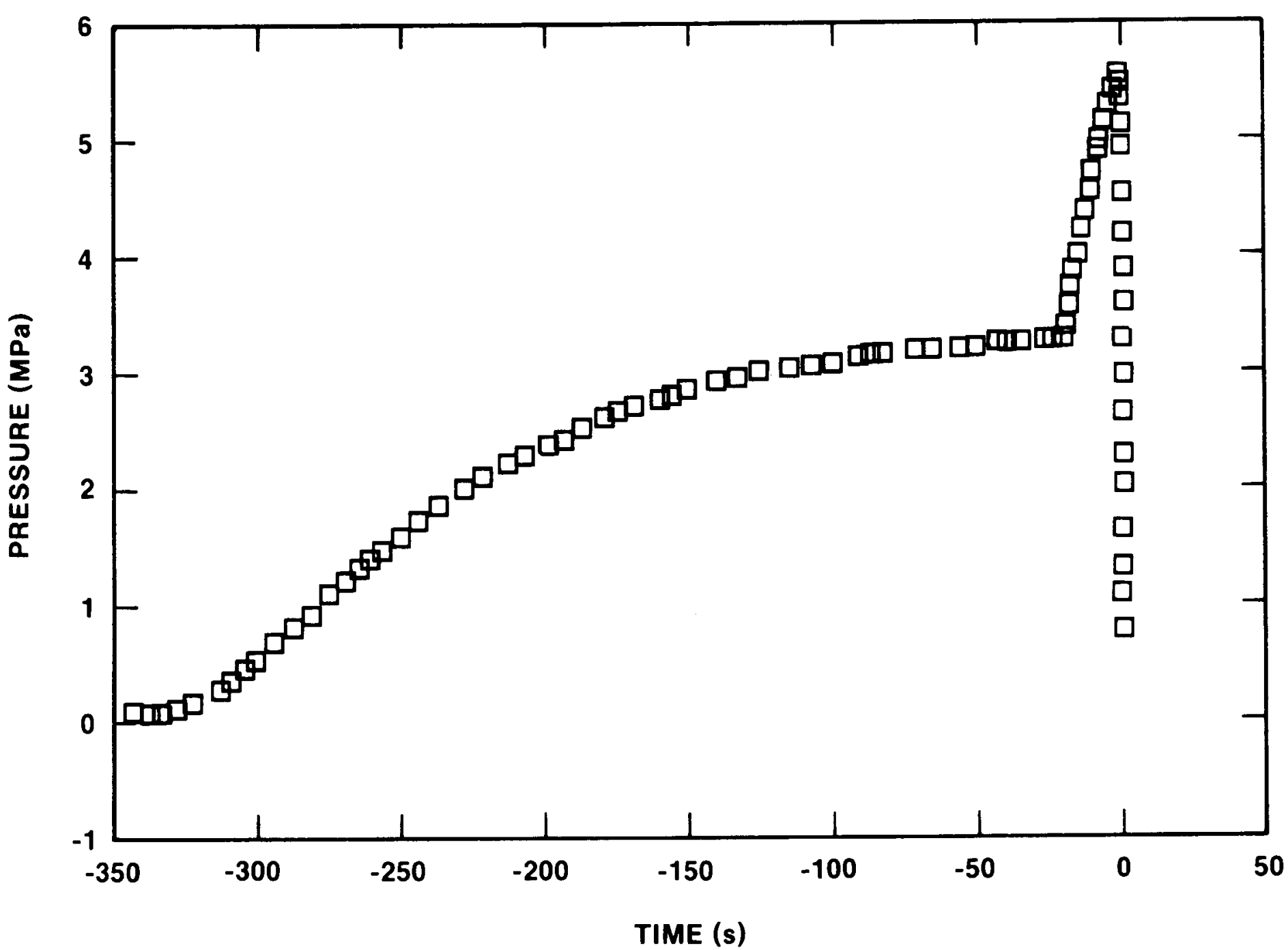

Figure 3.5: Pressurization History of the Melt Generator 


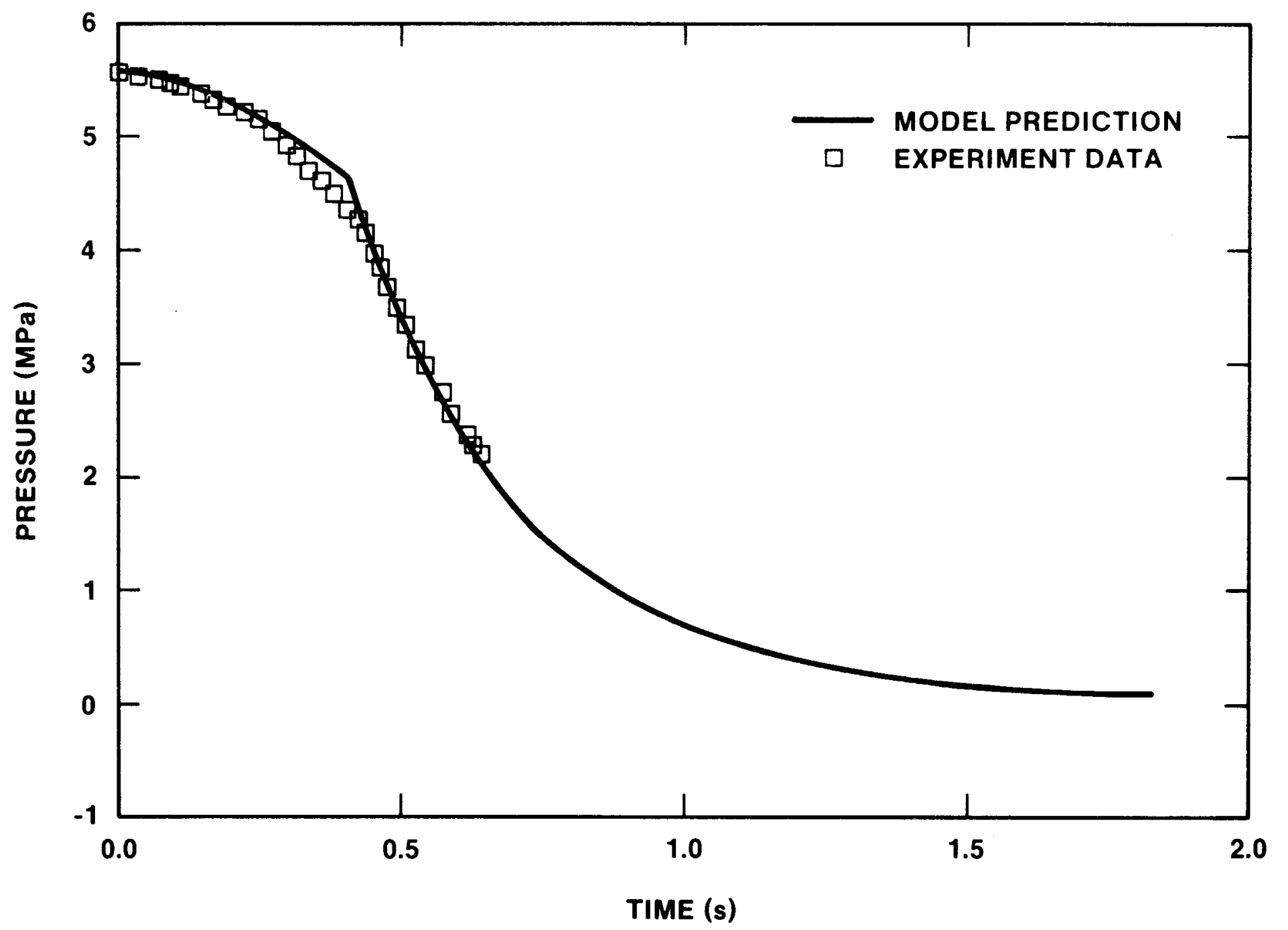

Figure 3.6: Blowdown History of the Melt Generator 


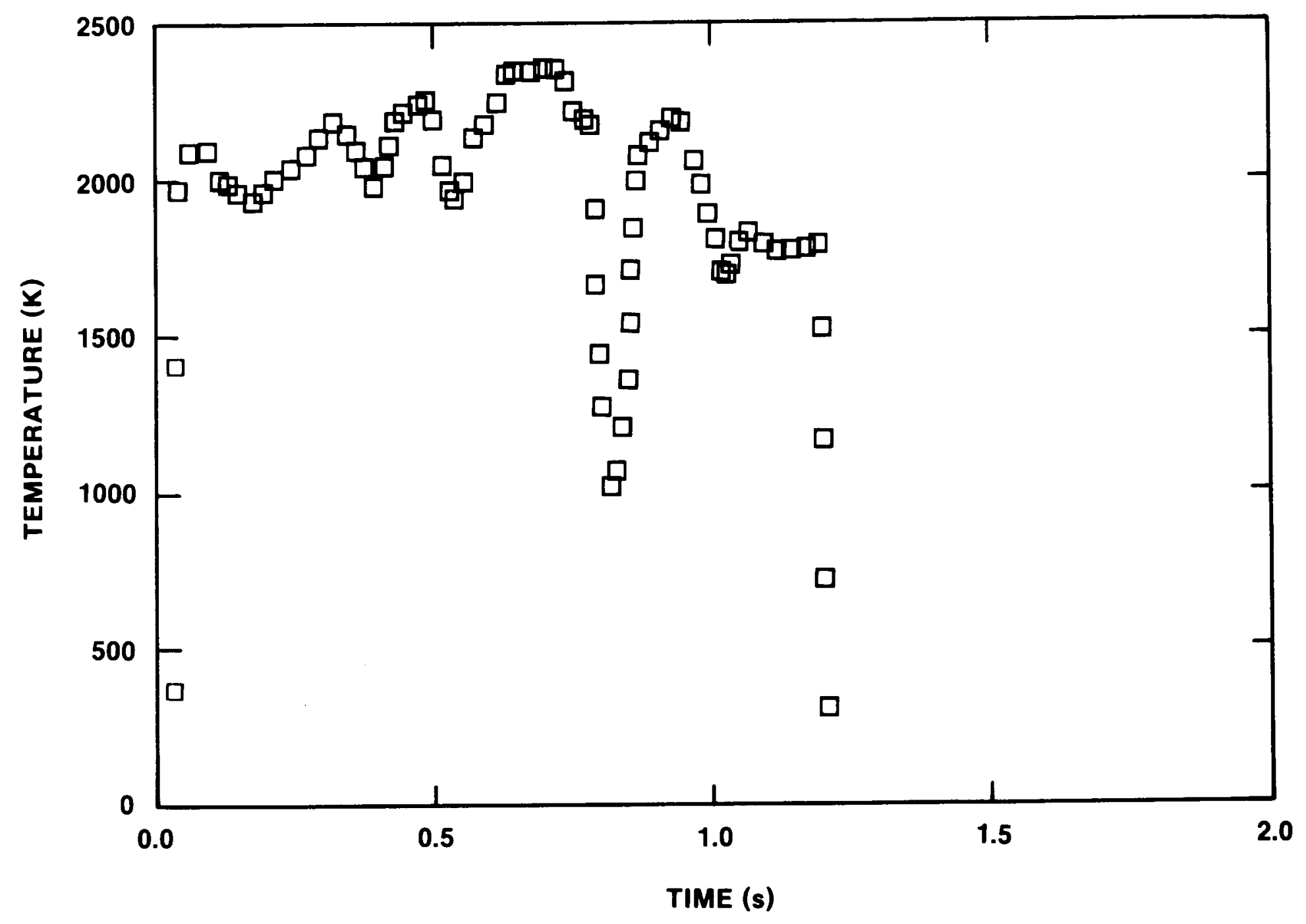

Figure 3.7: Temperature Measurements Outside the Cavity Using a 2-Color Pyrometer 
Figure 3.8 shows pressure measurements made at three different locations in the cavity. The measured back pressures in the cavity are small compared to pressures in the melt generator. The measured pressures drop abruptly at about $0.8 \mathrm{~s}$, which coincides with the temporary drop in the pyrometer output. This might be an indication of the end of the dispersal phase. Beyond $0.8 \mathrm{~s}$, the measured pressure in the cavity oscillates wildly from positive to negative values and are not shown on Figure 3.8. It is believed that hot aerosol or high heat fluxes were adversely affecting the pressure transducers.

\subsubsection{Structure Interactions}

Table 3.4 shows the posttest location of the debris for the HIPS-7C test, which accounts for $97 \%$ of the melt. Some of the melt particles that come out the opening in the chamber, land on the concrete pad and some land in the dirt beyond the pad. The latter are not accounted for in the posttest mass inventory. In addition, some aerosol mass is unaccounted for in the aerosol cloud that billows out of the chamber.

The posttest mass inventory shows that approximately $2.7 \mathrm{~kg}$ of melt remained in the melt generator. This agrees well with the predicted value of $2.2 \mathrm{~kg}$ using the model of Pilch \& Tarbell (1985). The model couples the competing rates of melt and gas discharge with hole ablation calculations and a criteria for the onset of gas blowthrough.

Approximately $1.3 \mathrm{~kg}$ of debris was found adhering to the inside of the concrete cavity, as a very thin crust (Figure 3.9). Thus, $98 \%$ of the melt ejected from the melt generator was dispersed from the cavity. This result is consistent with other HIPS tests using concrete cavities (Tarbell et al. 1986). Dispersal from cavities of this type is nearly complete.

The design of the HIPS-7C apparatus places the melt generator in the path of some of the debris that leaves the excavity structure. Posttest examination of the outside of the melt generator (Figure 3.10) reveals a crust of melt that is $1.0-$ $1.4 \mathrm{~mm}$ thick. The expected crust thickness that could develop during the melt relocation time $(0.4-1.0 \mathrm{~s})$ is given by:

$$
\delta=2 \lambda(\alpha t)^{1 / 2}
$$

where $\lambda=504$ and $\alpha=2.8 \times 10^{-6}$ for molten iron/aluminamelt on steel. Thus, a crust thickness of 1.1-1.7 $\mathrm{mm}$, which is in substantial agreement with observation for this test. In this test, the mass flux of melt onto the steel surface of the melt generator could be. two orders of magnitude larger than the freezing flux (assuming all the dispersed melt strikes the steel surface). Consequently, the melt/steel interaction is predominantly hydrodynamic with only a small fraction of the melt being trapped by freeze-out and with the bulk of the melt splashing from the surface. 


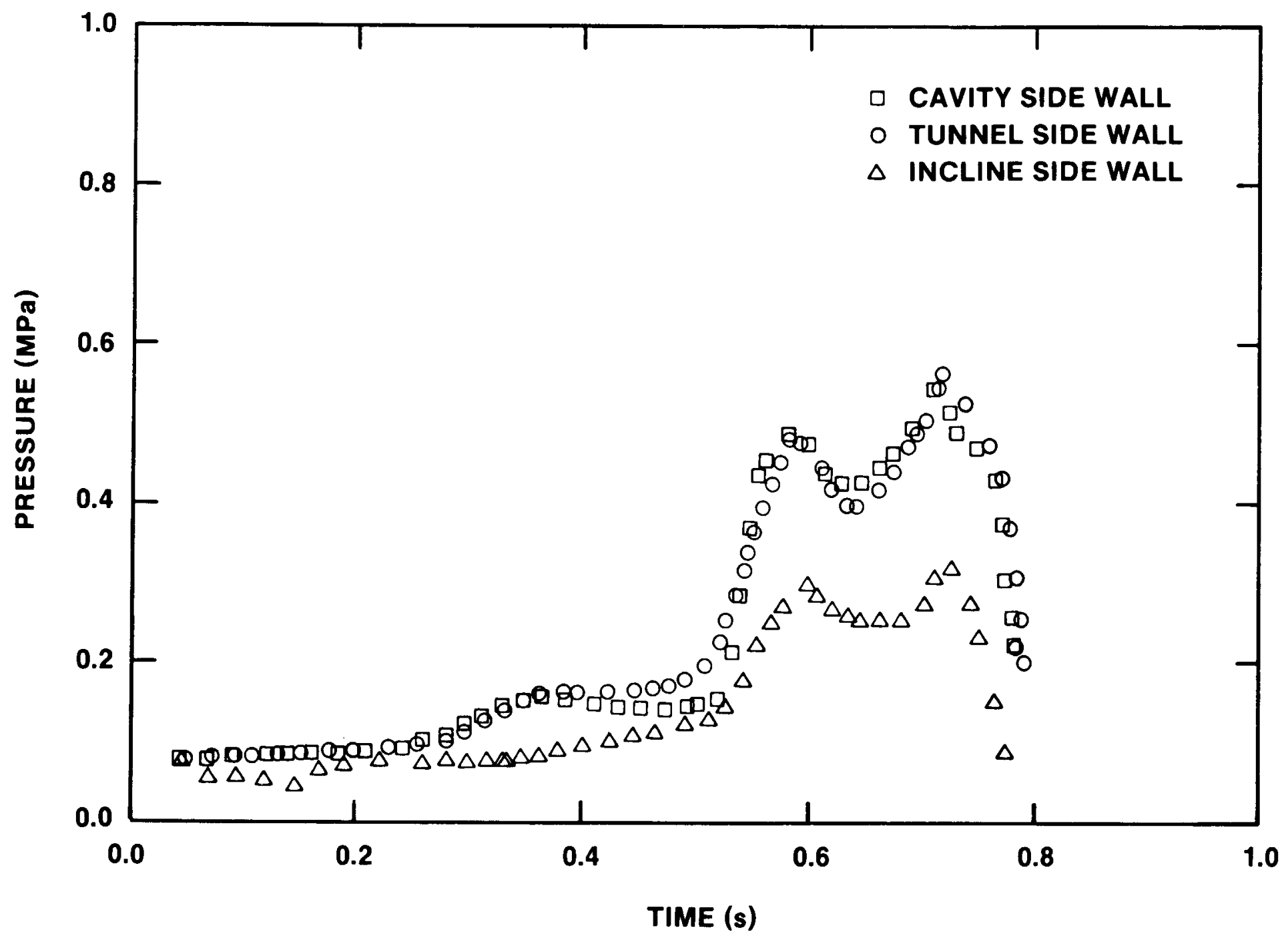

Figure 3.8: Pressure Measurements at Three Locations in the Cavity 
Table 3.4

Posttest Debris Inventory

Mass $(\mathrm{kg})$

Remaining inside melt generator

2.716

Adhering to inside of concrete cavity

1.295

Adhering to outside of melt generator and its mounting plate to concrete cavity

13.313

Adhering to ceiling above the excavity structure

0.210

On floor of chamber, back $1 / 4$

24.219

On floor of chamber, back center $1 / 4$

9.826

On floor of chamber, front center $1 / 4$

14.314

On floor of chamber, front $1 / 4$

8.584

On concrete pad outside chamber

1.845

Retained by excavity structure

3.290

79.612 

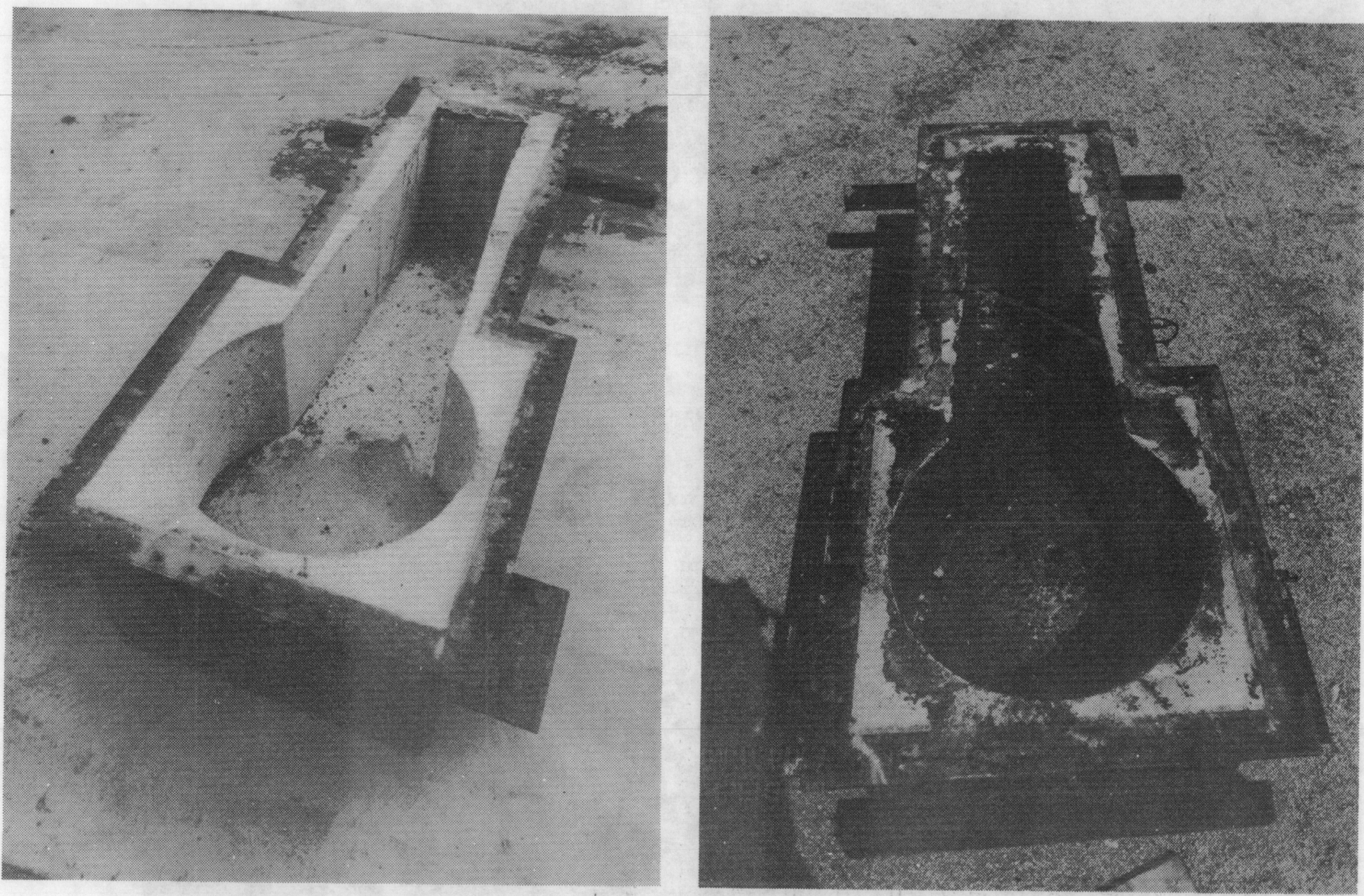

Figure 3.9: Pretest and Posttest Comparison of Lower Assembly of the Cavity Mockup 


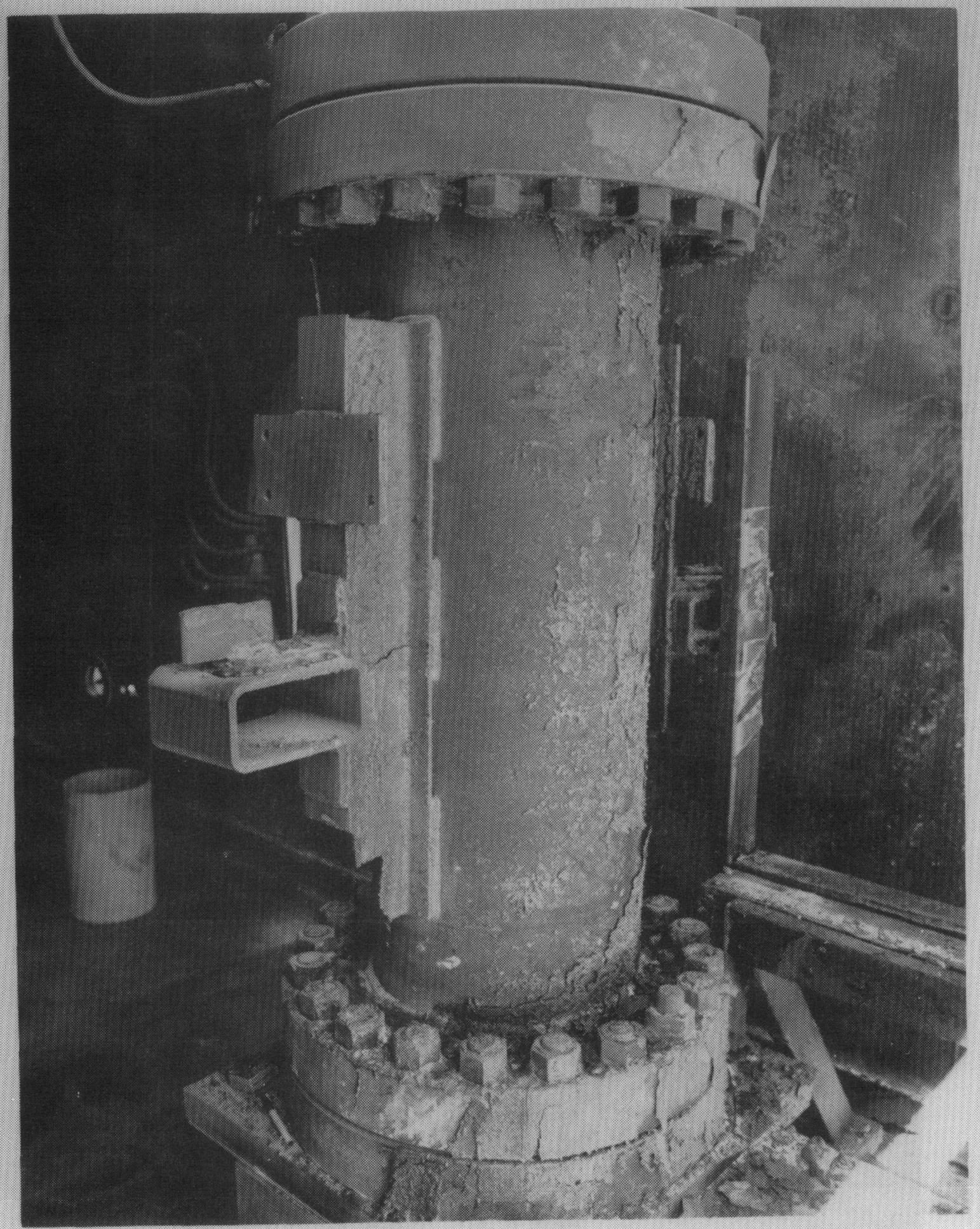

Figure 3.10: Posttest View of the Melt Generator With Frozen Crust on its Surface 
The $0.21 \mathrm{~kg}$ of material collected from the ceiling of the containment chamber directly over the excavity structure has the appearance of fine particles sprayed onto the ceiling. Photomicrographs show the bulk of this material to be comprised of sintered particles with diameters less than about $10 \mu \mathrm{m}$. Analysis shows that particles of this size will deflect with the gas stream and not impact the structure. Details of this analysis will be discussed later.

Most of the debris $(56.9 \mathrm{~kg})$ recovered after the test was found on the floor of the interaction chamber. Of this debris, $42.5 \%(24.2 \mathrm{~kg})$ was recovered along the back wall of the chamber. High speed films reveal that a large, though indeterminant, portion of this melt rains down from the ceiling near the back wall of the chamber. Most of the debris recovered from the floor was in the form of large coherent masses, indicating that the material was still molten when it struck the floor.

Finally, Table 3.4 shows that only $3.3 \mathrm{~kg}$, representing only $4 \%$ of the melt swept from the cavity, was retained by the excavity structure. The quantity of retained material is significantly less than the geometry of the structure might suggest. If the roof of the structure is filled with melt to the lip of the overhang, then $24.5 \mathrm{~kg}$ of material could be retained, which in turn is significantly less material than could be supported by the peak stagnation pressure of gas. Figure 3.11 shows the structure as it appeared before and after the test. A coherent crust ( $\langle 1.5 \mathrm{~cm}$ thick) was found along the top back edge, which is where the melt struck the structure. Elsewhere on the structure, the melt appears as splatter clinging to the surface. Much of the retained material was found along the bottom back edge of the structure with an additional crust spread over the steel "floor" outside the cavity.

The following analysis suggests that nearly all the melt struck the structure, although retention was minimal. Figure 3.12 depicts a melt particle that is being swept from the cavity by blowdown gas moving at velocity $V_{0}$. Outside the cavity, the gas is assumed to deflect 90 degrees by the structure. The gas velocity $\left(V_{1}\right)$ after deflection is less than the gas velocity in the cavity because of an increase in flow area. Melt particles are deflected from their straight line path by the gas stream. Owing to their inertia, large particles will not be deflected sufficiently to escape impact with the structure walls. The fraction ( $f$ ) of particles with diameter (d) that impact (and are potentially trapped by) the structure is given by Cook [1987] as

$$
f=\frac{1}{\lambda W} \ln \left\{1+\lambda W\left[\frac{W}{L}-\left(\frac{W}{L}-1\right) f\right]\right\}
$$

where

$$
\lambda W=\frac{3}{4} C_{d} \frac{\rho_{g}}{\rho_{1}} \frac{W}{d}
$$



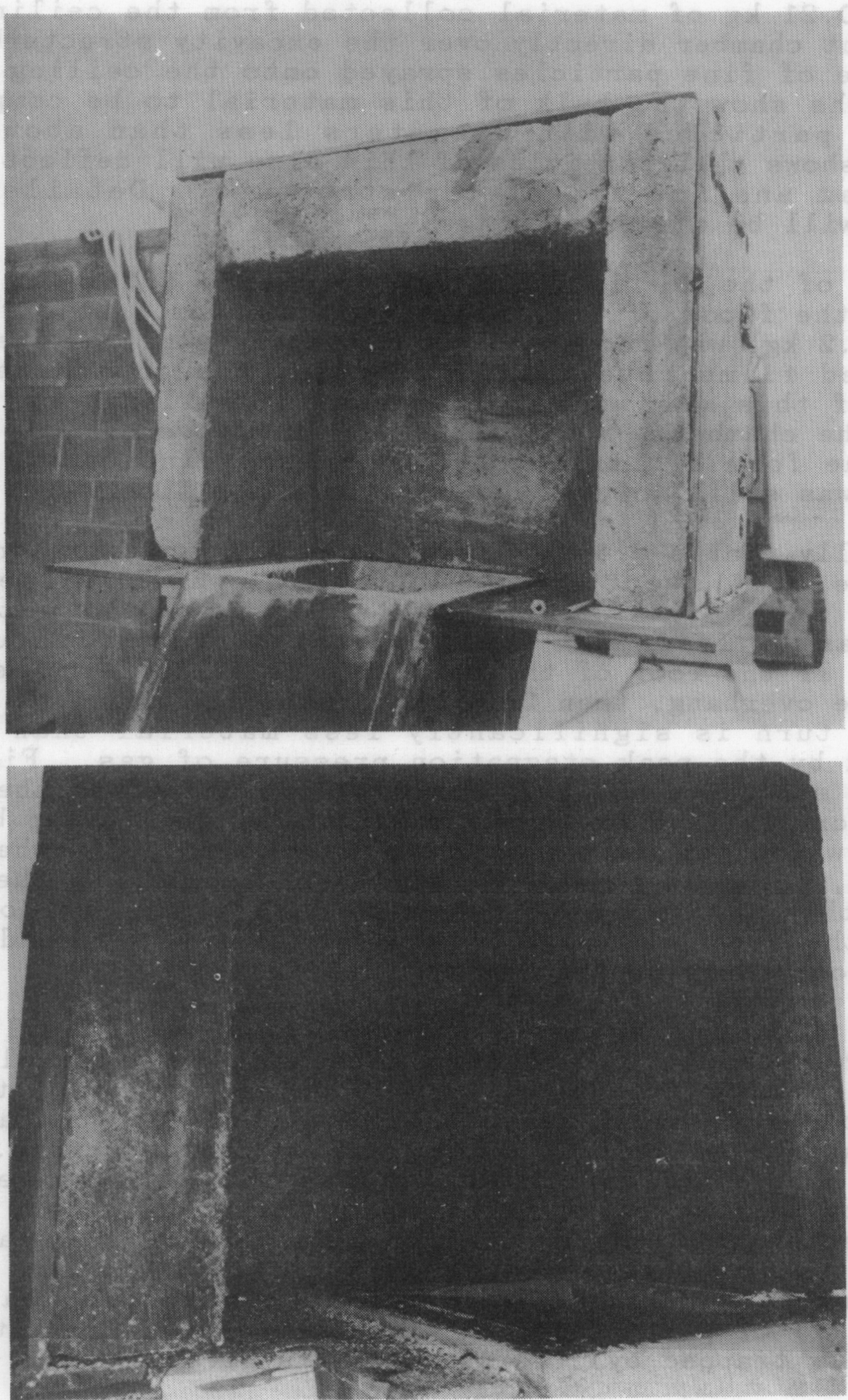

Figure 3.11: Pretest and Posttest Comparison of the Excavity Structure 
Here, $C_{d}$ is the drag coefficient on the particle, $\rho_{\gamma}$ is the gas density, $\rho_{F}$ is the particle density; and $W$ and $L$ are geometric dimensions as illustrated in Figure 3.12 .

Figure 3.13 shows the fraction of particles that are deflected away from the structure by the redirected gas stream without ever striking it. For a mass mean particle size of 500 $\mu \mathrm{m}$ (Tarbell et al., 1986), more than $95 \%$ of the particles are expected to strike the HIPS-7C structure. Figure 3.13 shows that the foreshortened geometry enhances the potential for trapping in scaled experiments over the full-size reactor geometry. The results from the HIPS-7C experiment show that the debris does interact with the enclosure, but the test observations do not support the implied analytical assumption that the debris is trapped.

The discrepancy in the trapped fraction arises because the analysis assumes that particles striking the structure are trapped. The bulk of the melt does strike the structure; however, vigorous splashing "reentrains" the melt back into the deflected gas stream. The vigorous splashing of melt from the concrete slab in the HIPS-3J test supports this hypothesis. Splashing as a dominant reentrainment mechanism was also reported by Dallman \& Kirchner (1980) in their studies of water drop deentrainment in the upper plenum of a PWR during the reflood stage of a loss-of-coolant accident. They reported that 80-90\% of the water striking the structures was reentrained by splashing. They observed even more reentrainment if the gas velocity was sufficiently high to cause reentrainment by the classic mechanisms of Kelvin-Hemholtz instability.

The material collected from the ceiling of the containment chamber directly over the excavity structure supports the theory that small particles can be deflected with the gas stream and not interact with the excavity structure. The $0.21 \mathrm{~kg}$ of material found in this location has the appearance of fine particles being sprayed onto the ceiling. Photo-micrographs show that the bulk of this material to be comprised of sintered particles with diameters less than $10 \mu \mathrm{m}$. Particles of this size are consistent with the preceding analysis, which predicts that they will deflect with the gas stream and not impact the structure.

\subsubsection{Aerosols}

An intense cloud of aerosols has been observed in all HIPS tests [Tarbel1, Brockmann \& Pilch, 1983, 1984; Brockmann \& Tarbell 1984A, 1984B; Tarbe11 et al., 1986], and the HIPS-7C test is no exception. Aerosol measurements were made inside the HIPS-7C containment chamber. Figure 3.14 shows that the aerosol size distribution is bimodal: a small size peak (aerodynamic diameters $(3 \mu \mathrm{m})$ characteristic of condensation aerosols, and a large size peak characteristic of fragmentation processes. Similar aerosol distributions have been reported for unconfined jet experiments and other scaled cavity tests [Tarbell et al., $1986]$. 


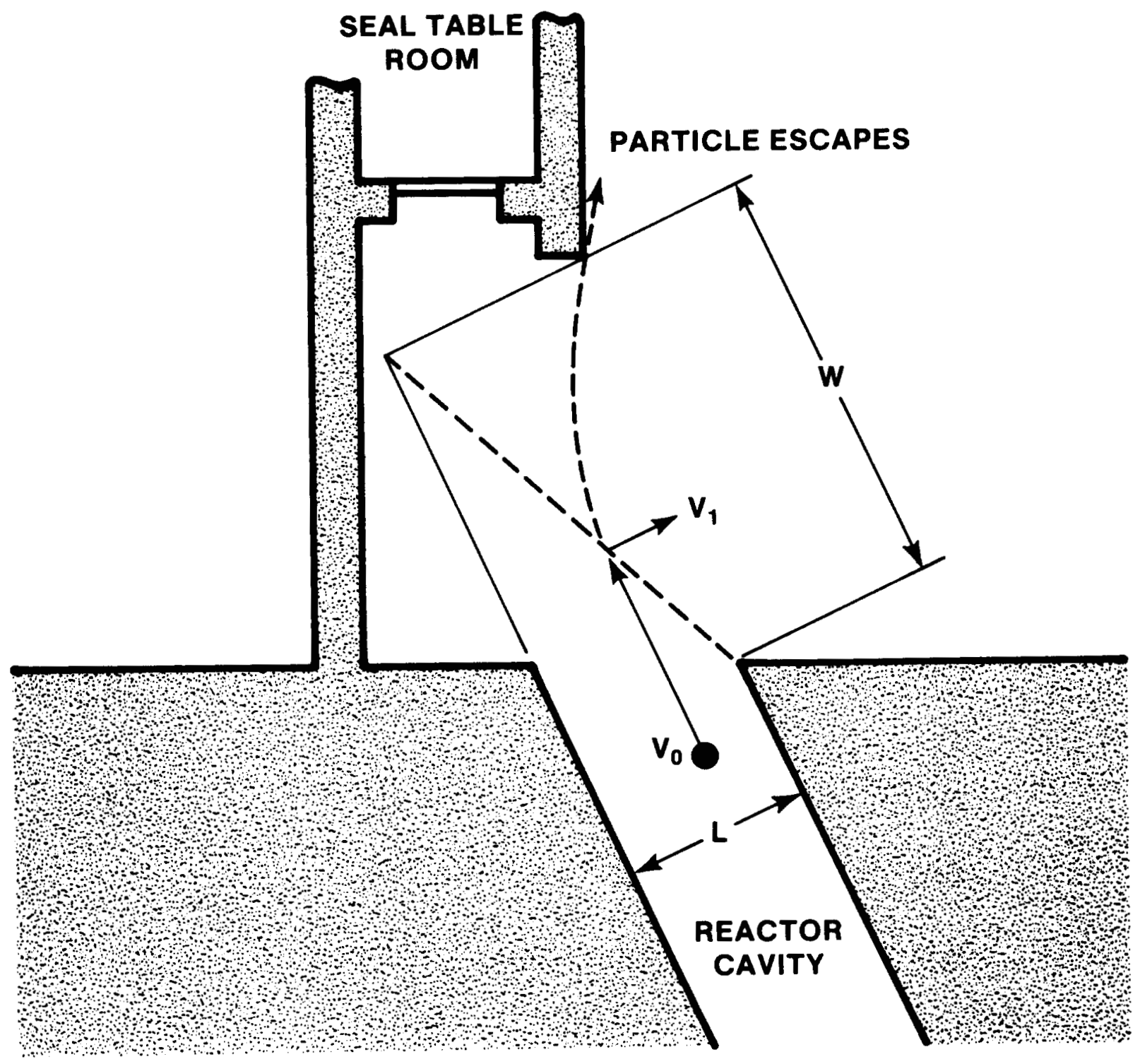

Figure 3.12: Particle Trapping by Excavity Structure 


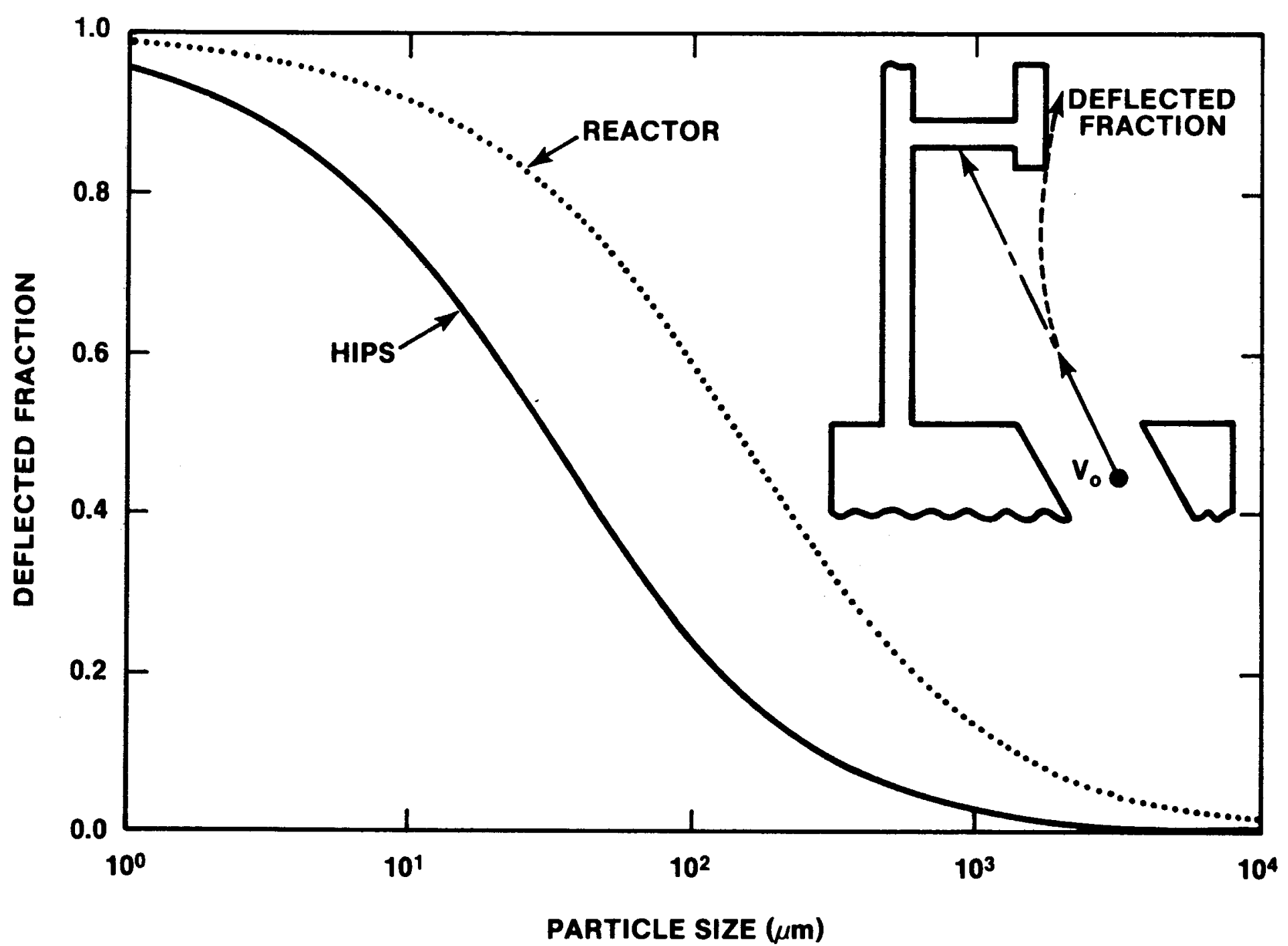

Figure 3.13: Influence of Containment Structures on Debris Behavior 


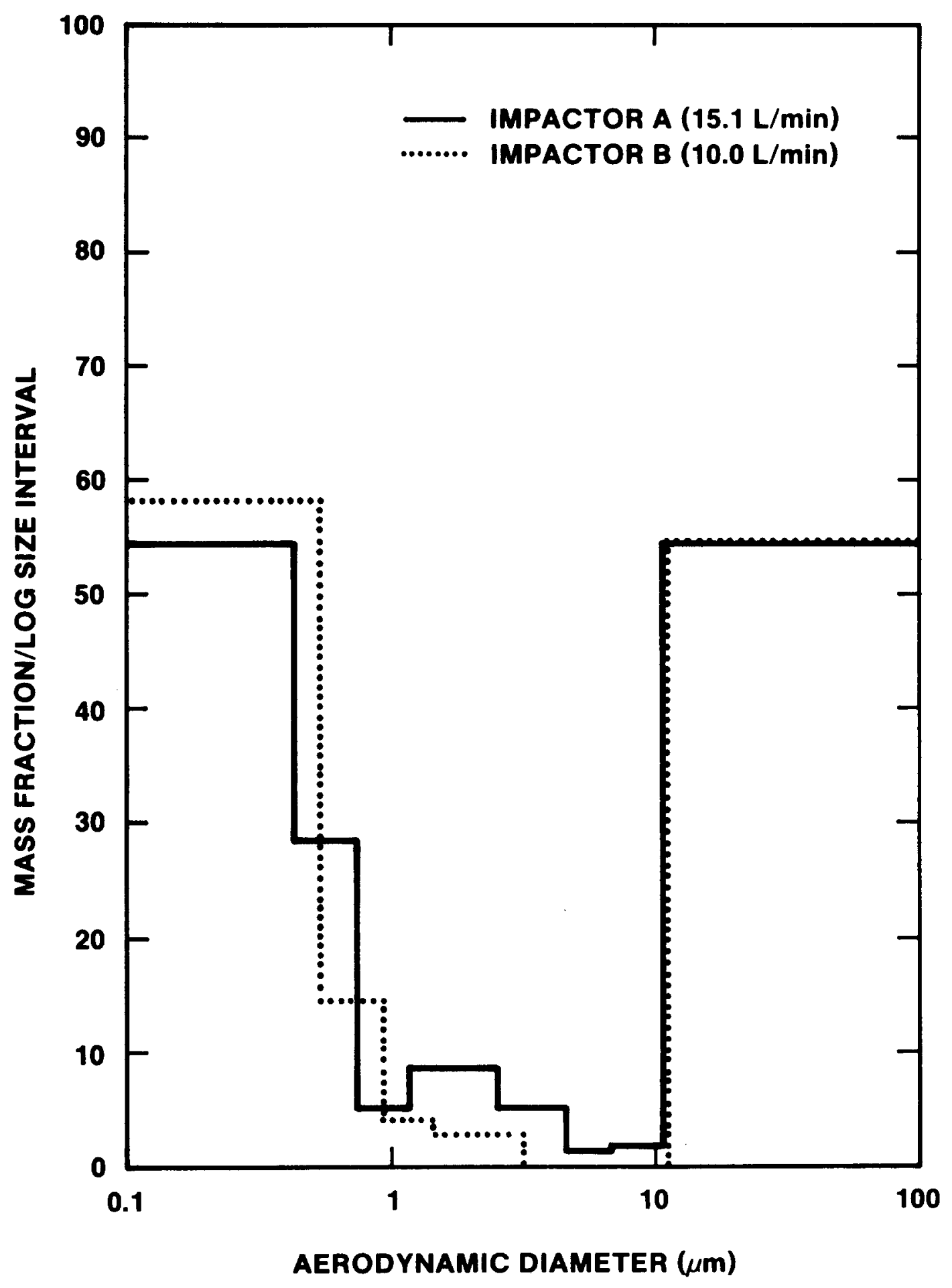

Figure 3.14: Aerosol Size Distributions 
Figure 3.15 shows the estimated fractions of relocated melt that are less than $10 \mu \mathrm{m}$ and less than $1 \mu \mathrm{m}$ in size. The two SPIT tests [Tarbell et al., 1986] indicated in Figure 3.15 are $1: 20$ linearly scaled cavity tests involving $10.3 \mathrm{~kg}$ of iron/alumina melt. The uncertainty in these results is an indication of the difficulty in obtaining accurate aerosol mass loadings unless complete containment of the atmosphere can be attained. In the HIPS-7C test, the aerosols were not completely confined in the chamber and the cloud volume is estimated from photographs. There appears to be a higher fraction of condensation aerosols in the HIPS-7C test than in the two SPIT experiments. It is not clear whether this effect is related to the larger melt mass or whether it is related to the excavity structure.

Brockmann \& Tarbell (1984A) showed that the abundance of iron and alumina (the bulk constituents of the melt) in the condensation aerosols could be ranked by their respective vapor pressure at the melt temperature. Fission product mocks were added to the melt in HIPS-7C in an attempt to extend these results to other constituents. All melt constituents, including fission product mocks, were detected in the aerosols using $X$-ray microprobe analysis. Release fractions for the constituents were not attempted because of the large uncertainty in the total mass of aerosol. 


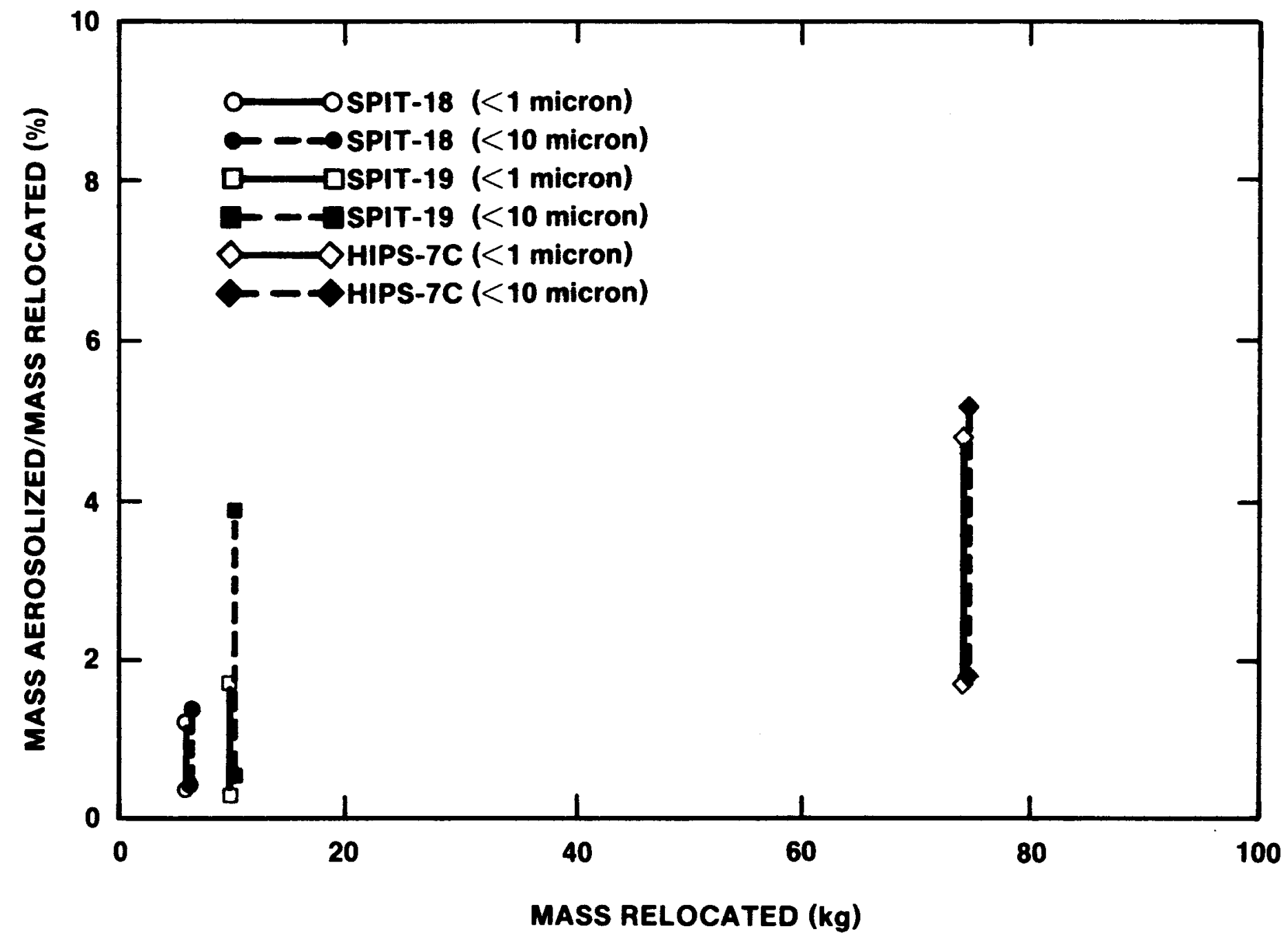

Figure 3.15: Fraction of Relocated Melt That is Aerosolized 


\section{THE HIPS-8C EXPERIMENT}

The objective of the HIPS-8C experiment was to determine the potential for debris to escape the cavity via the annular gap between the reactor pressure vessel and the cavity wall. In most plants (and the Zion plant in particular, see Figure 1.1), this gap represents a pathway through which core debris can be dispersed directly from the cavity into the upper dome of the containment. This escape path bypasses the potential mitigation of structures located outside the normal cavity exit and the lower regions of the containment. The melt generator and cavity assembly (but not the excavity structure) used in the HIPS-7C test was modified to include a mockup of this escape path. The fixture was placed in a chamber in such a way that debris escaping the cavity through the annular gap could be separated and collected.

\subsection{Apparatus}

The experiment used the same melt generator and scale model of the Zion cavity from the HIPS-7C test except that a simulated annular gap was placed at the scaled height of the RPV. As depicted in Figure 4.1, the melt generator and cavity model were connected by a transition piece. The transition piece was used to form the annular gap and to deflect dispersed melt away from the bottom flange of the melt generator. The transition piece was made from 6.4-mm thick steel plate and included a 15.2-cm ID tube to duct material from the discharge orifice in the melt generator to the cavity below.

In the Zion plant, the gap between the RPV and concrete wall is partially filled by thermal insulation, constructed of multiple layers of thin metal sheets, each separated by a $1-2 \mathrm{~cm}$ air space. The width of the gap, with and without the insulation in place, is estimated to be $7 \mathrm{~cm}$ with and $14 \mathrm{~cm}$, respectively. It is assumed that the insulation will be an insignificant hindrance to the flow of debris through the gap region. Therefore, the width of the gap in the experimental apparatus (1.3-1.4 cm) was based on a $1: 10$ linear scaling of the Zion geometry without the thermal insulation.

The apparatus in the HIPS-8C experiment is placed so that the normal cavity exit is just outside the end cover of the interaction chamber (see Figure 4.2). The cover was sealed around the apparatus so that the annular gap was inside the chamber. In this manner, the division of dispersed debris between the two exits could be estimated by a posttest collection of the mass in the apparatus and chamber. The debris leaving the normal cavity exit was directed against an inclined Plexiglass surface (see Figure 4.2) to observe the interaction of the particles with the surface of an obstruction. The rear wall of the interaction chamber was modified to include a baffle that would trap all debris within the chamber while allowing the heated chamber atmosphere to vent, thus preventing over pressurization. 


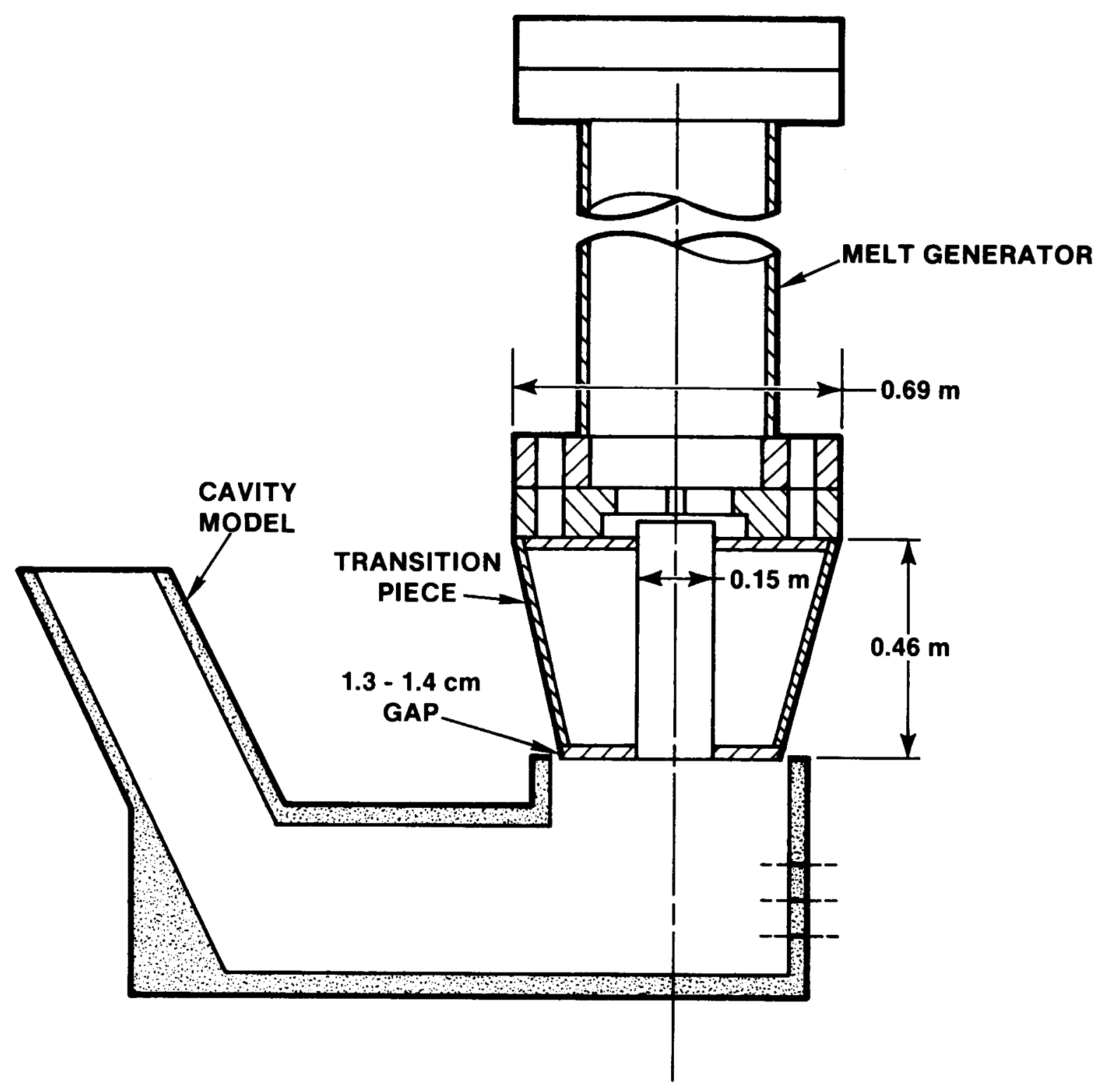

Figure 4.1: Details of the Melt Generator, Transition Piece, and Cavity Configuration 


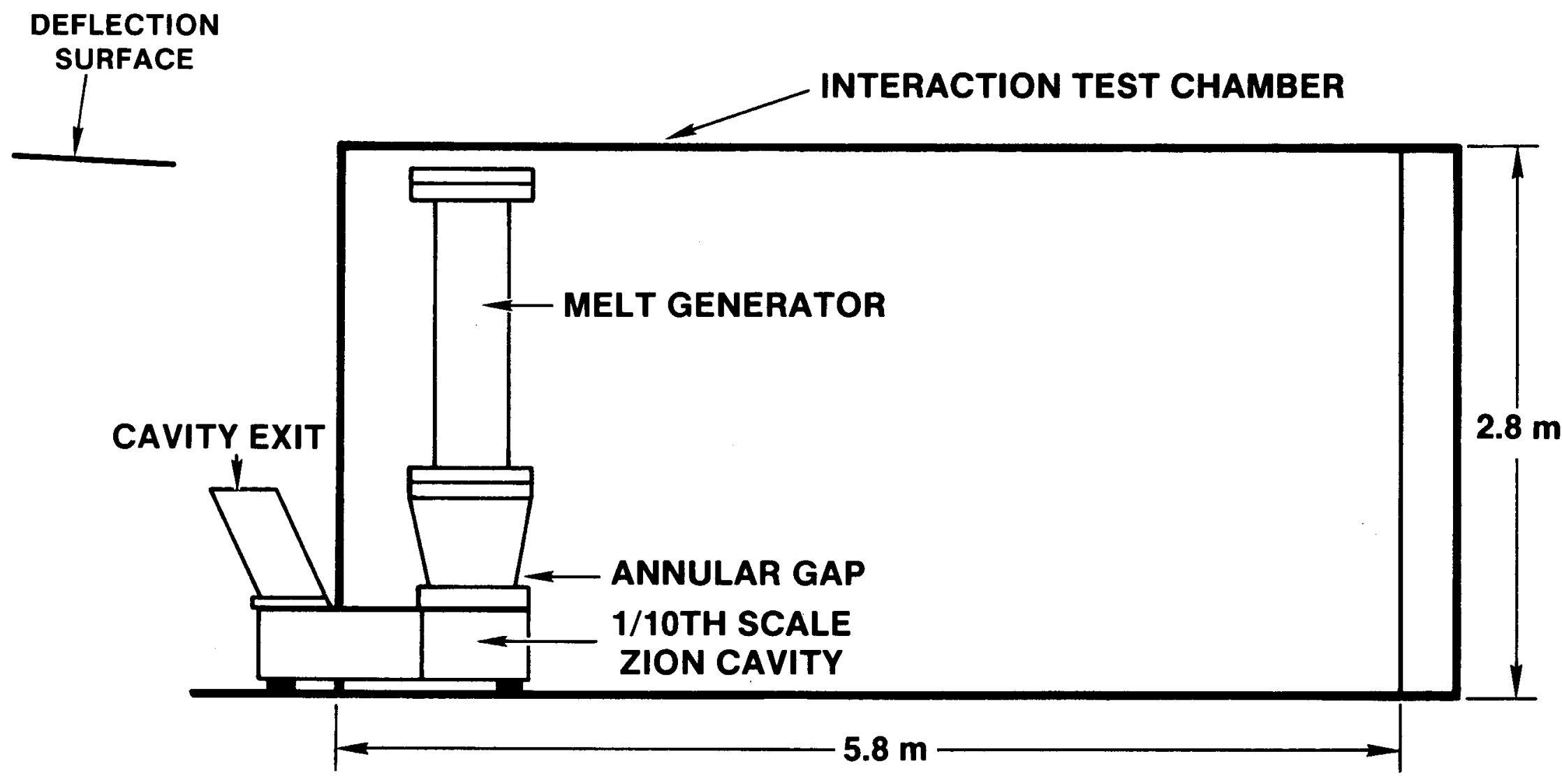

Figure 4.2: Arrangement of the Test Apparatus In the Interaction Chamber 


\subsection{Instrumentation}

A summary of the HIPS-8C instrumentation is given in Table 4.1. Two pressure gauges (Kulite He14-375) were used to monitor the pressurization and blowdown of the melt generator. One was placed in a machined recess in the top flange cover, protected by steel metal turnings. The second was inserted in a tee fitting in the gas line near to the melt generator. The latter was intended as a backup device in a location well away from the hot environment of the space above the melt pool.

Two pressure gauges (Kulite XT-180) were used to monitor the gas pressure in the tunnel region of the cavity. Both were installed on a common toe fitting connected to a short section of 9.5-mm diameter steel tubing that penetrated the cavity wall midway along the tunnel length. A small amount of steel turnings was placed in the tube to mitigate the migration of debris particles to the sensing face of the gauges. An analysis of the influence of the tube on the response of the gauges is discussed in (Tarbell et al., 1987A).

The possible pressure increase caused by debris into the chamber atmosphere was monitored by two gauges (Kulite XT-190). One gauge was placed at the midpoint of the west chamber wall while the second was located at the center of the chamber door away from the apparatus. Both gauges were installed in drilled and tapped holes in the 7.9-mm thick chamber wall. No protection of the gauge sensing elements was attempted.

The two-color pyrometer (Ircon Model 35G10) was the same device as used in the HIPS-7C experiment (Section 3.2). For this test, the device was located outside the chamber and aimed at the debris emerging from the cavity exit. The line of sight was from the east to the west at a distance of approximately $2 \mathrm{~m}$ from the cavity. The spot size at the cavity exit was nominally $2 \mathrm{~cm}$ diameter.

Thermocouples were used to measure gas temperature inside the melt generator and the chamber. The melt generator device was a Type-K with a $3.2 \mathrm{~mm}$ diameter steel sheath. The sensor was inserted through the top flange cover to a depth of about $46 \mathrm{~cm}$ into the melt generator. Two Type-K thermocouples, $0.5 \mathrm{~mm}$ in diameter, were installed adjacent to the chamber pressure gauges. The small diameter was selected to improve the response time of the device relative to the larger devices previously used. Each thermocouple penetrated into the chamber approximately $8 \mathrm{~cm}$ to avoid possible boundary layer effects near the wall surface.

A phototransistor (Motorola Type MRD310) was placed under the fusible plug to provide an accurate timing reference to the start of melt ejection. The output of the device was also used to trigger a strobe lamp unit that allowed synchronization of the electrical and film records. 
Table 4.1

Summary of HIPS-8C Instrumentation

\begin{tabular}{|c|c|c|c|c|}
\hline Type & No. & $\underline{\text { Range }}$ & Location & Purpose \\
\hline Pressure & 1 & $0-6.9 \mathrm{MPa}$ & Melt Gen & Melt Generator Blowdown \\
\hline Pressure & 1 & $0-6.9 \mathrm{MPa}$ & Gas Line & Reference \\
\hline Pressure & 1 & $0-3.4 \mathrm{MPa}$ & Cavity & Cavity Pressure \\
\hline Pressure & 1 & $0-0.7 \mathrm{MPa}$ & Cavity & Cavity Pressure \\
\hline Pressure & 2 & $0-0.4 \mathrm{MPa}$ & Int Chamber & Atm Heating \\
\hline Pyrometer & 1 & 1500-3500R C & Cavity Exit & Debris Temperature \\
\hline $\mathrm{TC}$ & 1 & $0-1500 \mathrm{R} \mathrm{C}$ & Melt Gen & Gas Temperature \\
\hline $\mathrm{TC}$ & 2 & $0-1500 \mathrm{R} C$ & Int Chamb Walls & Atm Temperature \\
\hline Photo Det & 1 & -- & Fusible Plug & Timing \\
\hline Filters & 10 & -- & Chamber & Aerosol Mass Concentration \\
\hline Cameras & 10 & -- & -- & Observation \\
\hline Real Time X-Ray & 1 & $2000 \mathrm{fps}^{\mathrm{s}}$ & Cavity Exit & Debris Character \\
\hline
\end{tabular}

- Frames per second 
The X-ray imaging device was employed to view the debris emerging from the cavity and impacting onto the Plexiglass deflection shield. The advantage of X-ray over normal optical observation is that aerosol and illumination do not hamper the view of the debris. The X-ray source was provided by a Norelco Model CK-150 that produced a continuous stream of $150 \mathrm{keV}$ photons. The imaging device (Precise Optics P600) converted the incident photons to electrons that were then focused on an internal fluorescent screen. The screen image was detected by a high-speed digitizing video camera (SPIN-Physics Model 2000 camera and recorder). This system permitted a full-screen image to be recorded at framing rates of up to $2000 \mathrm{fps}$.

The image intensifier was placed along side the Plexiglass deflection plate so that plane of the shield was across the face of the detector. The distance from the center line of the Plexiglass as the face of the image intensifier was approximately $60 \mathrm{~cm}$. The X-ray head was mounted on a tripod directly opposite the image intensifier so that photons emitted from the center of the source would be parallel to the surface of the Plexiglass. This technique eliminated distortion that would be caused by nonnormal incident X-rays. Locating the X-ray approximately $2 \mathrm{~m}$ from the object gave a geometric expansion factor of 1.3 for the image at the center of the Plexiglass. For a framing rate of $2000 \mathrm{fps}$, the recorder could operate for a total time of $45 \mathrm{~s}$.

The cameras employed to give a visual record of the test are summarized in Table 4.2 Most of the units were Hycam's (Redlake Corp.), operating at either 100 or 400 fps. The two Hulcher cameras use 70-mm film to give high quality still pictures. The framing rates of these devices ( 10 and $20 \mathrm{fps}$ ) were inadequate to provide fine resolution of the events during the experiment.

\subsection{Initial Conditions}

The initial conditions for the HIPS-8C test are summarized in Table 4.3. The gas volume, pressure, and temperature are values at the onset of melt ejection. The thermocouple, intended to measure the gas temperature in the melt generator, was adversely affected during the thermite reaction. The temperature value reported in Table 4.3 was estimated from the measured pressure rise, estimated volume change (of melt), and the estimated increase in gas mass (from HIPS-3J) during the thermite burn.

\subsection{Experiment Results and Analysis}

This section presents the results obtained from the HIPS-8C experiment. Analysis of the test is also presented where appropriate to aid in the understanding and interpreting of the experiment observations. 
Table 4.2

Summary of HIPS-8C Camera Coverage

\begin{tabular}{|c|c|c|c|}
\hline Device & $\begin{array}{c}\text { Start } \\
\text { Time (a) } \\
\text { (s) } \\
\end{array}$ & $\begin{array}{l}\text { Speed }^{(b)} \\
(\mathbf{f p s})\end{array}$ & Field of View \\
\hline Camera & -5 & 100 & 100' Overall from East \\
\hline Camera & +5 & 400 & 30' Normal to Cavity Exit \\
\hline Camera & +5 & 400 & 30' Parallel to Cavity Exit \\
\hline Camera & +5 & 400 & Chamber Top Viewport \\
\hline Camera & +5 & 400 & Chamber Side Viewport \\
\hline Camera & +5 & 400 & Chamber Rear Viewport \\
\hline Camera & +5 & 400 & Deflection Shield \\
\hline Camera & +5 & 400 & Deflection Shield \\
\hline Hulcher & +15 & 20 & 100' Normal to Cavity Exit \\
\hline Hulcher & +15 & 10 & 100' Parallel to Cavity \\
\hline Video & -- & 30 & \\
\hline
\end{tabular}

- Relative to ignition of thermite powder.

b Frames per second. 
Table 4.3

HIPS-8C Initial Conditions

Melt Mass

Thermite Composition

Melt Composition

Gas

Gas Volume

Initial Pressure

Ambient Temperature

Melt Plug Diameter
$80 \mathrm{~kg}$

Iron Oxide $\left(\mathrm{Fe}_{3} \mathrm{O}_{\mathrm{r}}\right) \quad 61.04 \mathrm{~kg}$ Aluminum (Al) $18.96 \mathrm{~kg}$

Iron $(\mathrm{Fe})+\mathrm{Alumina}\left(\mathrm{Al}_{2} \mathrm{O}_{3}\right)$

Carbon Dioxide $\left(\mathrm{CO}_{2}\right)$

$0.118 \mathrm{~m}^{3}$

$3.5 \mathrm{MPa}$

$525 \mathrm{~K}$

$0.0355 \mathrm{~m}$ 


\subsubsection{Camera Coverage}

Melt dispersal from the HIPS- $8 \mathrm{C}$ cavity is partitioned into two streams. One stream emanates from the normal cavity exit, which discharges into the desert outside the interaction chamber. Figure 4.3 shows this stream before and after it is redirected by the deflection shield. The sequence of events is similar to that reported in other tests (Tarbell et al., 1986): particles are launched great distances into the desert with the now expected aerosol generation accompanying the process.

The second stream of dispersed material leaves the cavity through the annular gap where it is confined within the interaction chamber. The sequence shown in Figure 4.4 shows the dispersal process through the annular gap. In the first three frames, there is an ordered venting of luminous gas with the visual intensity increasing as more melt is injected into the cavity. There is no evidence that deflected or splashed melt is leaving the cavity through the gap. The last frame depicts the process after the melt generator starts discharging gas into the cavity. The process suddenly becomes chaotic with melt particles being swept through the gap. Failure to plug thermocouple holes in the cavity model (used in a previous test) results in two jets of gas and melt that can be seen in the lower right hand corner of each frame.

\subsubsection{Pressurization and Blowdown History of the Melt Generator}

Figure 4.5 summarizes the pressurization history of the melt generator. The start of melt discharge is taken as the reference time. Gradual charging of the melt generator with $\mathrm{CO}_{2}$ gas begins at $-275 \mathrm{~s}$. Prior to ignition of the thermite at $-20 \mathrm{~s}$, the melt generator is isolated from the gas source. The burn time is $20 \mathrm{~s}$.

Figure 4.6 shows an expanded version of the depressurization history of the melt generator following the onset of melt ejection. Also shown are model predictions (Pilch \& Tarbell, 1985) for the same period. Two phases can be distinguished. The first phase lasting about $350 \mathrm{~ms}$, corresponds to liquid phase discharge during which the pressure decreases because the free volume is increasing as melt is expelled from the generator. Despite the lower pressures in this test, this phase is shorter than that reported for the HIPS-3J and HIPS-7C tests because the initial diameter of the discharge orifice is nearly twice as large in this test. The onset of gas flow out the orifice marks the beginning of the second phase. Gas discharge is accompanied by continued, but reduced, discharge of melt ( $\mathrm{Pilch}$ \& Tarbell, 1985). The second phase lasts $1-1.5 \mathrm{~s}$ at which time the blowdown of the generator is complete.

Figure 4.7 shows that the peak temperature recorded by the two color pyrometer was $2200 \mathrm{~K}$, which is well below the 


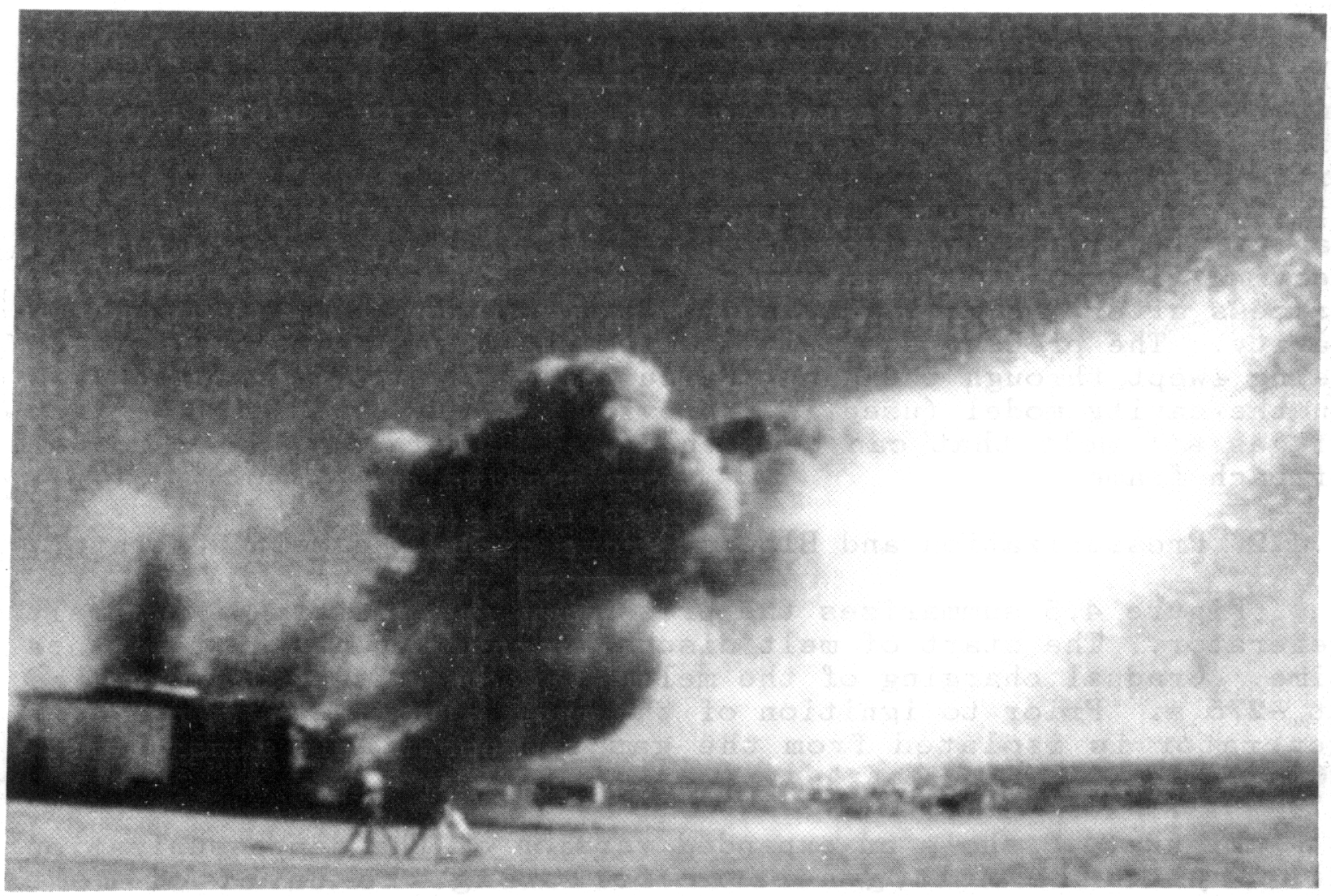

Figure 4.3: Debris Dispersal Through the Normal Cavity Exit 


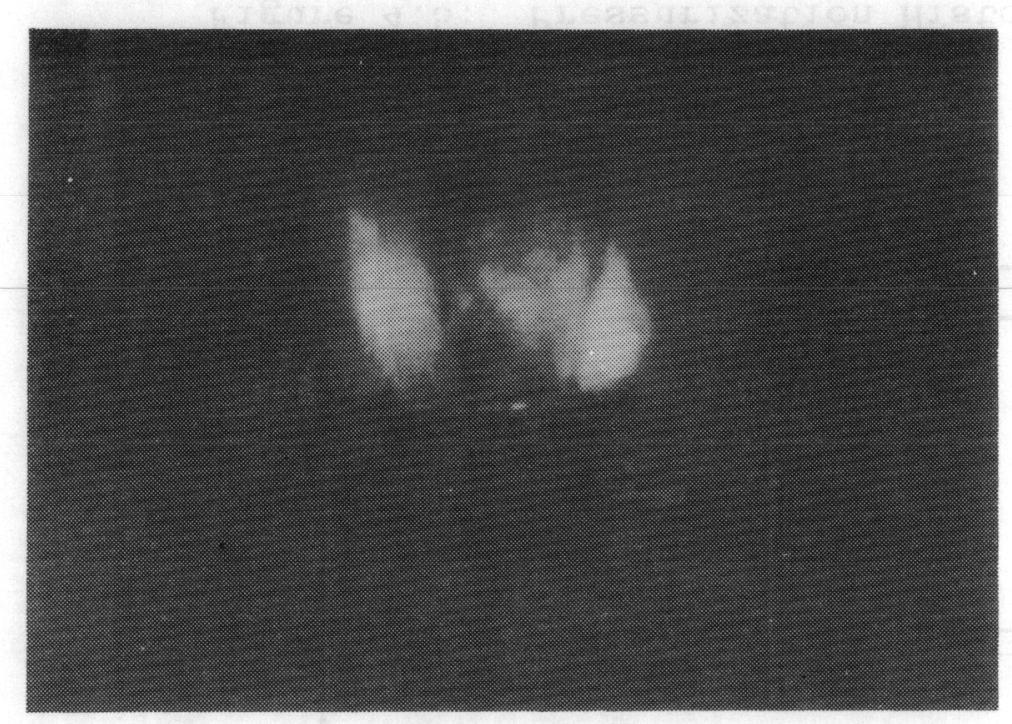

TIME $=20 \mathrm{~ms}$

1
0
0
1

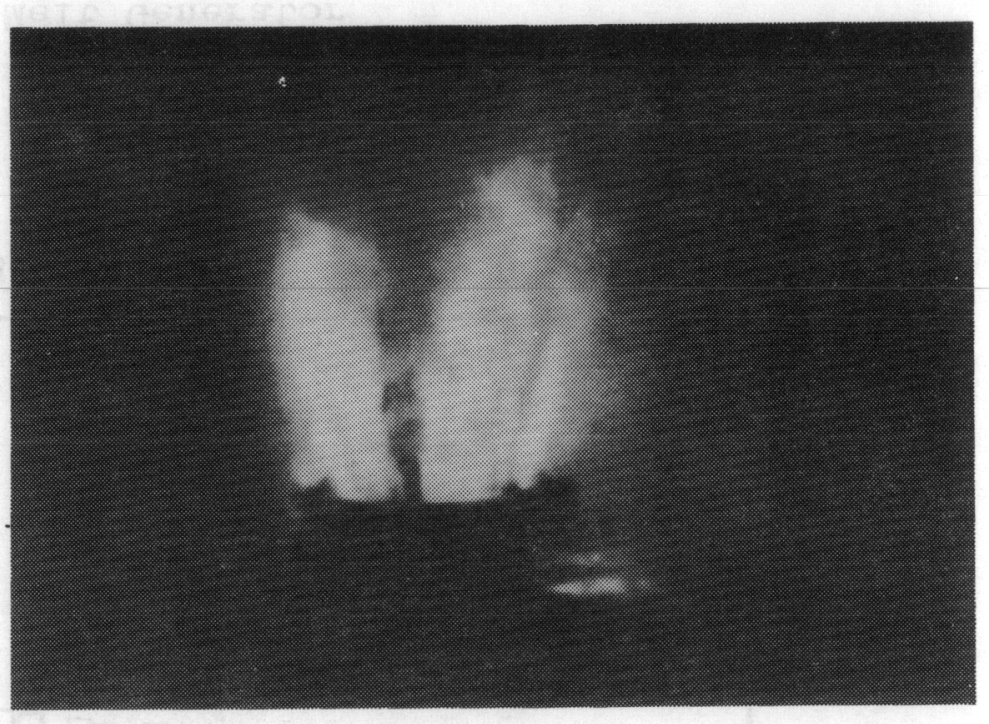

TIME = $50 \mathrm{~ms}$

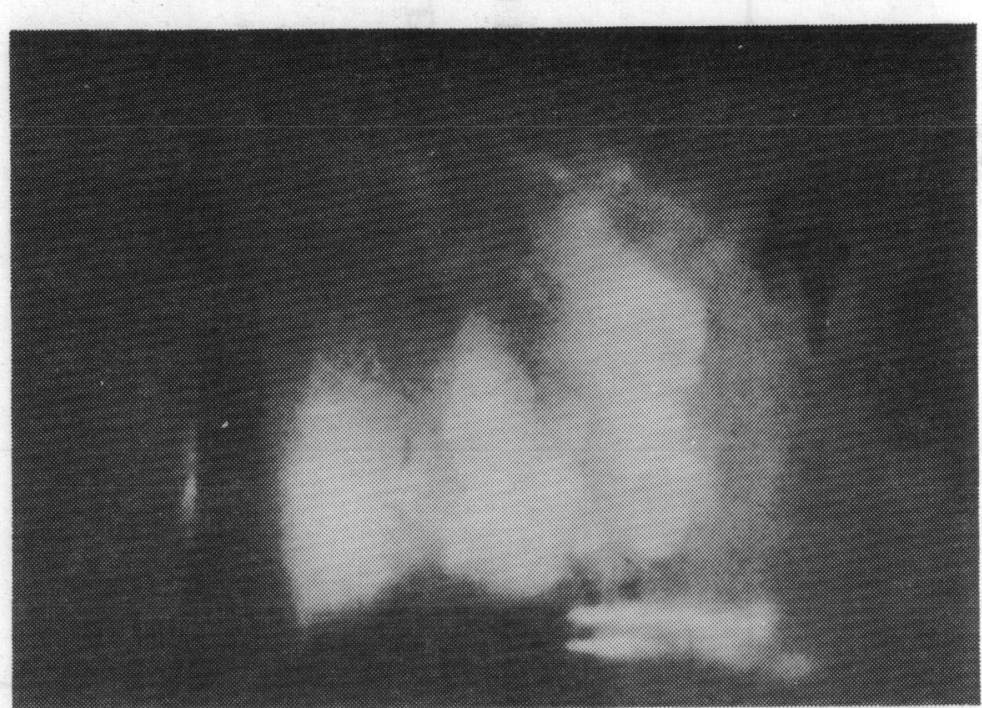

TIME $=\mathbf{4 0 0} \mathbf{~ m s}$

Figure 4.4: Debris Dispersal Through the Annular Gap 


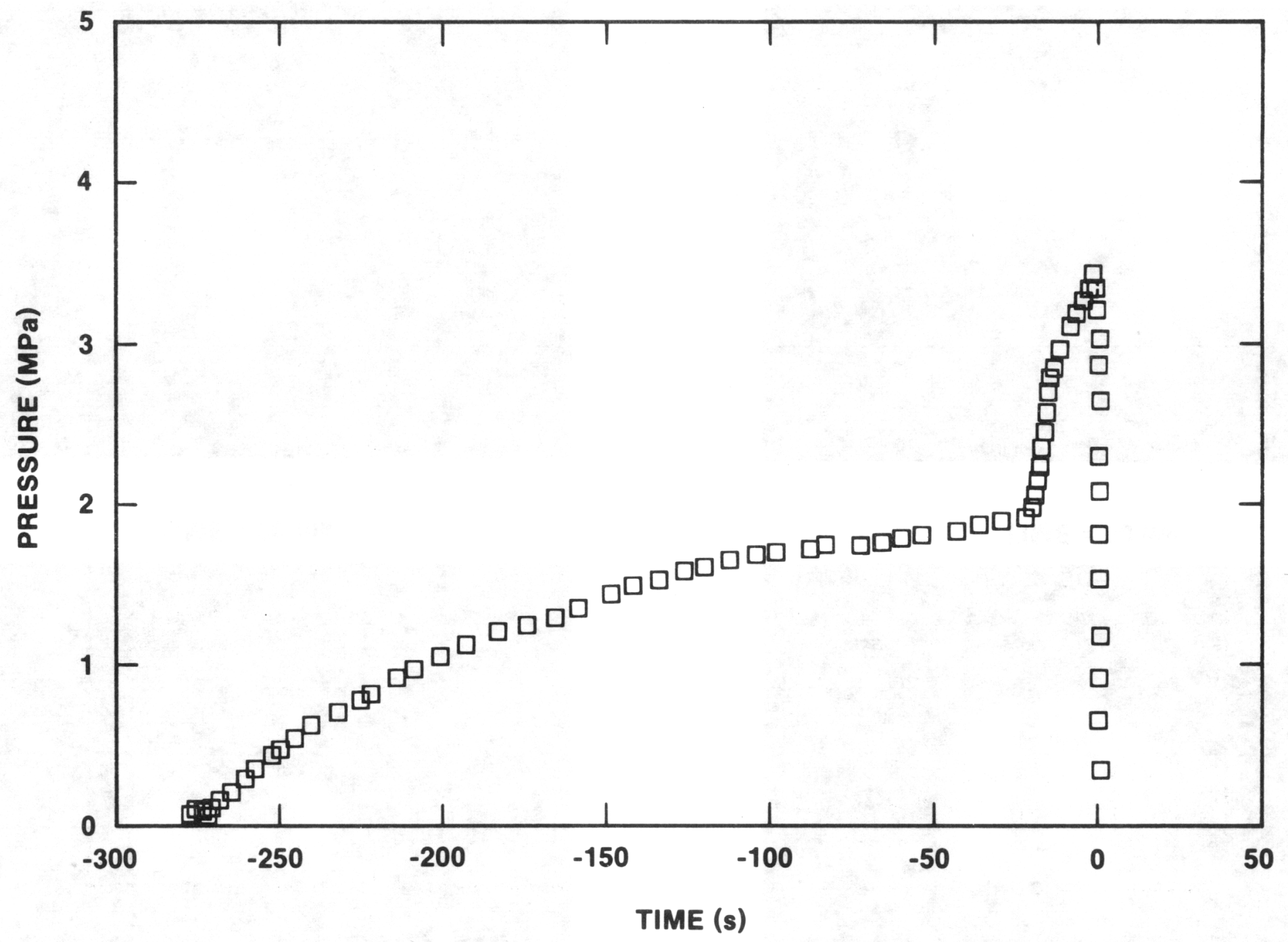

Figure 4.5: Pressurization History of the Melt Generator 


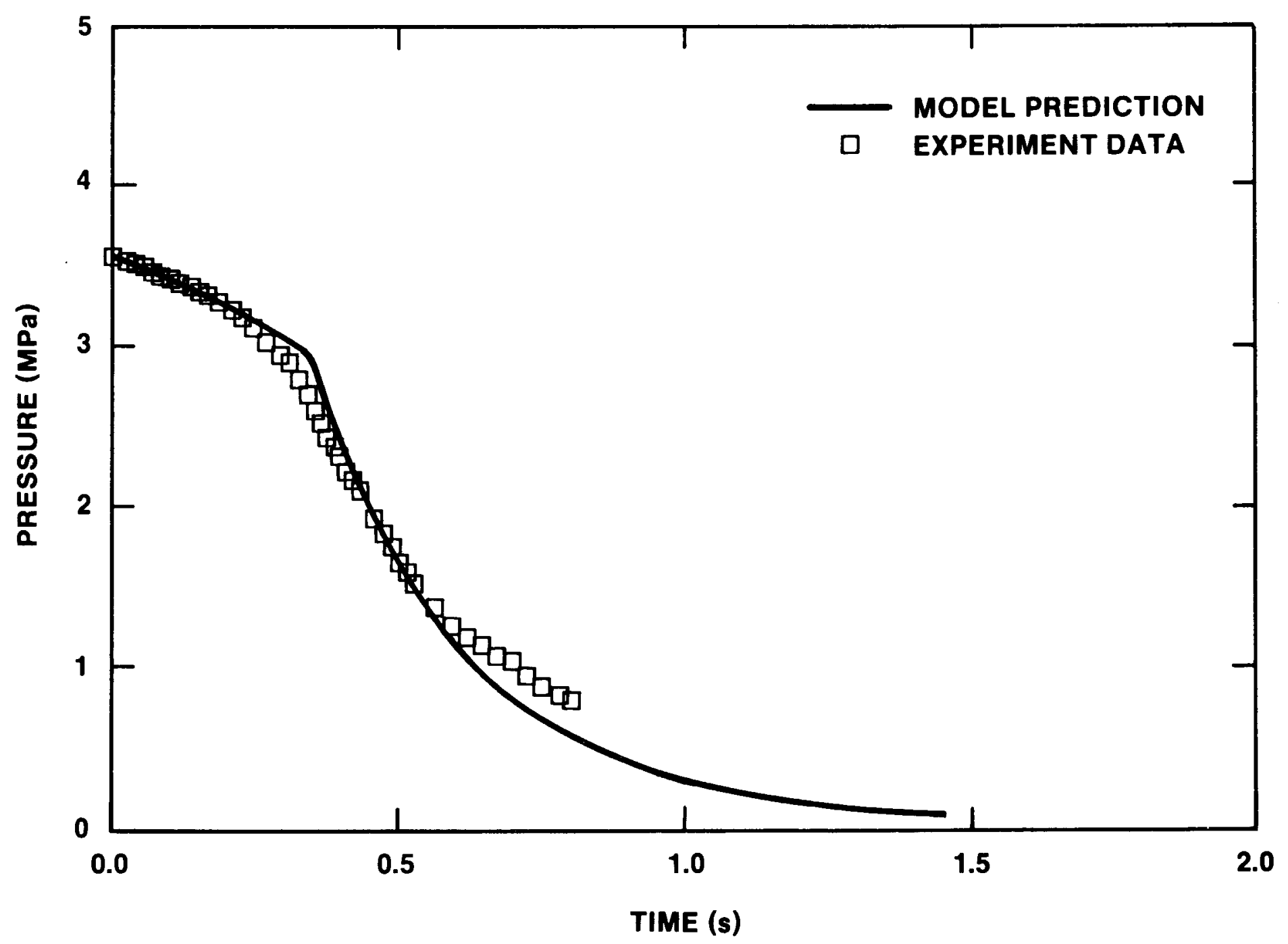

Figure 4.6: Blowdown History of the Melt Generator 


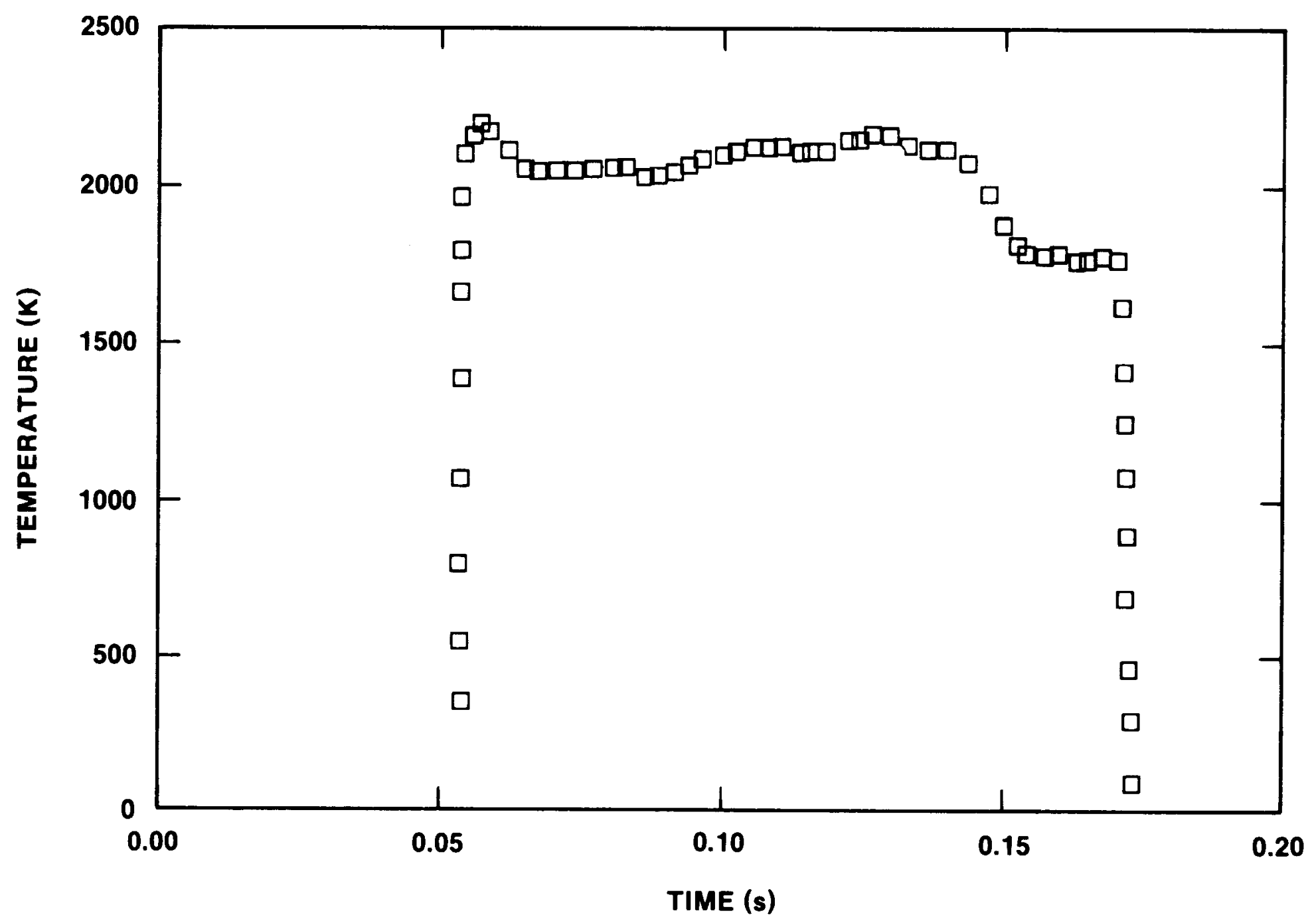

Figure 4.7: Temperature Measurement Outside the Cavity Using a 2-Color Pyrometer 
theoretical value of $3200 \mathrm{~K}$ for a complete and adiabatic reaction. The measured temperatures are well above the freezing point $(1700 \mathrm{~K})$ and well below the boiling point $(3200 \mathrm{~K})$ of the iron phase of the melt. The measured peak temperature is essentially at the freezing point $(2300 \mathrm{~K})$ for the alumina phase of the melt.

Figure 4.7 shows that the initial temperature readings are delayed $0.05 \mathrm{~s}$ after the start of melt ejection. This delay represents the expected transit time for the melt to pass through the cavity. The pyrometer output abruptly drops to zero at $0.17 \mathrm{~s}$, which is significantly less than the melt ejection time. The two-color pyrometer is a threshold device that provides a negative output when the temperature drops below $1500 \mathrm{C}$. For this test, it is speculated that relatively cold aerosols shielded the melt from the pyrometer causing the output to vanish at $0.17 \mathrm{~s}$.

Figure 4.8 shows pressure measurements made at the cavity sidewall. The measured pressures in the cavity are small compared to the pressure in the melt generator. The magnitude of the cavity overpressurization is about a factor of two lower than observed at the same location in the HIPS-7C test.. This is because the annular gap provides an additional area through which gases can vent.

Real time X-rays taken near the deflection shield indicate that peaks in the measured cavity pressure are related to periods of high material dispersal. The X-rays show a buildup of dispersed material followed by a relatively quiescent period. The quiescent period is seen to occur in the X-ray film at approximately $0.3 \mathrm{~s}$, which corresponds closely with a minimum in the cavity pressure. The quiescent period occurs before the onset of gas discharge into the cavity.

Gas discharge begins at about $0.35 \mathrm{~s}$ (Figure 4.6), which corresponds to the beginning of the second peak in the cavity pressure curve. The real time $X$-rays confirm that this marks the beginning of a more vigorous period of melt dispersal. The $X$-rays also reveal that dispersal from the cavity ceases abruptly at about $0.6 \mathrm{~s}$, which corresponds to the end of the third peak in the cavity pressure curve. Thus, dispersal ends approximately $0.25 \mathrm{~s}$ after the onset of gas discharge into the cavity.

\subsubsection{Structure Interactions}

The extent of debris dispersed from the cavity through the annular gap is important in determining the potential direct heating of the containment atmosphere. In order to extrapolate the experimental results to a realistic scale, the mechanisms of debris dispersal through the gap must be identified. It is assumed that debris may be driven or carried out of the reactor cavity via the annular gap around the RPV by one or more distinct 


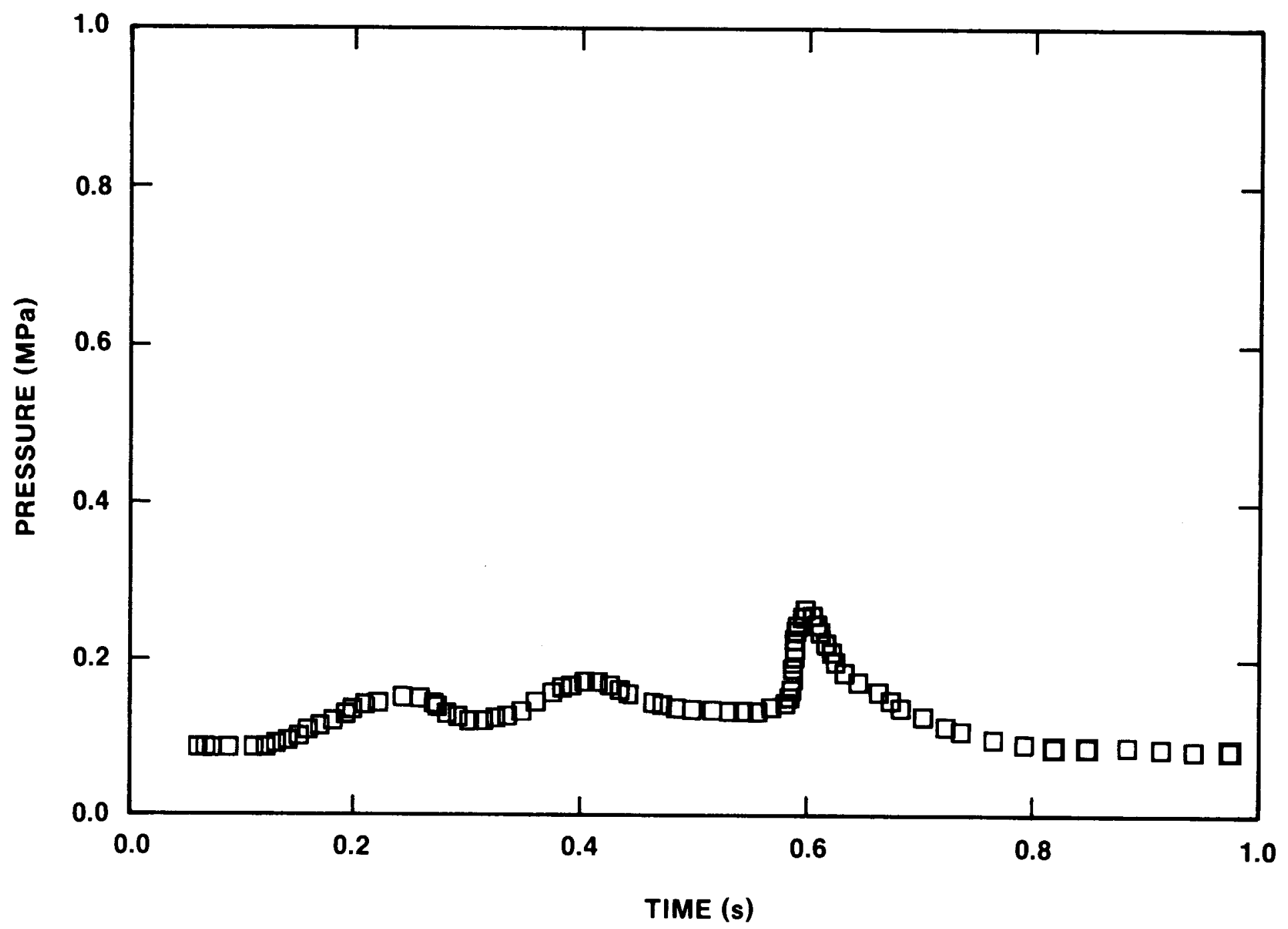

Figure 4.8: Pressure Measurements in the Cavity 
mechanisms; splashout, jet deflection, or entrainment. Splashout can occur if the debris entering the cavity forms a hydraulic jump of sufficient height to allow material to enter the gap region. It is unlikely that this will be the dominant mechanism because the vertical dimensions of most reactor cavities are significantly greater than the predicted jump height. For example, the zion cavity is more than twice as high as the calculated height of the hydraulic jump.

Jet deflection occurs when the ejected debris impacts the cavity floor and deflects upward along the cavity walls towards the RPV. The height attained by the deflected material is dependent on its initial velocity and the amount of energy lost during interactions with the floor and walls of the cavity. For the accident conditions depicted by the HIPS-8C experiment, the debris could reach a height on the order of 50 meters.

Melt entrained and removed via the annular gap occurs by the same mechanism attributed to debris dispersal from the normal cavity exit. The high-velocity gas from the RPV during primary system blowdown will divide between the gap and the tunnel according to the flow patterns established by the geometry of the cavity. Linear scaling of the cavity dimensions maintains the correct relationship between the flow areas and should preserve the flow patterns.

Determining the mechanism responsible for debris removal through the annular gap can be inferred by observing the nature and timing of the dispersal. For example, both splashout and jet deflection will occur soon after the start of ejection, and will be in the form of a film or sheet of material. Figure 4.4 shows that this was not observed. Particle entrainment depends on the flow of gas out of the vessel and will occur later in the sequence of events. This was the observed mechanism of dispersal. In the HIPS-8C experiment, the onset of gas discharge begins nominally 200-300 ms after the start of the ejection cycle. Observing when material begins to exit the gap and its form will identify the predominant removal mechanisms.

The debris retained by the interaction chamber was collected after the experiment to determine the amount of material discharged through the annular gap. Aluminum collection pans were placed on the floor of the enclosure in an attempt to resolve the distribution of the debris with respect to the apparatus. Aluminum proved to be a poor selection for this purpose because many of the pans were severely damaged by the deposited debris. Approximately $20 \mathrm{~kg}$ of debris material was collected in this manner with a small contribution due to the melted aluminum adhered to the debris. 
A portion of the extension tube connecting the melt generator with the cavity (Figure 4.1) was eroded during the discharge process. Approximately $14 \mathrm{~kg}$ of the melt was trapped within the hollow portion of the transition piece. An additional $4 \mathrm{~kg}$ of debris was recovered from the melt generator and cavity. of the $62 \mathrm{~kg}$ actually dispersed from the cavity, $20 \mathrm{~kg}$ (32\%) was actually dispersed through the annular gap.

Figure 4.1 depicts the geometry of the cavity. There are two paths by which melt can escape the cylindrical region under the melt generator; the annular gap, and the tunnel leading to the normal exit from the cavity. The flow area into the tunngl (for the test) is $0.0955 \mathrm{~m}^{2}$; and the gap flow area is $0.0209 \mathrm{~m}^{2}$, which represents $18 \%$ of the total area.leading to escape from the cavity. In comparison, the test revealed that $32 \%$ of the melt escaped the cavity through the gap, thus indicating a preferential dispersal out the gap.

Preferential dispersal out the gap is expected given the flow patterns of melt and gas in the region beneath the vessel. Melt and gas striking the floor spreads radially until it is deflected vertically along the cylindrical portion of the cavity. This deflected melt is inline with the annular gap and its flight path is not easily influenced by further changes in gas direction that might occur under the vessel.

Only that portion of the radially flowing melt (along the cavity floor) that is aimed at the tunnel is immune from potential dispersal out through the gap. Thus, the geometry places an upper limit of about $79 \%$ that potentially can be dispersed through the gap. The observed value lies closer to the flow area ratio. 


\section{SUMMARY AND CONCLUSIONS}

The experiments discussed in this report are not intended to directly simulate HPME accidents. They are intended to provide insight into relevant processes and to support development of phenomenological models which in turn are incorporated into the system level codes, such as MELPROG and CONTAIN. Realistic assessments of reactor accidents are obtained through integrated analysis using these system level codes.

The results of the HIPS-3J and HIPS-7C experiments suggest that melt retention by freezing on structures may be only a small fraction of the melt actually striking the structure. Freezing of melt on concrete structures is not an efficient retention mechanism. Melt does not stick to concrete due to degradation and outgassing of the surface. Melt does freeze on steel structures. Retention of melt on steel surfaces is limited by the flux of melt striking the surface or the freezing flux based on conduction freezing, whichever is the smaller. The quantity of melt striking the surface is much in excess of the freezing flux; it will splash or drip from the surface and continue to contribute to $\mathrm{DCH}$.

The excavity structure in the HIPS-7C experiment retained only $4 \%$ of the melt dispersed from the cavity. The remaining melt splashed or was otherwise reentrained from the structure. Much of this material was directed upwards along the roof of the chamber. Analysis suggests that even less material would be trapped at reactor scale because more debris can be deflected directly by the gas stream.

Preferential dispersal through the annular gap was observed in the HIPS-8C experiment, where $32 \%$ of the melt escaped the cavity through the gap. Geometry places an upper 1imit of $79 \%$ on this value while the gap-to-total flow area ratio of $18 \%$ represents a lower limit to the possible amount dispersed through the gap. Additional two-phase flow modeling, accounting for gas flow patterns and melt distribution, is required in order to predict the actual quantity of melt that may be dispersed through the annular gap in other geometries or at reactor scales.

The dispersal time is approximately $600 \mathrm{~ms}$ for these tests. Real time X-rays of the dispersal process correlate well with pressure measurements in the cavity. The observed dispersal times can be used to verify dispersal rate models that may be developed in the future. Pressure measurements in the cavity may. be used in future tests to infer dispersal time.

Pyrometer measurements of the melt consistently yielded temperatures that were at the freezing point of the alumina phase of the melt. This probably represents the surface temperature of a thin crust surrounding a molten core and may not be indicative of the bulk temperature of the drop because of the very fluid 
behavior of the melt at locations beyond the measurement location. The surface temperature, however, is the driving potential for the vaporization processes leading to aerosol production.

Copius quantities of aerosols were observed in all tests. The fraction of dispersed debris that is in the form of aerosols (dia<10 $\mu \mathrm{m}$ ) is approximately $1-5 \%$, and appears to increase with melt mass and/or interactions with structures. The mechanisms leading to aerosol production in the tests are believed to be operable at reactor scale, but the quantity of aerosol may be different in the reactor case because the melt composition is different. Predictions of aerosol production in reactor accidents await a comprehensive model that incorporates all the relevant phenomena.

These experiments demonstrate that selected containment structures may not decisively mitigate the dispersal and transport of debris throughout the containment. Dispersal can occur through multiple paths if available. Clearly, structure interactions alter the direction and character of melt while multiple interactions with structures can actually promote mixing of melt with itself and with the atmosphere.

Melt does not easily follow changes in gas direction and multiple impacts with structures are assured for most of the melt during the dispersal and transport phases. Structure interactions are characterized by skidding, splashing, and freezing. However, melt interactions with structures do not imply retention.

Models already developed for high pressure melt ejection, gas blowdown, and hole ablation are verified by the experiments. Models characterizing the impact of high velocity melt with surfaces are required and currently under development. Results reported herein show that such models must account for not only retention of melt by interactions with plant structures but also must deal with further break up at the melt stream as it splashes and fragments from these interactions. Additional models describing the dispersal rate and aerosol production rates are also required. 
Bergeron, K. D. et al., User's Manual for CONTAIN 1.0. A Computer Code for Severe Nuclear Reactor Accident Containment Analysis, Sandia National Laboratories, Albuquerque, NM, NUREG/CR-4085, SAND84-1204, May 1985.

Brockmann, J. E. and Tarbell, W. W., "Aerosol Generation by Pressurized Melt Ejection," Aerosols: Science, Technology, and Industrial Applications of Airborne Particles, Elsevier, Proceedings of the First International Aerosol Conference, Minneapolis, Minnesota, USA, 489-492, (Sept. 17-21, 1984).

Brockmann, J. E. and Tarbe11, W. W., "Aerosol Source Term in High Pressure Melt Ejection," Nuclear Science and Engineering, 88 342356,1984 .

Butland, A. T. D. et al., Report on Phase 1 of the PWR Severe Accident Containment Study, United Kingdom Atomic Energy Authority, AEEW-R1842, December 1984.

Camp, W. J. et al., MELPROG-PWR/MODO: A Mechanistic Code for Analysis of Reactor Core Melt Progression and Vessel Attack Under Severe Accident Conditions, Sandia National Laboratories, Albuquerque, NM, NUREG/CR-4908, SAND85-0237, April 1987.

Carslaw, H. S. and Jaegar, J. C. Conduction of Heat in Solids, Oxford Press, 2nd Edition, 1959.

Cook, I., Contribution to: Reactor Safety Research Semiannual Report, July-December 1987, Sandia National Laboratories, Albuquerque, NM, NUREG/CR-5039 (2 of 2), SAND87-2411 (2 of 2), Vol 38, to be published.

COMED, Zion Probabilistic Safety Study, Commonwealth Edison Co., Chicago, IL, 1981 .

CONED, Indian Point Probabilistic Safety Study, Power Authority of the State of New York, Consolidated Edison Company of New York, Inc., Buffalo, NY, 1982.

Dallman, J. C. and Kirchner, W. L., De-entrainment Phenomena of Vertical Tubes in Droplet Cross Flow, NUREG/CR-1421, LA-8316-MS, Apr. 1980 .

Denny, V. E. and Sehgal, B. R., "Analytical Prediction of Core Heatup/Liquefaction/Slumping," Paper 5.4, Proceedings of the International Meeting on Light-Water Reactor Severe Accident Evaluation, Cambridge, $\overline{M A}$, August 1983.

Fauske \& Associates, Inc., Technical Support for Issue Resolution, Technical Report 85.2 Industry Degraded Core Rulemaking Program Report, July 1985. 
IDCOR, Nuclear Power Plant Response to Severe Accidents IDCOR Technical Summary Report, Technology for Energy Corp., Knoxville, TN, November 1984 .

Pilch, M. and Tarbell, W. W., High Pressure Ejection of Melt from aeactor Vessel = The Discharge Phase, Sandia National Laboratories, Albuquerque, NM, NUREG/CR-4383, SAND85-0012, September 1985 .

Spencer, B. W., Sienicki, J. J., and McUmber, L. J., Hydrodynamics and Heat Transfer Aspects of Corium-Water Interactions, EPRI NP-5127, March 1987.

Spencer, B. W. et al., Sweepout Thresholds in Reactor Cavity Interactions, ANL/LWR/SAF 82-1, April 1982.

Squarer, D., "The Impact of Heat-Generating Debris on Containment Loading - An Overview," Preliminary Proceedings of Sixth Information Exchange Meeting on Debris Coolability, UCLA, Los Angeles, CA, November 7-9, 1984.

Tarbel1, W. W., Brockmann, J. E., and Pilch, M., "High Pressure Melt Ejection," NUREG/CP-0048, Vol. 3, Proceedings of the Eleventh Water Reactor Safety Research Information Meeting, Gaithersburg, MD, 204-217, (Oct. 24-28, 1983).

Tarbell, W. W., Brockmann, J. E., and Pilch, M., High-Pressure Melt Streaming (HIPS) Program Plan, Sandia National Laboratories, Albuquerque, NM, NUREG/CR-3025, SAND82-2477, August 1984.

Tarbe11, W. W. et al., Pressurized Melt Ejection Into Water Beds, Sandia National Laboratories, Albuquerque, NM, NUREG/CR-3916, SAND84-1531 (to be published).

Tarbell, W. W. et al., Initial Test Results: SPIT-19, Sandia National Laboratories Memorandum, April 1984.

Tarbell, W. W. et al., Pressurized Melt Ejection into Scaled Reactor Cavities, Sandia National Laboratories, Albuquerque, NM, NUREG/CR-4512, SAND86-0153, October 1886.

Tarbell, W. W. et al., Results from the DCH-1 Experiment, Sandia National Laboratories, Albuquerque, NM, NUREG/CR-4871, SAND862483 , June 1987 .

Touloukian Ed., Thermophysical Properties of High Temperature Solid Material, MacMillan, 1967. 
Tutu, N. K. et al., Debris Dispersal from Reactor Cavities During High Pressure Melt Ejection Scenarios (to be published).

USNRC̈, Reactor Safety Study, An Assessment of Accident Risks in U.S. Commercial Nuclear Power Plants, WASH-1400, USNRC, Washington, DC, NUREG/75-014, October 1975.

WEC, Sizewe11-B Probabilistic Safety Study, Westinghouse Electric Corporation, Pittsburgh, PA, WCAP-981, 1882.

Wheeler, C. L., and Thurgood, M. J., "COBRA-NC Application to Containment Analysis," NUREG/CP-0058, Vol. 3, Proceedings of the Twelfth Water Reactor Safety Research Information Meeting Gaithersburg, MD, 445-459, (Oct. 22-26, 1983).

Williams, D. C., "Impact of Chemical Phenomena in Direct Containment Heating," SAND86-2020C, Presented at American Chemical Society Severe Accident Symposium, Anaheim, CA, September 8-12, 1986. 
Distribution:

U.S. Nuclear Regulatory Commission (25)

Office of Nuclear Regulatory Research

Washington, DC 20555

Attn: E. S. Beckjord

D. F. Ross

T. P. Speis

C. N. Kelber

M. Silberberg

G. Marino

L. Chan

C. Ryder

R. W. Wright

T. Walker

R. O. Meyer

J. A. Mitchell

S. B. Burson

T. Lee (5)

M. Cunningham

J. Murphy

P. Wood

F. Eltawilla

L. G. Hulman

B. Hardin

Z. Rosztoczy

U.S. Nuclear Regulatory Commission (3) office of Nuclear Regulatory Regulation Washington, DC 20555

Attn: R. Barrett

S. Long

w. Lyon

U.S. Department of Energy (2)

Albuquerque Operations office

P.O. Box 5400

Albuquerque, NM 87185

Attn: J. R. Roeder, Director

J. A. Morley, Director

For: C. B. Quinn

R. N. Holton

U.S. Department of Energy

office of Nuclear Safety Coordination

Washington, DC 20545

Attn: R. W. Barber 
Electric Power Research Institute (4)

3412 Hillview Avenue

Palo Alto, CA 94303

Attn: R. Vogel

R. Ritzman

W. Lowonstein

R. Sehgal

Brookhaven National Laboratory (5)

Upton, NY 11973

Attn: R. A. Bari

T. Pratt

N. Tutu

G. Greene

T. Ginsberg

Professor R. Seale

Department of Nuclear Engineering

University of Arizona

Tucson, AZ 85721

Oak Ridge National Laboratory

P.O. BoX Y

Oak Ridge, TN 37830

Attn: T. Kress

K. Holtzclaw

General Electric - San Jose

Mail Code 682

175 Kurtner Avenue

San Jose, CA 95125

Argonne National Laboratory (5)

9700 South Cass Avenue

Argonne, IL 60439

Attn: J. Rest

C. Johnson

L. Baker, Jr.

D. Cho

B. Spencer

Cathy Anderson

Nuclear Safety oversight Commission

1133 15th St., NW

Room 307

Washington, DC 20005

Battelle Columbus Laboratory (3)

$505 \mathrm{King}$ Avenue

Columbus, OH 43201

Attn: P. Cybulskis

R. Denning

J. Giesek. 
J. E. Antill

Berkeley Nuclear Laboratory

Berkeley GL 139 PB

Gloucestershire

ENGLAND, U.K.

W. G. Cunliffe

Bldg. 396

British Nuclear Fuels, Ltd.

Springfields Works

Salwick, Preston

Lancashire

ENGLAND， U.K.

R. Deem

Power Authority state of NY

10 Columbus circle

New York, NY 10019

Professor Agustin Alonso

E.T.S. Ingenieros Industriales

Jose Gutierrez Abascal, 2

28006 Madrid, SPAIN

Dr. Alfonso Perez

Department de Seguridad Nuclear

Junta de Energia Nuclear

Avenida Complutense, 22

Madrid - 3, SPAIN

R. Sherry

JAYCOR

P.O. BoX 85154

San Diego, CA 92138

Ktech Corp. (5)

901 Pennsylvania NE

Albuquerque, NM 87110

Attn: R. E. Blose

R. T. Nichols

M. S. Oliver

J. Jackson

J. W. Ross

Los Alamos National Laboratories

P.O. Box 1663

Los Alamos, NM 87545

Attn: M. Stevenson

UCLA (2)

Nuclear Energy Laboratory

405 Hilgaard Avenue

Los Angeles, CA 90024

Attn: I. Catton

D. Okrent 
University of Wisconsin

Nuclear Engineering Department

1500 Johnson Drive

Madison, WI 53706

Attn: M. L. Corradini

EG\&G Idaho

Willow Creek Building, W-3

P.O. Box 1625

Idaho Falls, ID 83415

Attn: R. Hobbins

Battelle Pacific Northwest Laboratory

P.O. Box 999

Richland, WA 99352

Attn: M. Freshley

wiktor Frid

Swedish state Power Board

S-162 FACH 87 VALLINGBY

SWEDEN

W. stratton

2 Acoma Lane

Los Alamos, NM 87544

Geselischaft fur Reaktorsicherheit (GRS)

Postfach 101650

Glockengrasse 2

5000 Koeln 1

Federal Republic of GERMANY

Kraftwerk Union

Hammerbacher Strasse 1214

Postfach 3220

D-8520 Erlangen 2

Federal Republic of GERMANY

Attn: Dr. M. Peehs

UKAEA

Reactor Development Division (5)

Winfrith, Dorchester

Dorset DT2 8DH

ENGLAND, U.K.

Attn: R. Potter

A. Nichols

B. Bowsher

P. Smith

T. Butland 
Nucleare e della Protezione Sanitaria (DISP)

Ente Nazionnle Energie Alternative (ENEA)

Viale Regina Margherita, 125

Casella Postale M. 2358

I-00100 Roma A.D., ITALY

Attn: Mr. Manilia

Mr. G. Petrangeli

Dr. K. J. Brinkman

Reactor Centrum Nederland

1755 ZG Petten

THE NETHERLANDS

Dr. S. J. Niemczyk

1545 18th street, NW

\#112

Washington, DC 20036

Kernforschungszentrum Karlsruhe

Postfach 3640

75 Karlsruhe

Federal Republic of GERMANY

Attn: H. Rininsland

Mr. H. Bairiot, Chief

Department LWR Fuel

Belgonucleaire

Rue de Champde Mars. 25

B-1050 Brussels, BELGIUM

Japan Atomic Energy Research Institute

Tokai-Mura, Naka-Gun

Ibaraki-Ken 319-11

JAPAN

Attn: s. Saito

Wang Lu

TVA

400 Commerce, W9C157-CK

Knoxville, TN 37902

M. Fontana

Director, IDCOR Program

ENERGEX

575 Oak Ridge Turnpike

oak Ridge, TN 37830

Fauske and Associates, Inc. (2)

16 W070 West 83rd street

Burr Ridge, IL 60521

Attn: R. Henry

M. Plys 
Peter Bieniarz

Risk Management Associates

2309 Dietz Farm Road, NW

Albuquerque, NM 87107

Dr. K. Soda

Manager,

Chemical Engineering Safety Laboratory

Department of Nuclear Fuel safety

Japan Atomic Energy Research Institute

Tokai-Muri, Naku-Gun, Ibaraki-Ken

319-11

JAPAN

K. Sato, Director

Department of Reactor Safety Research

Japan Atomic Energy Research Institute

Tokai-Mura, Naka-Gun, Ibaraki-Ken

JAPAN

P. Fehrenbach

Atomic Energy Canada, Ltd.

Chalk River, ontario

CANADA KOJ IJO

M. Hayns

UKAEA

Safety and Reliability Directorate

Wigshaw Lane

Culcheth

Warrington WA3 $4 \mathrm{NE}$

Cheshire,

ENGLAND, U.K.

J. R. Mathews

Aere Harwell

Didcot

Oxfordshire OXI1 ORA

ENGLAND, U.K.

F. Briscoe

UKAEA Culham Laboratory

Abingdon

Oxfordshire OX14 3DB

ENGLAND， U.K.

H. J. Teague (3)

UKAEA

Safety and Reliability Directorate

Wigshaw Lane

Culcheth

Warrington, WA3 4NE

ENGLAND, U.K. 
M. Jankowski

IAEA

Division of Nuclear Reactor Safety

Wagranerstrasse 5

P.O. Box 100

A/1400 Vienna, AUSTRIA

Statens Karnkraftinspektion

L. Hammer

P. 0.27106

S-10252 Stockholm, SWEDEN

Studsvik Energiteknik AB

K. Johansson

S-611 82 Nykoping, SWEDEN

Atomic Energy Canada Ltd.

M. Notley

Chalk River, Ontario

CANADA KOJ IJO

Atomic Energy Canada Ltd. (2)

Pinawa, Manitoba

CANADA ROE 1 LO

Attn: H. Rosinger

D. Wren 
Sandia Distribution:

$\begin{array}{ll}3141 & \text { S. A. Landenberger (5) } \\ 3151 & \text { W. I. Klein } \\ 6400 & \text { D. J. McCloskey } \\ 6412 & \text { A. L. Camp } \\ 6413 & \text { E. Bergeron } \\ 6415 & \text { R. M. Cranwell } \\ 6420 & \text { J. V. Walker } \\ 6421 & \text { P. S. Pickard } \\ 6422 & \text { D. A. Powers (5) } \\ 6422 & \text { F. E. Arellano } \\ 6422 & \text { J. E. Brockmann (2) } \\ 6422 & \text { E. R. Copus } \\ 6422 & \text { T. M. Kerley } \\ 6422 & \text { D. A. Lucero } \\ 6422 & \text { W. W. Tarbell (5) } \\ 6423 & \text { B. W. Marshall, Jr. } \\ 6425 & \text { W. J. Camp } \\ 6425 & \text { M. Pilch (5) } \\ 6427 & \text { M. Berman } \\ 6427 & \text { L. Pong } \\ 6429 & \text { K. D. Bergeron } \\ 6429 & \text { D. E. Carroll } \\ 6429 & \text { J. L. Tills } \\ 6429 & \text { K. E. Washington } \\ 6429 & \text { D. C. Williams } \\ 6440 & \text { D. A. Dahlgren } \\ 6442 & \text { W. A. Von Riesemann } \\ 6454 & \text { G. L. Cano } \\ 7530 & \text { T. B. Lane } \\ 7537 & \text { N. R. Keltner } \\ 8363 & \text { W. Sanders } \\ 8363 & \text { K. Marx } \\ 8524 & \text { P. W. Dean }\end{array}$




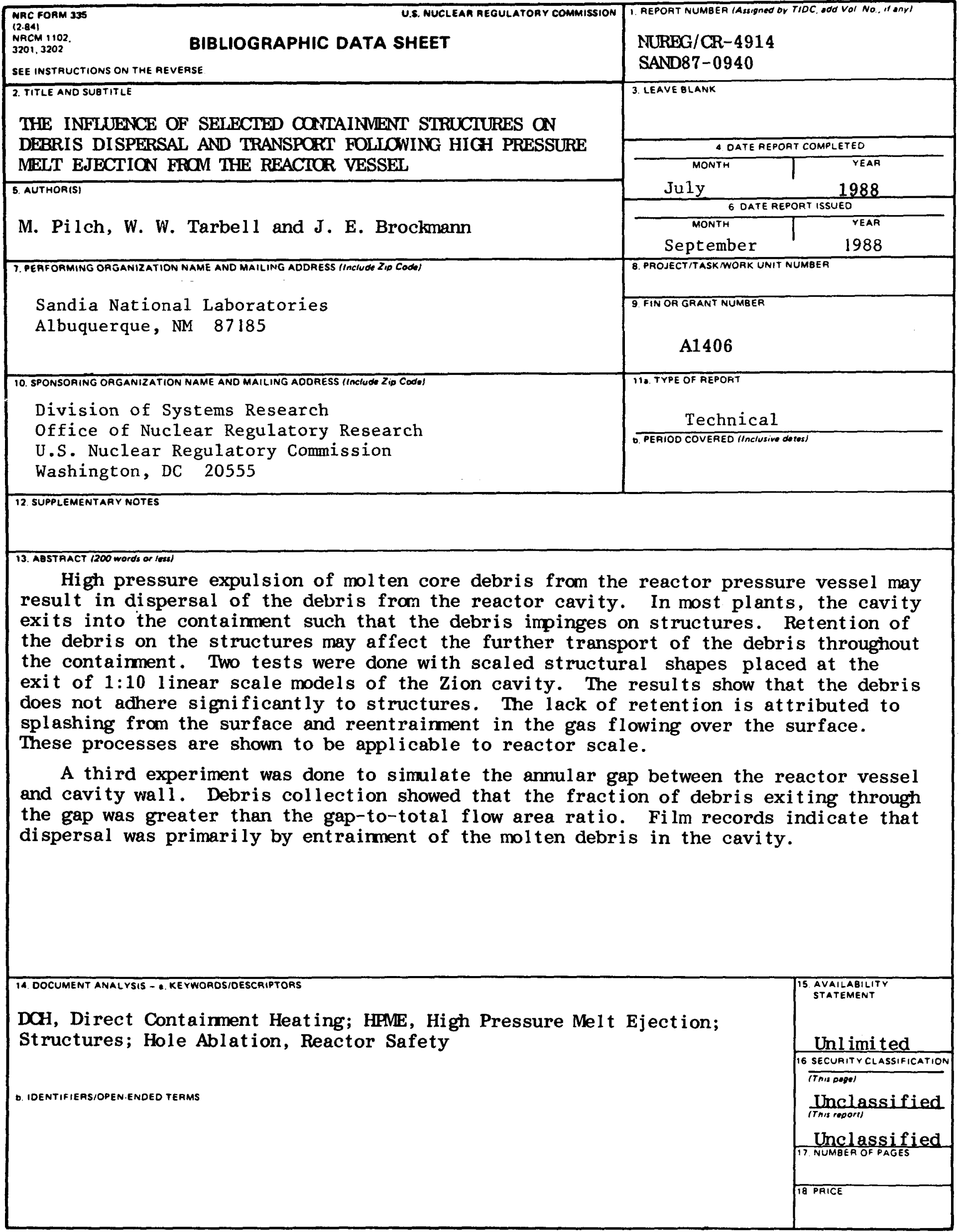

